\title{
Proposed Guidance for Preparing and Reviewing Molten Salt Nonpower Reactor License Applications (NUREG-1537)
}

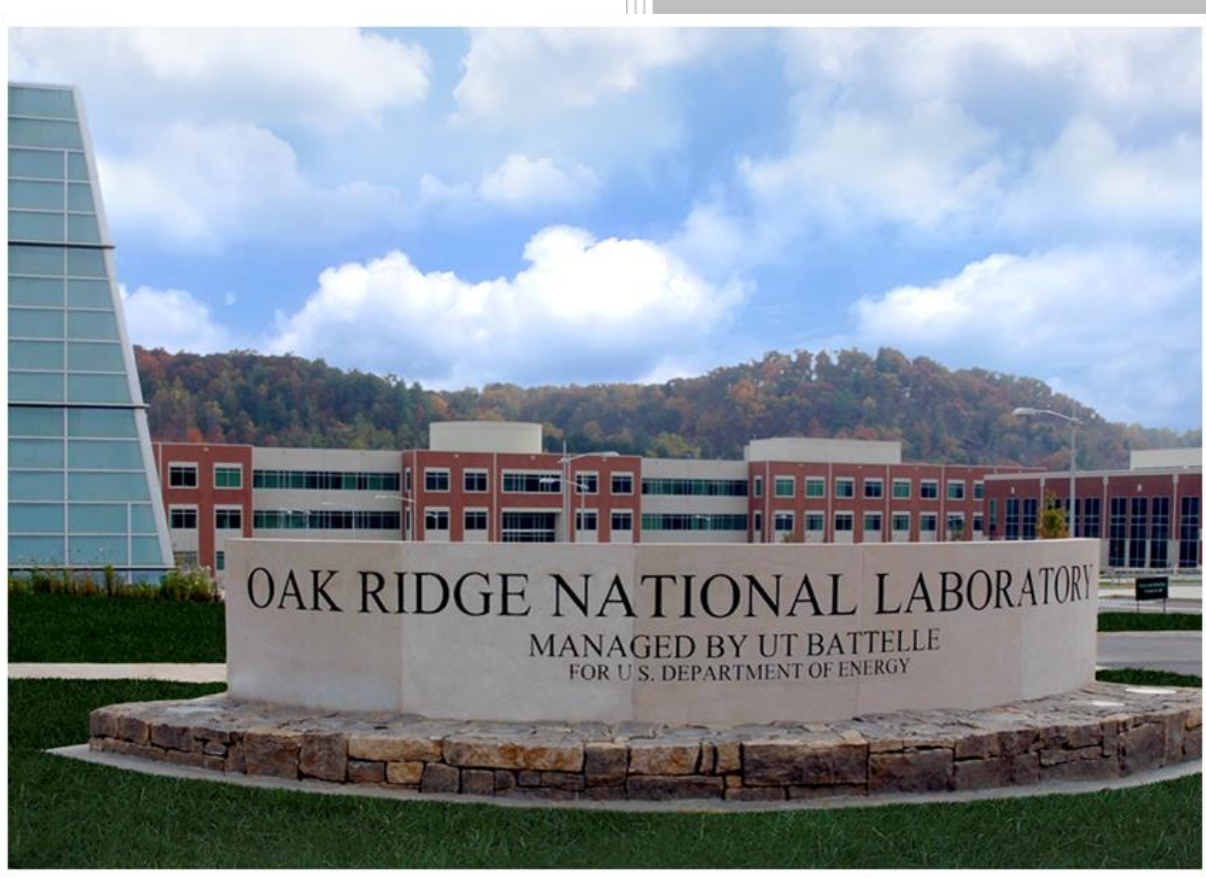

\section{Approved for public release.} Distribution is unlimited.

Randy J. Belles, ORNL George F. Flanagan, ORNL Marcus Voth, Boston Government Services, LLC

May 2018 


\title{
DOCUMENT AVAILABILITY
}

Reports produced after January 1, 1996, are generally available free via US Department of Energy (DOE) SciTech Connect.

Website www.osti.gov

Reports produced before January 1, 1996, may be purchased by members of the public from the following source:

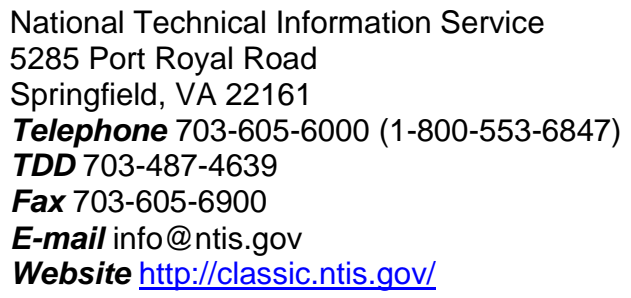

Reports are available to DOE employees, DOE contractors, Energy Technology Data Exchange representatives, and International Nuclear Information System representatives from the following source:

Office of Scientific and Technical Information

PO Box 62

Oak Ridge, TN 37831

Telephone 865-576-8401

Fax 865-576-5728

E-mail reports@osti.gov

Website http://www.osti.gov/contact.html

\begin{abstract}
This report was prepared as an account of work sponsored by an agency of the United States Government. Neither the United States Government nor any agency thereof, nor any of their employees, makes any warranty, express or implied, or assumes any legal liability or responsibility for the accuracy, completeness, or usefulness of any information, apparatus, product, or process disclosed, or represents that its use would not infringe privately owned rights. Reference herein to any specific commercial product, process, or service by trade name, trademark, manufacturer, or otherwise, does not necessarily constitute or imply its endorsement, recommendation, or favoring by the United States Government or any agency thereof. The views and opinions of authors expressed herein do not necessarily state or reflect those of the United States Government or any agency thereof.
\end{abstract}


Reactor and Nuclear Systems Division

\title{
PROPOSED GUIDANCE FOR PREPARING AND REVIEWING MOLTEN SALT NONPOWER REACTOR LICENSE APPLICATIONS (NUREG-1537)
}

\author{
Randy J. Belles \\ George F. Flanagan \\ Marcus Voth, Boston Government Services, LLC
}

Date: May 2018

Prepared by OAK RIDGE NATIONAL LABORATORY

Oak Ridge, TN 37831-6283

managed by

UT-BATTELLE, LLC

for the

US DEPARTMENT OF ENERGY

under contract DE-AC05-00OR22725 



\section{CONTENTS}

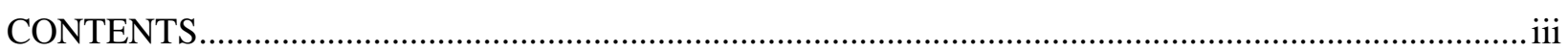

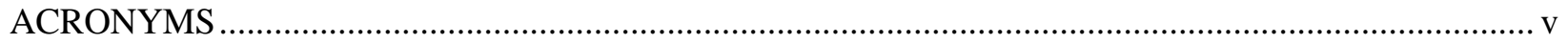

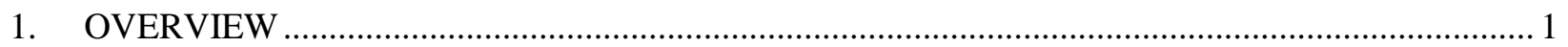

2. DESCRIPTION OF WORK

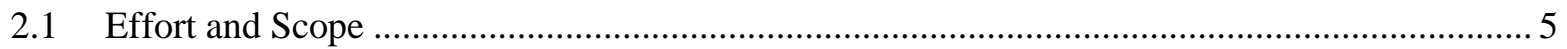

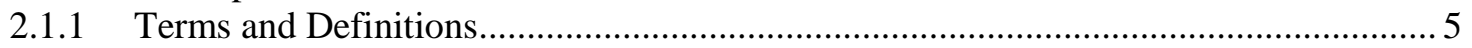

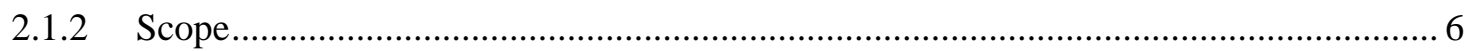

2.2 Production Facility Considerations ….............................................................................. 9

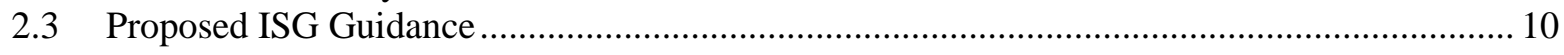

3. OBSERVATIONS ON SIGNIFICANT NUREG-1537 ADAPTATIONS .................................... 11

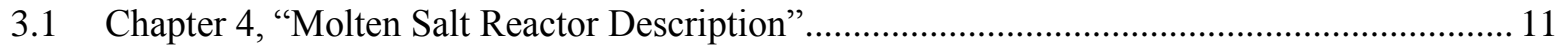

3.2 Chapter 5, "Molten Salt Reactor Cooling Systems" ............................................................ 12

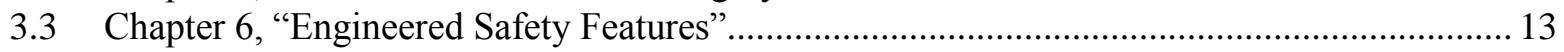

3.4 Chapter 9, "Auxiliary Systems" ......................................................................................... 14

3.5 Chapter 11, "Radiation Protection Program and Waste Management" ................................... 14

APPENDIX A. Chapter 4, "Molten Salt Reactor Description”-MSR Adaptation of Part 1 .................. A-3

APPENDIX A. Chapter 4, "Molten Salt Reactor Description"-MSR Adaptation of Part 2 ................ A-17

APPENDIX B. Chapter 5, "Molten Salt Reactor Cooling Systems"-MSR Adaptation of Part 1 .......... B-3

APPENDIX B. Chapter 5, "Molten Salt Reactor Cooling Systems"-MSR Adaptation of Part 2 ........ B-19

APPENDIX C. Chapter 6, "Engineered Safety Features"-MSR Adaptation of Part 1 ........................ C-3

APPENDIX C. Chapter 6, "Engineered Safety Features"-MSR Adaptation of Part 2 ..................... C-13

APPENDIX D. Chapter 9, "Auxiliary Systems”-MSR Adaptation of Part 1 ..................................... D-3

APPENDIX D. Chapter 9, "Auxiliary Systems"-MSR Adaptation of Part 2 ................................... D-15

APPENDIX E. Chapter 11, "Radiation Protection Program and Waste Management"-MSR

Adaptation of Part 1 ......................................................................................................... E-3

APPENDIX E. Chapter 11, "Radiation Protection Program and Waste Management"-MSR

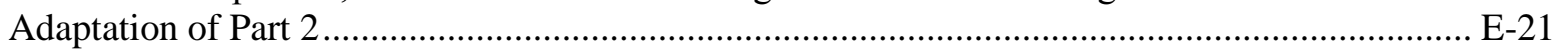





\section{ACRONYMS}

$\begin{array}{ll}\text { AHR } & \text { aqueous homogeneous reactor } \\ \text { ALARA } & \text { as low as reasonably achievable } \\ \text { ALI } & \text { annual limits on intake } \\ \text { ANS } & \text { American Nuclear Society } \\ \text { DAC } & \text { derived air concentration } \\ \text { DOE } & \text { US Department of Energy } \\ \text { ECS } & \text { emergency cooling system } \\ \text { ESF } & \text { engineered safety feature } \\ \text { HEU } & \text { highly enriched uranium } \\ \text { HVAC } & \text { heating, ventilation, and air conditioning } \\ \text { IAEA } & \text { International Atomic Energy Agency } \\ \text { I\&C } & \text { instrumentation and control } \\ \text { ISG } & \text { interim staff guidance } \\ \text { LBE } & \text { licensing basis event } \\ \text { LCO } & \text { limiting conditions for operation } \\ \text { LOCA } & \text { loss-of-coolant accident } \\ \text { LSSS } & \text { limiting safety system setting } \\ \text { LWR } & \text { light water reactor } \\ \text { MSR } & \text { molten salt reactor } \\ \text { MSRE } & \text { Molten Salt Reactor Experiment } \\ \text { NFPA } & \text { National Fire Protection Association } \\ \text { NRC } & \text { US Nuclear Regulatory Commission } \\ \text { ORNL } & \text { Oak Ridge National Laboratory } \\ \text { RAM } & \text { remote area monitor } \\ \text { SAR } & \text { safety analysis report } \\ \text { SER } & \text { safety evaluation report } \\ \text { SL } & \text { safety limit } \\ \text { SNM } & \text { special nuclear material } \\ \text { SR } & \text { surveillance requirement } \\ \text { SRP } & \text { standard review plan } \\ \text { TS } & \text { technical specifications } \\ & \end{array}$





\section{OVERVIEW}

Development of nonpower molten salt reactor (MSR) test facilities is under consideration to support the analyses needed for development of a full-scale MSR. These nonpower MSR test facilities will require review by the US Nuclear Regulatory Commission (NRC) staff. Standard review plan (SRP) guidance for large light water reactors (LWRs) is available in NUREG-0800, Standard Review Plan for the Review of Safety Analysis Reports for Nuclear Power Plants; Light Water Reactor (LWR) Edition. However, NRC staff observed that NUREG-0800 is very cumbersome to apply to nonpower reactors "because of the great differences in complexity and hazards between nonpower reactors and nuclear power plants." Therefore, a program to develop performance-based guidance applicable to nonpower reactors was initiated.

In 1996, NUREG-1537, Parts 1 and 2, Guidelines for Preparing and Reviewing Applications for the Licensing of Non-Power Reactors, was published. ${ }^{1}$ Part 1 , the format and content guide, suggests a uniform format for presenting information in nonpower reactor applications that is acceptable to the NRC staff, but conformance with the format and content is not required. Part 2, the SRP, ensures the quality and uniformity of the staff review of an application. Unfortunately, the application guidelines and SRP do not provide adequate guidance for all advanced non-LWR technologies. This discrepancy eventually led to the 2012 development of interim staff guidance (ISG) for NUREG-1537, ${ }^{2}$ which includes criteria for describing and reviewing aqueous homogeneous reactors (AHRs); the 1996 version of NUREG-1537 addressed only aqueous heterogeneous nonpower reactors. Specifically, NUREG-1537 ISG, $2012^{3}$ expanded the original document to address three areas:

1. updated criteria for aqueous heterogeneous nonpower reactors,

2. criteria for licensing AHRs, and

3. criteria for licensing a Part 50-licensed isotope production facility.

Now, an additional ISG for NUREG-1537 is necessary for the description and review of other nonpower MSRs because numerous vendors are beginning to reconsider this technology and the associated test facilities that might be required to support the technology.

This report proposes chapter adaptations for NUREG-1537 in the form of an MSR ISG to address preparation and review of molten salt nonpower reactor license applications. The proposed adaptations are based on a previous regulatory gap analysis of select chapters from NUREG-1537 for their applicability to nonpower MSRs operating with a homogeneous fuel salt mixture.

\footnotetext{
${ }^{1}$ Guidelines for Preparing and Reviewing Applications for the Licensing of Non-Power Reactors: Format and Content, NUREG-1537, Part 1, February 1996. Guidelines for Preparing and Reviewing Applications for the Licensing of Non-Power Reactors: Standard Review Plan and Acceptance Criteria, NUREG-1537, Part 2, February 1996.

${ }^{2}$ Final Interim Staff Guidance Augmenting NUREG-1537, Part 1, “Guidelines for Preparing and Reviewing Applications for the Licensing of Non-Power Reactors: Format and Content, " for Licensing Radioisotope Production Facilities and Aqueous Homogeneous Reactors, ADAMS Accession number ML12156A069, October 17, 2012. Final Interim Staff Guidance Augmenting NUREG-1537, Part 2, “Guidelines for Preparing and Reviewing Applications for the Licensing of Non-Power Reactors: Standard Review Plan and Acceptance Criteria," for Licensing Radioisotope Production Facilities and Aqueous Homogeneous Reactors, ADAMS Accession number ML12156A075, October 17, 2012.

${ }^{3}$ NUREG-1537 ISG, 2012 is a shortened reference for the full titles shown in the previous footnote.
} 
Proposed adaptations are included for the following NUREG-1537 chapters:

- Chapter 4, "Reactor Description"

- Chapter 5, "Reactor Coolant Systems"

- Chapter 6, "Engineered Safety Features"

- Chapter 9, "Auxiliary Systems"

- Chapter 11, "Radiation Protection Program and Waste Management"

The proposed adaptations were prepared by staff members from Oak Ridge National Laboratory (ORNL) with support from Boston Government Services, LLC, as part of a US Department of Energy (DOE) initiative to support the research, development, and demonstration of advanced (non-light water) reactor technologies. MSRs represent one of the advanced non-LWR technologies selected by DOE for development through a multiyear cost share award with Southern Company. The NUREG-1537 chapters listed previously were selected for review because of expected differences in addressing advanced nonLWR technologies, specifically nonpower MSRs, compared with heterogeneously fueled nonpower reactors. All proposed MSR text adaptations are intended to be generic.

The revision of Chapter 11 is intended to provide guidance for categorizing the waste-handling process for a nonpower MSR operating with homogenous fuel. The introduction included with Parts 1 and 2 of NUREG-1537 ISG, 2012, provide guidance for the application and review of production facilities included as part of the nonpower reactor or utilization facility. After a period of operation, nonpower MSRs with homogenous fuel will include gaseous and soluble fission products. The gaseous fission products will be collected and held for decay in an off-gas system. There might also be a desire to polish or filter the soluble fission products in the fuel salt by some mechanical or chemical means. The treatment and handling of fission products in the nonpower MSR fuel salt and the description of this process in the safety analysis report (SAR) must be very precise to avoid the waste treatment facility being construed as a co-located special nuclear material (SNM) fuel cycle facility.

In addition, Chapter 13, "Accident Analyses," has been subjected to a preliminary gap analysis review. However, further design-specific accident analysis information is necessary before preparing a proposed review guidance adaptation for a nonpower MSR. Variability in design detail regarding fuel, neutron spectrum, salt selection, and other parameters make generic accident analysis discussions problematic. This design-specific information is currently closely held by the active vendors.

The accident analyses for the Molten Salt Reactor Experiment (MSRE) is informative but will not be appropriate for all nonpower MSR design variations. Possible accidents considered in the $1961 \mathrm{MSRE}$ hazards analysis ${ }^{4}$ include reactivity excursions, fuel separation, loss of flow, control rod failure, and several mechanical possibilities for containment failure. A 1964 MSRE design and operations report ${ }^{5}$ confirmed that many traditional Chapter 13 analyses are relevant to MSRs, including reactivity excursions, loss-of-flow, and loss-of-coolant accidents. MSRE-specific accidents include premature criticality during fuel filling and increased fissile material in the core during operation.

There are ongoing activities supported by the nuclear industry regarding the selection of licensing basis events (LBEs) for advanced non-LWR reactors. These activities are supported by DOE and the Nuclear

\footnotetext{
${ }^{4}$ S. E. Beall, W. L. Breazeale, and B. W. Kinyon, Molten-Salt Reactor Experiment Preliminary Hazards Report, including Addendums 1 and 2, ORNL-CF-61-2-46, February 28, 1961.

${ }^{5}$ S. E. Beall, et al., MSRE Design and Operations Report, Part V, Reactor Safety Analysis Report, ORNL-TM-732, August 1964.
} 
Energy Institute. These techniques for the selection of LBEs may have implications for nonpower MSR accident analyses in Chapter 13. In addition, the American Nuclear Society (ANS) intends to address MSR LBE selection in its standard, ANS 20.2, Nuclear Safety Design Criteria and Functional Performance Requirements for Liquid-Fuel Molten-Salt Reactor Nuclear Power Plants.

The remaining NUREG-1537 chapters are not expected to differ significantly in their applicability to a nonpower MSR design relative to current nonpower reactors. Therefore, no proposed guidance adaptations are anticipated for those chapters.

Section 2 of this report describes the structured process that guided the development of the proposed ISG for NUREG-1537. Section 3 presents an overview of the results. Appendixes A, B, C, and D present the proposed nonpower MSR ISG guidance for NUREG-1537, Chapters 4, 5, 6, and 9, respectively. This guidance replaces the corresponding chapters in NUREG-1537 Parts 1 and 2 in their entirety and is applicable only to nonpower MSR designs. 



\section{DESCRIPTION OF WORK}

The NUREG-1537 sections included in the appendixes of this report were evaluated relative to (1) the DOE-sponsored December 2016 nonpower MSR regulatory gap analysis, (2) NUREG-1537 ISG, 2012, and (3) a generic working knowledge of MSRs operating with homogenous fuel based on documentation of the MSRE operation at ORNL. Unlike the heterogeneous fuel and coolant concepts for an LWR, NUREG-1537 Chapters 4 and 5 become uniquely interrelated for an MSR application because the liquid fuel and the carrier salt (primary coolant for an LWR) are a homogenous mixture. Most nonpower reactors contain heterogeneous fuel elements consisting of rods, plates, or pins where the fuel cladding acts as the initial fission product barrier. In an MSR, the initial fission product barrier is the fuel salt system boundary and interfacing system boundaries. These elements further impact some of the traditional discussion of fuel and coolant systems, as well as some of the auxiliary systems required.

\subsection{EFFORT AND SCOPE}

ORNL and Boston Government Services team members selected specific chapters of NUREG-1537 and conducted the proposed chapter adaptations individually. Each section within the chapters was reviewed to address the nonpower MSR regulatory gaps identified by the gap analysis completed in December 2016. Specifically, each section was reviewed, and proposals were made to remove references to LWR designs or to assess the applicability of LWR-related statements to MSR designs. The unique characteristics of nonpower MSRs were also considered when formulating performance-based criteria for these reactors. The chapter revisions were compared among the team members and iterated for better compatibility. Finally, a team group meeting was held to review and align all the proposed chapter adaptations to ensure adequate coverage and placement of nonpower MSR design detail.

The review team included some limited instructional material in the proposed adaptations to serve as a basic reference to reviewers addressing the unique nature of MSR designs. This approach is similar to that taken in NUREG-1537 ISG, 2012.

The proposed nonpower MSR ISG for NUREG-1537 is intended to be generic enough to cover different design alternatives, many of which are included in the ISG discussion. It is understood that any given MSR design might not employ all the MSR design characteristics (structures, systems, and components) discussed in the proposed ISG. The proposed ISG also includes MSR nomenclature that is intended to be generic. Specific vendor designs will certainly include alternate system or component terminology. For example, fuel salt, the primary cooling system, and the heat dissipation system are likely to be referred to by design-specific system names. To that end, a glossary was developed and inserted into each chapter for reference. Terms in the glossary are in title case (initial capital letters on principal words) in the chapter text where they are used.

\subsubsection{Terms and Definitions}

The glossary contains the following terms and definitions:

Active Reactor Core: In an MSR, the Vessel region occupied by the fuel salt where the majority of prompt neutrons are generated and where most fissions occur. In an MSR, the core geometry might change with time as a result of changes in density and voiding of the solution. The core does not include the part of the fuel salt that can become entrained into the cover gas.

Coating: Intervening protective layer of material between the corrosive fuel salt and the structural container alloy. Multiple layer configurations are possible (ranging in thickness from $>1 \mathrm{~mm}$, similar to 
liners used in current LWRs, to $<500 \mathrm{~nm}$, which adhere to the underlying substrate). Also included are embedded coatings, which are chemically resistant material that is embedded into the surface of the structural alloy, allowing surface modification to be performed to the structure to enhance its corrosion resistance.

Control Element(s): Object(s) employed to interact with an MSR's neutron population to adjust reactivity. Control elements can act through fuel displacement, neutron absorption, neutron reflection, neutron spectral adjustment, or a combination of these methods. Control elements can be solids, liquids, or gases, and they can be passively or actively positioned.

Emergency Cooling System: System that provides decay heat removal from the Reactor Fuel following an accident (e.g., a direct reactor auxiliary cooling system or a reactor vessel auxiliary cooling system).

Fission Product Barrier: Portion of the Fuel System Boundary in contact with fission products only (e.g., the gas management system boundary).

Fuel Barrier: Portion of the Fuel System Boundary in contact with the fuel salt (principally the Vessel, heat exchanger, control element thimbles, instrumentation thimbles, piping, tanks, and valves).

Fuel System Boundary: All structures that prevent the release of fuel, fission gas, or other fission products. For an MSR, this includes the Vessel, waste-handling tank, pumps, valves, and piping. (Essentially includes the Fission Product Barrier and the Fuel Barrier.)

Heat Dissipation System: Set of components or system(s) that interface with the Primary Cooling System to provide the principal means of transferring the heat from the core to the environment. The Heat Dissipation System might use a variety of coolants (e.g., salt, liquid metal, or water) but does not contain fuel.

Neutron Moderator: In an MSR, materials in or near the core that consist of light elements. Moderators are generally solid form.

Primary Cooling System: Directly interfaces with the Fuel System Boundary at the fuel salt/primary cooling system heat exchanger(s) to provide the principal means of removing heat from the fuel salt by transferring the heat to the Heat Dissipation System. The Primary Cooling System typically contains a salt but does not contain fuel.

Reactor Fuel: In an MSR, fuel salt which consists of fissionable and possibly fertile halide salts, fission products, and generally solvent halide salt(s).

Vessel: For an MSR, structure containing the Active Reactor Core. Other components might reside in the Vessel but outside the Active Reactor Core, such as heat exchangers in certain design configurations.

\subsubsection{Scope}

NUREG-1537, Chapter 4, "Reactor Description," (revised to "Molten Salt Reactor Description") addresses several areas related to reactor design in the following sections:

- 4.2, "Reactor Core," includes discussion of Reactor Fuel, Control Elements, Neutron Moderator and reflector, neutron startup source, and core support structure (revised to "Active Reactor Core" for nonpower MSR adaptation) 
- 4.3, "Reactor Tank or Pool" (revised to "Vessel" for nonpower MSR adaptation)

- 4.4, "Biological Shield"

- 4.5, "Nuclear Design," includes normal operating conditions, Active Reactor Core physics parameters, and operating limits

- 4.6, "Thermal-Hydraulic Design"

- 4.7, "Gas Management System” (new section)

NUREG-1537, Chapter 5, "Reactor Coolant Systems" (revised to "Molten Salt Reactor Cooling Systems"), addresses several areas related to reactor heat removal:

- 5.2, "Primary Coolant System" (revised to "Fuel Salt System Heat Transport" for nonpower MSR adaptation)

- 5.3, "Secondary Coolant System" (revised to "Cooling Systems" for nonpower MSR adaptation)

- 5.4, "Primary Coolant Cleanup System" (revised to "Fuel Salt Cleanup System" for nonpower MSR adaptation)

- 5.5, "Primary Coolant Makeup Water System" (revised to "Salt Makeup Systems" for nonpower MSR adaptation)

- 5.6, "Nitrogen-16 Control System" (revised to "MSR Nitrogen-16 Control System" for nonpower MSR adaptation)

- 5.7, "Auxiliary Systems Using Primary Coolant" (revised to "Auxiliary Systems Using Coolant Salts" for nonpower MSR adaptation)

- 5.8, "Fuel Salt Drain System" (new section)

NUREG-1537, Chapter 6, "Engineered Safety Features," addresses several areas related to engineered safety features:

- 6.2.1, "Confinement"

- 6.2.2, "Containment"

- 6.2.3, "Emergency Core Cooling System" (revised to "Emergency Cooling System" for nonpower MSR adaptation)

NUREG-1537, Chapter 9, “Auxiliary Systems,” addresses several areas related to essential auxiliary systems:

- 9.1, "Heating, Ventilation, and Air Conditioning Systems"

- 9.2, "Handling and Storage of Reactor Fuel"

- 9.3, "Fire Protection Systems and Programs"

- 9.4, "Communication Systems"

- 9.5, "Possession and Use of Byproduct, Source, and Special Nuclear Material"

- 9,6, "Gas Management System” 
- 9.7, "Cooling Systems" (new section)

- 9.8, "Other Auxiliary Systems" (moved)

NUREG-1537, Chapter 11, "Radiation Protection Program and Waste Management," addresses several areas related to waste management and programs:

- 11.1, "Radiation Protection"

- 11.1.1, "Radiation Sources"

- 11.1.2, "Radiation Protection Program"

- 11.1.3, “ALARA Program"

- 11.1.4, "Radiation Monitoring and Surveying"

- 11.1.5, "Gas Management System”

- 11.1.6, "Contamination Control"

- 11.1.7, "Environmental Monitoring"

- 11.2, "Radioactive Waste Management"

- 11.2.1, "Radioactive Waste Management Program"

- 11.2.2, "Radioactive Waste Controls"

- 11.2.3, "Release of Radioactive Waste"

- 11.3, "Respiratory Protection Program" (added by NUREG-1537 ISG, 2012)

In NUREG-1537 ISG, 2012, some chapters are marked for complete replacement relative to those in NUREG-1537, and others are simply outlined with a limited number of changes to make the document applicable to AHRs. For this report, each updated chapter is marked as a complete replacement for the respective NUREG-1537 chapter due to the added glossary in each chapter, the updated terminology specific to MSRs, and the addition of reasonable quantities of new material.

Although the introductory material for NUREG-1537 indicates that the guidance is for nonpower reactor facilities, the lead-in to each chapter reinforces this important point. It is noted in each chapter that whenever the term MSR or reactor appears in the chapter text, it is understood that this refers to a nonpower reactor facility. For clarity, it is also noted in a footnote to each chapter that MSRs are a class of reactors in which a molten salt performs a significant function in the core. A footnote in each chapter further clarifies that there are also salt-cooled reactor designs that propose using fixed-position, coatedparticle ceramic fuel, but discussions in the proposed MSR ISG chapters are focused on MSRs operating with liquid fuel.

All chapter updates are based on the original 1996 version of NUREG-1537 and are informed by NUREG-1537 ISG, 2012, except for Chapter 4, Part 2, which is based directly on NUREG-1537 ISG, 2012. The appendixes contain clean versions of the proposed MSR ISG text, but marked up versions are available on request. 


\subsection{PRODUCTION FACILITY CONSIDERATIONS}

The introduction to NUREG-1537 ISG, 2012, notes that the ISG was prepared to support the construction and operation of medical isotope production facilities based on the Energy Policy Act of 2005, which called for the National Research Council to study ways to ensure a reliable supply of medical isotopes. NUREG-1537 ISG, 2012, was published to be applied to future AHR applications "for a 10 CFR Part 50 utilization and radioisotope production facility license."

NUREG-1537 ISG, 2012, further notes that:

Facilities separating radioisotopes from irradiated special nuclear material (SNM) will be licensed as production facilities under 10 CFR Part 50 unless an exemption is applied for and granted, or the facility meets one of the subpart (3) exceptions to the definition for production facility found in 10 CFR 50.2.

A facility meeting any of these exceptions is by definition not a production facility and is therefore not subject to the 10 CFR Part 50 production facility requirements; rather, it would be considered an SNM fuel cycle facility subject to the requirements of 10 CFR Part 70, "Domestic Licensing of Special Nuclear Material." NUREG-1520, Standard Review Plan for the Review of a License Application for a Fuel Cycle Facility, Revision 1, issued May 2010, presents the standard review plan for a 10 CFR Part 70 facility.

Since the NRC had not previously developed review guidance in the form of an SRP for a 10 CFR Part 50 production facility, NUREG-1537 ISG, 2012, was prepared to provide such guidance. In NUREG-1537 ISG, 2012, a separate license under 10 CFR Part 70 was not deemed necessary for the operation of medical isotope production facilities.

Once operated, MSRs will contain gaseous, soluble, and nonsoluble fission products in the fuel salt. The gaseous fission products must be removed from the core and cover gas to allow continued operation of the nonpower MSR. In addition, some nonpower MSR designs might include a chemical or mechanical polishing system to filter soluble fission products. MSR vendors would intend these actions to be part of the routine waste handling of the nonpower MSR operation. As such, these activities would be covered under NUREG 1537, Chapter 11, "Radiation Protection Program and Waste Management." However, this separation of fission products could possibly be viewed as a colocated SNM fuel cycle facility. If so, this could require a separate license subject to the requirements of 10 CFR Part 70. Therefore, some enhanced discussion of MSR waste handling is warranted and is included in the adaptation of Chapter 11 for MSRs. Careful attention must be directed to the description of the waste management process. An application for a nonpower license should explain why the waste management process does not involve separation of special nuclear material. Strong discussion should reinforce the understanding that no facility exists to separate actinides.

A production facility is defined in 10 CFR Part 50.2 as the following:

1. Any nuclear reactor designed or used primarily for the formation of plutonium or ${ }^{233} \mathrm{U}$

2. Any facility designed or used for the separation of plutonium isotopes, except laboratory-scale facilities designed or used for experimental or analytical purposes only

3. Any facility designed or used for the processing of irradiated materials containing SNM, except

a. laboratory-scale facilities designed or used for experimental or analytical purposes 
b. facilities in which the only SNMs contained in the irradiated material to be processed are uranium enriched with ${ }^{235} \mathrm{U}$ isotopes and plutonium produced by the irradiation, if the material processed contains not more than $10^{-6}$ grams of plutonium per gram of ${ }^{235} \mathrm{U}$ and has fission product activity not in excess of $0.25 \mathrm{mCi}$ of fission products per gram of ${ }^{235} \mathrm{U}$

c. facilities in which processing is conducted pursuant to a license issued under parts 30 and 70 of this chapter, or equivalent regulations of an agreement state for the receipt, possession, use, and transfer of irradiated SNM, which authorizes the processing of the irradiated material on a batch basis for the separation of selected fission products and limits the process batch to not more than 100 grams of uranium enriched in ${ }^{235} \mathrm{U}$ and not more than $15 \mathrm{~g}$ of any other SNM

A utilization facility is defined in 10 CFR Part 50.2 as

1. any nuclear reactor other than one designed or used primarily for the formation of plutonium or ${ }^{233} \mathrm{U}$ or

2. an accelerator-driven subcritical operating assembly used for the irradiation of materials containing SNM and described in the application assigned docket number 50-608.

Based on these definitions, it would appear possible to license a nonpower MSR as a utilization facility using 10 CFR Part 50 and review guidance provided in NUREG-1537 as adapted for the unique characteristics of an MSR. A separate license under 10 CFR Part 70 is not anticipated. Chapter 11 was revised to reflect this understanding.

\subsection{PROPOSED ISG GUIDANCE}

Proposed adaptations to NUREG-1537 Chapters 4, 5, 6, 9, and 11 for an MSR ISG are presented in the appendixes to this report. For brevity, clarity, and readability, the adaptations are presented in clean text. Redline/strikeout versions of each chapter are available on request.

- Appendix A: Chapter 4 sections

- Appendix B: Chapter 5 sections

- Appendix C: Chapter 6 sections

- Appendix D: Chapter 9 sections

- Appendix E: Chapter 11 sections 


\section{OBSERVATIONS ON SIGNIFICANT NUREG-1537 ADAPTATIONS}

A gap analysis on NUREG- $1537^{6}$ Chapters 4, 5, 6, 9, and 11 revealed fundamental differences in the potential suitability of heterogeneous fuel-based technology applied to the assessment of reactor components for a nonpower MSR design. The material in NUREG-1537 is based on more than 50 years of experience with commercial and nonpower reactors using heterogeneous fuel, including extensive research conducted on topics pertinent to LWRs. NUREG-1537 documents a performance-based approach for establishing design criteria and ensuring they are met. This is a familiar, accepted approach for nonpower LWR application reviews proven by decades of operating experience, research, and revisions to the review methodology when justified and necessary. The MSR technology has historical precedence for demonstrating key principles of design and limited years of operating experience. However, this experience is not as comprehensive as it is for LWR technologies, so experience with performance-based methods applied to the nonpower LWR reviews is lacking for MSR technology. This observation was borne out as adaptations for NUREG-1537 were developed. The adaptations for MSR technology must consider review processes that ensure the adequacy of proposed designs while recognizing the reduced operating experience with MSR designs. The proposed changes are in accordance with the Atomic Energy Act of 1954, as amended, for the licensing of nonpower reactors. Highlights of the proposed adaptations follow.

\subsection{CHAPTER 4, "MOLTEN SALT REACTOR DESCRIPTION"}

The most significant change in Chapter 4 is regarding the references to heterogeneous fuel elements consisting of rods, plates, or pins with fuel cladding acting as the initial Fission Product Barrier. A liquidfueled MSR uses homogenous fuel with no cladding. The initial Fission Product Barrier in an MSR is the Fuel System Boundary. This requires modification of fuel discussions and descriptions throughout the chapter. References to fuel melting and integrity must be replaced with appropriate discussion of the fuel solution and the integrity of the Fuel System Boundary.

The discussion of Reactor Fuel chemistry in Section 4.2 was revised. The formation of gaseous, soluble, and nonsoluble fission products in the fuel salt will affect system chemistry. References to $\mathrm{pH}$ control were universally revised to redox in the acid-based fuel salt solution. Chemistry control, mitigation, and redox tactics must be identified by the applicant for short- and long-term changes in the chemistry of the fuel salt. Fuel purification might play a role in the nonpower MSR design; if so, it would be detailed by the applicant per the guidance in Chapter 5. In general, fuel qualification is a chemical process rather than a mechanical process, as it is for heterogeneous fuel.

Neutron-adsorbing control rods are the typical means to control reactivity in an LWR, but there are many more ways to control reactivity in an MSR. MSR designs can control reactivity through fuel displacement, neutron absorption, neutron reflection, neutron spectral adjustment, or a combination of these methods. As a result, the term "control elements" is universally used in place of the term "control rods." Control elements can be solids, liquids, or gases and can be passively or actively positioned.

The core support structure discussion has new implications regarding fuel salt. The fuel-positioning function of a heterogeneous reactor core support structure is not applicable to an MSR. Since the Active Reactor Core is fluid fuel salt, the MSR core support structure is the Vessel. The core support structure discussion was revised to include the Vessel and the reflector's vertical and lateral support structure, as

\footnotetext{
${ }^{6}$ R. J. Belles, G. F. Flanagan, and M. Voth, Regulatory Gap Analysis of Guidelines for Preparing and Reviewing Applications for Licensing of Non-Power Reactors (NUREG-1537) for Applicability to Molten Salt Reactors, ORNL/SR-2016/725, December 2016, Distribution controlled by sponsor.
} 
well as support for the reactor control, instrumentation, cooling components, and any other components connected to the Vessel.

Pool- or tank-type reactors are not viable MSR research or test design options based on the International Atomic Energy Agency (IAEA) definition for pool reactors in this category. The IAEA categorizes research reactors into three common types: ${ }^{7}$

1. pool-type, in which "the core is a cluster of fuel elements sitting in a large open pool of [fluid]"

2. tank-type, in which "the core is contained in a vessel"

3. tank-in-pool type, in which "the core is located in a pool, but enclosed in a tank through which the coolant is pumped"

For clarity, this terminology was revised to "use of a gas-tight vessel." Likewise, pulsing-power MSRs are not under consideration, so this design feature was removed.

Some delayed neutrons will be produced outside the Active Reactor Core because of the nature of the flowing fuel solution and its movement out of the Active Reactor Core. Any sudden reduction in flow, such as a transition from forced flow to natural circulation flow, will result in a subsequent reactivity addition. Therefore, the ability to control the core during normal operation and core flow changes must be considered by the applicant.

Gaseous, soluble, and nonsoluble fission products are generated within the fuel salt as an MSR is operated. Gaseous fission products accumulate within the Vessel or within a cover gas at a free surface boundary. Text was added in Section 4.7, "Gas Management System," that requires the applicant to describe the design of the system for removing fission product gases from the core and cover gas of the MSR. Any decay heat removal provided by the gas management system to the overall reactor cooling is summarized in Chapter 4 and detailed in Chapter 5. Heat removal from the gas management system by the auxiliary cooling system is addressed in Chapter 9.

Fuel burnup does not have the same limitations for a homogenous MSR core as it does for a heterogeneous core. The term "burnup" relative to the Reactor Fuel is universally replaced by the phrase "composition changes." Fuel composition changes over time, impacting core reactivity. This should be addressed by the applicant in Section 4.5, "Nuclear Design."

Regulatory Guide 2.1, "Shield Test Program for Evaluation of Installed Biological Shielding in Research and Training Reactors," shown in Appendix A, Section 4.1, has been replaced by Regulatory Guide 1.69, "Concrete Radiation Shields and Generic Shield Testing for Nuclear Power Plants," issued May 2009.

\subsection{CHAPTER 5, "MOLTEN SALT REACTOR COOLING SYSTEMS"}

Liquid homogeneous MSR fuel salt dissipates heat through a heat exchanger to cooling systems that do not include fuel. Therefore, the former heterogeneous fuel-based primary coolant system no longer exists with the same function as provided for LWR fuel. For clarity, the proposed title for Chapter 5 was revised from "Reactor Coolant Systems" to "Molten Salt Reactor Cooling Systems."

Some brief background on generic MSR heat transfer is provided in Chapter 5. The heat transfer systems are somewhat more complex than those required to cool heterogeneous-fueled reactors.

\footnotetext{
${ }^{7}$ IAEA, Research Reactors: Purpose and Future, https://www.iaea.org/OurWork/ST/NE/NEFW/Technical-Areas/RRS/documents/RR_Purpose_and_Future_BODY.pdf Accessed September 22, 2017
} 
Section 5.2 was retitled "Fuel Salt Heat Transport" since the discussion is no longer directed at the function of the coolant in direct contact with the heterogeneous fuel assemblies. This section was refocused for the applicant to discuss heat transport within the Fuel System Boundary to the fuel salt/primary cooling heat exchanger(s), including system drawings and operating parameters. The specifics for the fuel salt are discussed in Chapter 4, and general thermal-hydraulic properties are discussed in Section 4.6.

Section 5.3, "Secondary Coolant System," was retitled to simply "Cooling Systems" and was divided into two subsections. This section provides parameters for the applicant to describe how reactor heat is removed and transferred to the environment, typically through two or more cooling loops. The first subsection, "Primary Cooling System," provides parameters for the applicant to describe the salt system that directly interfaces the fuel salt through the fuel salt/primary cooling heat exchanger(s). The second subsection, "Heat Dissipation System," interfaces with the Primary Cooling System subsection and provides the parameters for the applicant to describe all remaining heat transport loops required by the design to disperse the reactor heat to the environment. Heat Dissipation Systems can use a variety of coolants, including salt, water, and liquid metal.

Gaseous, soluble, and nonsoluble fission products build up in the fuel salt as an MSR is operated. Gaseous fission products accumulate within the Vessel or within a cover gas at a free surface boundary. Because this is not an issue with the heterogeneous fuel discussed in the original document, a section was added to Chapter 4 that describes the gas management system and handling of gaseous fission product buildup. Section 5.4, "Fuel Salt Cleanup System," provides the complementary parameters for the applicant to describe any cleanup or salt polishing system included in the MSR design to handle the buildup of soluble and nonsoluble fission products.

Provisions are made for salt makeup in the various MSR salt loops. A section in Chapter 5 that addresses makeup was revised to provide for the addition of salt to the fuel salt and to the Primary Cooling System salt. Likewise, a drain tank is typically provided to allow for safe storage of the fuel salt in the event of a design-basis accident or for Fuel System Boundary maintenance. A new section in Chapter 5 was added to describe the parameters of a fuel salt drain tank (if applicable).

\subsection{CHAPTER 6, "ENGINEERED SAFETY FEATURES"}

The discussion of confinement and containment is generally applicable to all nonpower reactor designs. However, it is noted in the proposed chapter adaptation that multiple confinement or containment boundaries might be included for an MSR design depending on the relative location of the gas management system and other cleanup systems to the Fuel System Boundary.

The current version of Section 6.2.3, "Emergency Cooling System," assumes that heterogeneous fuel is used in the reactor design and that it must be continuously covered and cooled to maintain fuel integrity. Consequently, the issue of concern has been the continued heat removal from the fixed core to maintain fuel integrity and coolable core geometry. Loss-of-coolant accidents (LOCAs) figure prominently in the discussion of the current requirements because of the importance of cooling the heterogeneous fuel and preventing core melt, which can lead to uncoolable core geometry. However, the MSR LOCA concern is at the fuel solution boundary, which must be protected from overheating, as it can result in a boundary material failure. Therefore, the chapter was revised to indicate that for the homogenous fuel in an MSR, maintaining a decay heat removal path for continued boundary integrity is the key safety issue. Decay heat removal can be provided by multiple means, including a drain tank with a separate cooling system, a direct reactor auxiliary cooling system that passively rejects heat to air via a salt system, or a reactor vessel auxiliary cooling system that passively rejects heat to outside air via a water or air system. 


\subsection{CHAPTER 9, “AUXILIARY SYSTEMS"}

Chapter 9 notes that auxiliary systems should include homogeneous MSR fuel handling and storage of SNM used for Reactor Fuel (both new and irradiated), including systems (tanks, valves, pumps, instrumentation, controls), processes (chemical blending, SNM transfers, waste storage, preparation for shipment), criticality monitoring, vaults, shielding, and contamination control. A revision to the section indicated that the fuel handling discussion should address the form of the fuel during storage and handling. For facilities designed to fabricate fuel on site, the discussion should include a description of the form in which the fissile material is received, how and where it is stored before use, and how it is blended into a useable liquid fuel, including criticality control measures and monitoring.

The use of liquid fuel adds numerous new issues pertaining to quantification of the quantity of byproduct, source, and SNM that differ from the use of heterogeneous fuel elements. Two new issues regarding MSRs that should be addressed by an MSR applicant are added to section 9.5. First, an effective means should be defined for limiting the SNM at the reactor site to establish an envelope used for safety and security analyses. Consideration should be given to the fact that fuel isotope quantities in the fuel salt will change during normal operation, as ${ }^{235} \mathrm{U}$ is depleted and ${ }^{238} \mathrm{U}$ converts to ${ }^{239} \mathrm{Pu}$, or as ${ }^{232} \mathrm{Th}$ is converted to ${ }^{233} \mathrm{U}$. Second, the mission of a test MSR facility should be evaluated to determine limits on the quantity of byproduct materials created by experiments and routine operation.

Section 9.6, "Gas Management System," was revised to focus on control of the cover gas and any auxiliary cooling system for the gas management system. The revised text indicates that an applicant should describe cover gas systems that cool, circulate, decontaminate, recover, store, monitor, and dispose of the cover gas. Section 4.7 provides the parameters for the applicant to describe the design of the system for removing fission product gases from the core and cover gas of the MSR.

Section 9.7, "Cooling Systems," was added for the applicant to coordinate the necessary auxiliary cooling systems with the system discussions required by Chapter 5 .

\subsection{CHAPTER 11, "RADIATION PROTECTION PROGRAM AND WASTE MANAGEMENT"}

Chapter 11 notes that waste management is significantly different for an MSR when compared to an LWR. In an MSR, fission products are released to the liquid salt fuel solution and contained by the Fuel Barrier. However, in an LWR, fission products are released to the fuel rod gap space and contained by the fuel clad. MSR gaseous fission products will migrate directly to the gas space in the top of the Vessel and enter the gas management system to be processed within the Fission Product Barrier. The fission gas may require holdup for decay or further treatment before being recycled (cover gas), released to the environment or disposed as waste. If applicable, residue from mechanical cleanup or polishing of soluble fission products will require treatment as radioactive waste.

Part 1, Section 11.2.2, "Radioactive Waste Controls," was revised to emphasize vigilance in the use of terminology that could confuse the process of waste removal with the production of SNM. Some nonpower reactor licenses do not allow the "separation of isotopes" or the "separation of byproduct materials" to enforce regulations dealing with the separation of plutonium or the enrichment of ${ }^{233} \mathrm{U}$ or ${ }^{235} \mathrm{U}$ so as to produce SNM. In the strictest sense, that could be interpreted as not allowing the removal of wastes from MSR liquid fueled cores. Fission gases do this inherently by simply rising from the liquid. Other undesired fission products are removed from the liquid fuel by waste treatment processes with no intention of producing SNM. Therefore, waste treatment processes must be clearly defined using unambiguous terms. 
Section 11.2.2 has also been revised to note that the potential for criticality concerns in the waste treatment process for accident analysis and normal operation may exist. If a criticality concern does exist, the applicable provisions of 10 CFR Part 70.24 should be met.

Section 11.3, "Respiratory Protection Program," was added as part of NUREG-1537 ISG, 2012. It continues to be applicable to MSR facilities and is included as part of the recommended NUREG-1537 adaptation for MSRs.

In Part 2, Section 11.2.1, "Radioactive Waste Management Program," the reviewer is directed to ensure that the applicant has described the waste management program in a manner showing that processes effectively remove undesired materials from the liquid fuel without providing a means for fissile material separation and collection in the process.

Careful attention must be directed to the waste management process so that there is no indication that the MSR is a production facility. Strong discussion should reinforce the understanding that no facility exists to separate actinides. 



\section{APPENDIX A. CHAPTER 4, "MOLTEN SALT REACTOR DESCRIPTION"-MSR ADAPTATION}





\section{APPENDIX A. CHAPTER 4, “MOLTEN SALT REACTOR DESCRIPTION"-MSR ADAPTATION OF PART 1}

\section{MOLTEN SALT REACTOR DESCRIPTION (Part 1)}

Replace NUREG-1537, Part 1, Chapter 4, in its entirety with the following guidance.

NUREG-1537, Part 1, Chapter 4, of the format and content guide, as augmented by this ISG, is applicable to providing a description of the design and functional characteristics of the reactor for the licensing of a nonpower molten salt reactor (MSR) facility. Whenever the term MSR or reactor appears, it is understood to mean a nonpower reactor facility.

In this chapter of the SAR, the applicant should discuss and describe the principal features, operating characteristics, and parameters of the MSR. ${ }^{8}$ The analysis in this chapter should support the conclusion that the reactor design ensures adequate public safety through safe operation and shutdown under all credible operating conditions. Information in this chapter of the SAR should provide the design bases for many systems, subsystems, and functions discussed elsewhere in the SAR and for many technical specifications (TSs).

The following glossary contains terms often used when discussing an MSR.

Active Reactor Core: In an MSR, the Vessel region occupied by the fuel salt where the majority of prompt neutrons are generated and where most fissions occur. In an MSR, the core geometry might change with time as a result of changes in density and voiding of the solution. The core does not include the part of the fuel salt that can become entrained into the cover gas.

Coating: Intervening protective layer of material between the corrosive fuel salt and the structural container alloy. Multiple layer configurations are possible (ranging in thickness from $>1 \mathrm{~mm}$, similar to liners used in current LWRs, to $<500 \mathrm{~nm}$, which adhere to the underlying substrate). Also included are embedded coatings, which are chemically resistant material that is embedded into the surface of the structural alloy, allowing surface modification to be performed to the structure to enhance its corrosion resistance.

Control Element(s): Object(s) employed to interact with an MSR's neutron population to adjust reactivity. Control elements can act through fuel displacement, neutron absorption, neutron reflection, neutron spectral adjustment, or a combination of these methods. Control elements can be solids, liquids, or gases, and they can be passively or actively positioned.

Emergency Cooling System: System that provides decay heat removal from the Reactor Fuel following an accident (e.g., a direct reactor auxiliary cooling system or a reactor vessel auxiliary cooling system).

Fission Product Barrier: Portion of the Fuel System Boundary in contact with fission products only (e.g., the gas management system boundary).

\footnotetext{
${ }^{8}$ MSRs are a class of reactors in which a molten salt performs a significant function in the core.
} 
Fuel Barrier: Portion of the Fuel System Boundary in contact with the fuel salt (principally the Vessel, heat exchanger, control element thimbles, instrumentation thimbles, piping, tanks, and valves).

Fuel System Boundary: All structures that prevent the release of fuel, fission gas, or other fission products. For an MSR, this includes the Vessel, waste-handling tank, pumps, valves, and piping. (Essentially includes the Fission Product Barrier and the Fuel Barrier.)

Heat Dissipation System: Set of components or system(s) that interface with the Primary Cooling System to provide the principal means of transferring the heat from the core to the environment. The Heat Dissipation System might use a variety of coolants (e.g., salt, liquid metal, or water) but does not contain fuel.

Neutron Moderator: In an MSR, materials in or near the core that consist of light elements. Moderators are generally solid form.

Primary Cooling System: Directly interfaces with the Fuel System Boundary at the fuel salt/primary cooling system heat exchanger(s) to provide the principal means of removing heat from the fuel salt by transferring the heat to the Heat Dissipation System. The Primary Cooling System typically contains a salt but does not contain fuel.

Reactor Fuel: In an MSR, fuel salt which consists of fissionable and possibly fertile halide salts, fission products, and generally solvent halide salt(s).

Vessel: For an MSR, structure containing the Active Reactor Core. Other components might reside in the Vessel but outside the Active Reactor Core, such as heat exchangers in certain design configurations.

\subsection{Summary Description}

In this section, the applicant should briefly summarize the design and functional characteristics of the reactor. The applicant should present the principal safety considerations in the selection of the reactor type as well as the design principles for the components and systems that address those considerations. This section should contain summary tables of important reactor parameters and sufficient drawings and schematic diagrams to explain and illustrate the main reactor design features.

The applicant should briefly address the following features of the reactor:

- thermal power level

- $\quad$ fuel type and enrichment

- Vessel

- forced and/or natural-convection cooling

- $\quad$ type of fuel salt, moderator (if any), and reflector

- $\quad$ principal features for experimental programs (if any)

- $\quad$ novel concepts requiring substantial new development 


\subsection{Active Reactor Core}

In this section, the applicant should present all design information and analyses necessary to demonstrate that the core can be safely operated. The major core components to be described are fuel, Neutron Moderator, neutron reflector, Control Elements, neutron startup source, incore cooling components, and any incore experimental facilities. The source or basis of the information presented should be given.

\subsubsection{Reactor Fuel}

In this section, the applicant should describe the Reactor Fuel and the Fuel System Boundary. Included should be the design features selected to ensure that the Fuel System Boundary can withstand all credible environmental and irradiation conditions during its life cycle at the reactor site. The discussions should address the incore fuel operating conditions. Handling, transport, and storage of fuel should be discussed in Chapter 9, "Auxiliary Systems," of the SAR. Drawings and tables of design specifications and operating characteristics of the fuel should be presented.

In MSRs, fission product gases build up within the Vessel, or at a free surface provided above the liquid fuel. ${ }^{9}$ Gases generated during fission also collect in the cover gas space. Therefore, information relevant to the head space and gas management systems should be provided.

Information should be current; supported by referenced tests, measurements, and operating experience; and compared with additional applicant experience where applicable. The information should include the following:

- $\quad$ Chemical composition, enrichment, uranium loading, and chemistry of the fuel salt. Information should be provided for fresh and reloaded fuel composition, salt type, plutonium loading (if applicable), expected fissile density in solution at operational pressure, temperature and redox conditions, fissile material solubility, buildup of fission products and related decay daughters in the fuel salt, precipitates, and sparging and sweep gas system.

- Information on fission gas formation and impact on Active Reactor Core chemistry, homogeneity, and reactivity. Information on void formation collapse on reactor performance should be discussed.

- $\quad$ Short-term changes in the chemistry of the fuel, such as changes in redox, temperature fluctuations, and fission gas release. The range of these fluctuations, and their effects on reactor operation and controls should be described.

- Long-term changes in the chemistry of the fuel. In particular, buildup of fission products, activation products, and corrosion products would be of interest. Any plans for stabilizing or adjusting fuel characteristics or composition should be included. Any plans regarding periodic reconstitution or purification of the fuel should also be included. Any scheduled periodic analysis plans for the fuel should be described. Finally, a description of the fuel at the end of life should be given.

\footnotetext{
${ }^{9}$ There are also salt-cooled reactor designs that propose using fixed-position, coated-particle ceramic fuel. The discussion in this chapter is focused on MSRs operating with liquid fuel.
} 
- $\quad$ Description of the volume occupied by the fuel solution, including the height and diameter and portion of the volume occupied by solids. Separate descriptions should be given for conditions with and without significant power and fission gas generation. Special features such as moderators (if applicable) reflectors, external geometrical designs to enhance cooling capability, and inherent safety or feedback provisions should be discussed.

- $\quad$ Physical properties significant to safety that are important for the thermal-hydraulic analyses, such as fuel salt density, power density and distribution (composition change over time), temperature, pressure, heat capacity, viscosity, gas evolution or diffusion (including fission product gas), changes in void fraction, precipitation of fuel or fission product complexes, and sparging or sweep gas.

- $\quad$ Material and structural information for the Vessel and piping (including the fuel salt/primary cooling heat exchanger) that relate to the integrity of the Fuel Barrier, such as dimensions, fabrication methods, compatibility of materials, irradiation effects, temperatures, and specifications with tolerances.

- $\quad$ Descriptions of all types of fuel salt chemical constituents used should be described, as well as the fuel preparation method and location.

- Information on material parameters that could affect the integrity of the Vessel, the fuel salt/primary cooling heat exchanger, Control Element channels, and fuel transport piping, such as melting, softening, or blistering temperatures; corrosion; erosion; and mechanical factors, such as swelling, bending, twisting, compression, and shearing.

- A brief history of the fuel type, with references to the fuel development program, including summaries of performance tests, qualification, and operating history

- Hydraulic forces, thermal changes and temperature gradients, internal pressures including that from fission products and gas evolution (including removal to gas treatment), pressure, precipitation, malfunctions of the gas management system, and radiation effects on the solution chemistry. Extended and more detailed discussion of these characteristics and effects may be included in Section 4.7, "Gas Management System" (addressed below).

- $\quad$ Adequate mixing of the fuel solution based on convection and gas evolution.

Information and analyses should support the limits on operating conditions for the fuel. These limits are specified to ensure that the integrity of the Fuel System Boundary will not be impaired by loss of redox control, fission gas evolution, power oscillations, precipitation from fuel salt, temperature and pressure extremes or distributions, and materials compatibility. They should form the design bases for this and other chapters of the SAR, the reactor safety limits (SLs), and other fuel-related TS.

\subsubsection{Control Elements}

In this section, the applicant should provide information on the Control Elements, including all elements that are designed to change reactivity during reactor operation. The physical, kinetic, and electromechanical features demonstrating that the Control Elements can fulfill their control and safety functions should be described. Results of computing Control Element reactivity worths may be presented in this section, but details of the calculation of reactivity effects should 
appear in Section 4.5, "Nuclear Design," of the SAR. The information in this section should include the following:

- $\quad$ The number and types of Control Elements (e.g., shim, safety, regulating, transient), their designed locations in the core, and their designed reactivity worths. The considerations and bases for redundancy and diversity should be provided. Limits on core configuration should be discussed.

- $\quad$ The structural and geometric description, including control element withdrawal rate limits, shape, size, materials, cladding, fabrication methods, and specifications with tolerances for the Control Elements. This should include the type and concentration of neutron absorber, or emitter, if applicable. Also, calculations of changes in reactivity worth due to burnup and assessment of radiation damage, heating effects, and chemical compatibility with the fuel salt and other core components should be given. If the Control Elements have followers, the design, composition, and reactivity effects of the follower should be discussed.

- $\quad$ The structural and mechanical design relative to the Vessel penetrations provided for the Control Elements. Information should be included on whether the penetrations are closed or open-ended thimbles or tubes, whether the Control Elements require cooling during operation at power, and how the thermal-hydraulic design keeps the reactor within the specified operational and safety limits. Cooling calculations may be included in Chapter 5, "Molten Salt Reactor Cooling Systems."

- $\quad$ The design of mechanical supports for the active component, the method of indicating and ensuring reproducible positioning in the core, and the drive mechanism of each type of Control Element. This information should include the source of motive power, usually electrical, and the systems ensuring scram capability.

- $\quad$ The kinetic behaviors of the Control Elements, showing either the positive or negative rate of reactivity change, in the normal drive and scram modes of operation. This information should be supplied for all Control Elements.

- $\quad$ Evidence that the Control Elements design conforms to the shutdown margin requirements.

- Summarizations of the scram logic and circuitry, interlocks and inhibits on Control Element movement or withdrawal, trip release and insertion times, and trip or scram initiation systems. They should also be described in detail in Chapter 7, "Instrumentation and Control Systems."

- Special features of the Control Elements, their core locations, power sources, drive or release mechanisms designed to ensure operability and capability to provide safe reactor operation and shutdown under all conditions during which operation is required in the safety analysis if there is a single failure or malfunction in the control system itself. Such features may include mechanisms to limit the speed of Control Elements movement.

- $\quad$ TS requirements for the Control Elements and their justification. These are the limiting conditions for operation (LCOs), surveillance requirements (SRs), and design features as discussed in Chapter 14, "Technical Specifications," of this format and content guide. 


\subsubsection{Neutron Moderator (if applicable) and Reflector}

In this section, the applicant should discuss the materials and systems designed to moderate (if applicable) the neutrons within the fuel region and reflect leakage neutrons back into the fuel region. The information should include the materials, geometries, reflector or moderator structure including designs for changes or replacement, provisions for cooling, radiation damage considerations, and provisions for experimental facilities or special uses. Multiple use systems and features such as moderator coolant, fuel moderator, and reflector shield should be described. If moderators or reflectors are encapsulated to prevent contact with fuel salt, the effect of failure of the encapsulation should be analyzed. It should be possible to operate the reactor safely until failed encapsulations are repaired or replaced. If reactor operations cannot be safely continued, the reactor should be placed and maintained in a safe condition until encapsulations are repaired or replaced. TS requirements should be proposed and justified for the moderator and reflector in accordance with the guidance in Chapter 14 of this format and content guide. The nuclear design of the moderator and reflector should be discussed in Section 4.5 of the SAR.

\subsubsection{Neutron Startup Source}

In this section, the applicant should present design information about the neutron startup source and its holder. The applicant should show that the source will produce the necessary neutrons to allow a monitored startup with the reactor instrumentation. The information should include the neutron strength and spectrum, source type and materials, its burnup and decay lifetime, and its regeneration characteristics. Other necessary information includes the material and geometry of the holder, the method of positioning the source in the core, and the core locations in which the source is designed to be used. Utilization information and such limitations as radiation heating or damage and chemical compatibility with fuel salt and other core components should be discussed. Any TS limits on the source should be proposed and justified in this section of the SAR in accordance with the guidance in Chapter 14 of this format and content guide. Examples include the maximum power level the reactor can be run with the source in place (for plutoniumberyllium sources and other source types that can act as fuel) or surveillance requirements to ensure source integrity.

\subsubsection{Core Support Structure}

In this section, the applicant should present design information about the mechanical structures that support and position the core and its components. The information should include the following:

- The Vessel and reflector vertical and lateral support structure, as well as the support for the reactor control and cooling components and any other components connected to the Vessel. It is important to include these items because the Active Reactor Core is fluid fuel salt and, therefore, the MSR core support structure is the Vessel. The fuel-positioning function of a heterogeneous reactor core support structure is not applicable to an MSR.

- The materials of construction, including considerations for radiation damage, corrosion, erosion, chemical compatibility with fuel salt and core components, potential effects on reactivity, induced radioactivity, and maintenance.

- Design features of the support structures that accommodate other systems and components such as radiation shields, reflectors, fuel salt piping (including accommodation for hydraulic forces, buoyant forces, and dynamic loads such as 
vibration), Control Element drive thimbles, fuel salt plenums or deflectors, gas treatment systems, and nuclear detectors. Piping for fuel transfer to and from the core should be specifically addressed.

- $\quad$ TS that control important design features, LCOs, and SRs, as discussed in Chapter 14 of this format and content guide. The applicant should justify these TS in this section of the SAR.

\subsection{Vessel}

The core of the MSR is a solution of fuel salt within a gas-tight vessel. In this section, the applicant should present all information about the Vessel necessary to demonstrate its integrity. The information should include the following:

- Design and considerations to ensure that no hydrodynamic, hydrostatic, mechanical chemical, and radiation forces or stresses could cause failure or loss of integrity of the Vessel during its projected lifetime over the range of design characteristics.

- $\quad$ Design and dimensions to ensure sufficient shielding to protect personnel and components. (Also see Sections 4.4 and 4.6 and Chapter 11, "Radiation Protection Program and Waste Management," of this format and content guide.)

- Designs and description of materials, including dimensions, supporting structures, chemical compatibility with the fuel salt and other reactor system components, radiation fields and any consequences of radiation damage, protection from corrosion in inaccessible regions, and capability to replace components, if necessary.

- Locations of penetrations and attachment methods for other components and pipes. The relationships of these penetrations to salt surface elevations should be discussed. Safetyrelated features that prevent loss of fuel salt should be discussed and related to Sections 4.4 and 4.6 and to the reduction in cooling scenarios analyzed in Chapter 13, "Accident Analyses," as applicable.

- If the inner surface of the Vessel is coated to alleviate the impact of contact with the fuel, the effect of failure of the Coating should be analyzed.

- $\quad$ Planned methods for assessing radiation damage, chemical damage, erosion, pressure pulses, or deterioration during the projected lifetime. In this section the applicant should assess the possibility of uncontrolled leakage of fuel solution into the reactor cavity and should discuss preventive and protection features.

- $\quad$ TS that control important design features, LCOs, and SRs as discussed in Chapter 14 of this format and content guide. The applicant should justify these TS in this section of the SAR.

\subsection{Biological Shield}

In this section, the applicant should present information about the principal biological shielding designed for the reactor. The information should include the following:

- $\quad$ The design bases for the radiation shields (e.g., water, concrete, or lead), including the projected reactor power levels and related source terms and the criteria for determining 
the required protection factors for all applicable nuclear radiation activity. Chapter 11 should present information about conformance with the regulations for radiation exposure and the facility's ALARA (as low as reasonably achievable) program. The design basis should include the designed reactor power levels, associated radiation source terms, and other radiation sources within the Vessel as well as systems outside the Vessel that require shielding.

- $\quad$ The design details and methods used to achieve the design bases. The applicant should discuss the protection of personnel and equipment functions. The information should specify the general size and shape of the shields and the methods used to ensure structural strength, rigidity, and functional integrity. The applicant should discuss the distribution of shielding factors between liquid (water) and solid (concrete, lead, etc.) materials. If loss of shield integrity could cause a reduction in cooling, the features to prevent the loss of integrity should be described.

- $\quad$ The materials used and their shielding coefficients and factors, including a detailed list of constituents and their nuclear and shielding properties. The applicant should discuss radiation damage and heating or material dissociation during the projected lifetime of the reactor, induced radioactivity in structural components; potential radiation leakage or streaming at penetrations, interfaces, and other voids; shielding at experimental facilities (if applicable); and shielding for facilities that store fuel and other radioactive materials within the Vessel and outside the Vessel.

- $\quad$ The assumptions and methods used to calculate the shielding factors, including references to and justification of the methods. Detailed results of the shielding calculations should give both neutron and gamma-ray dose rates at all locations that could be occupied. The applicant should calculate shield penetrations, as well as the shielding of piping and other components that could contain radioactive materials or allow radiation streaming.

- $\quad$ Methods used to prevent neutron irradiation and activation of groundwater or soils surrounding the reactor shield that could enter the unrestricted environment. The applicant should estimate the maximum activity in case such activation occurs and describe remedial actions.

- $\quad$ TS that control important design features, LCOs, and SRs as discussed in Chapter 14 of this standard format and content guide. The applicant should justify these TS in this section of the SAR.

Regulatory Guide 2.1, "Shield Test Program for Evaluation of Installed Biological Shielding in Research and Training Reactors," has been replaced by Regulatory Guide 1.69, "Concrete Radiation Shields and Generic Shield Testing for Nuclear Power Plants," issued May 2009.

\subsection{Nuclear Design}

In this section, the applicant should give information on the nuclear parameters and characteristics of the Active Reactor Core and should analyze the kinetic behavior of the reactor for steady-state and transient operation throughout its life cycle as discussed in the safety analysis. The descriptions, analyses, and results should address all safety issues in the design and operation of the reactor and should support the conclusion that the reactor can be built and operated without unacceptable risk to the health and safety of the public. A detailed description of the analytical methods used in the nuclear design should be given. Computer codes that are used should be described in detail as to the name and type of code, the way it is used, and its 
validity on the basis of experiments. Code descriptions should include methods of obtaining parameters such as cross sections. Estimates of the accuracy of the analytical methods should be included. Tables and figures should be used as necessary to present information clearly.

\subsubsection{Normal Operating Conditions}

In this section, the applicant should present information on the core geometry and configurations. The limiting core configurations for a reactor are the core conditions that would yield the highest power density, the highest excess reactivity, and other possible limiting parameters that are of safety interest using the fuel specified for the reactor. All other core configurations should be demonstrated to be encompassed by the safety analysis of the limiting core configuration. Sections 4.5.3 and 4.6 should give further information on power density limitations. The information in the SAR should include the following:

- $\quad$ Discussion and analyses to reflect the impact of the gas management system that is contained within the Fission Product Barrier on the core physics. The discussion should include holdup times and subsequent release of fission product gases. Sweep gas or sparging gas operation and discharge limits, and reactivity impacts associated with these operations will need to be included in this section and in Section 4.7.

- Discussions and analyses of the reactor operating characteristics. The applicant should describe in detail the effects of changes in configuration and fuel chemistry, including effects related to redox, pressure, temperature, reactivity, and power oscillation, and the control philosophy and methodology for each parameter. If applicable, the applicant should analyze safety-related considerations for all requested operating modes.

- $\quad$ Changes in core reactivity with fuel composition changes, fissile material buildup, and poisons - both fission products and those added by design. The reactivity impacts of fission gas and void formation, fission product gas removal, and fuel salt addition.

- $\quad$ Analyses of the reactor kinetic behavior and the design requirements and dynamic features of the Control Elements that allow controlled operation for all possible reactor conditions. This includes the expected effects of fission product gases on power oscillations resulting from formation, collapse, and movement of voids and the effects of temperature changes or gradients in the fuel salt.

- $\quad$ Analyses of the basic reactor criticality physics, including the interacting effects of fuel, Neutron Moderators (if any) and neutron reflectors, and Control Elements. This also includes discussion of the subcritical storage and handling of the full Reactor Fuel mass outside the Vessel and during transport from and to the Active Reactor Core, the reactivity swing of the processed fuel salt material after selected fission product removal, and any compensatory measures (such as fissile addition or dilution) to achieve or maintain criticality after reinsertion into the Vessel.

- Discussion of the safety considerations for different core configurations, including a limiting core configuration that would yield the highest power densities and fuel temperatures achievable with the planned fuel. This includes the power stability effects of phenomena that might affect stability.

- $\quad$ The individual reactivity worths of fuel elements, reflector components, incore and inreflector components, experimental components, and Control Elements in allowed positions. If experimental facilities or components could be voided or flooded, the reactivity effects and safety considerations should be included. 
- $\quad$ The calculated core reactivities for all core configurations, including the limiting configuration that would yield the highest possible power density.

- Discussion of the administrative and physical constraints to prevent inadvertent addition of positive reactivity.

- $\quad$ The magnitude and impact of the distribution of delayed neutrons, in fuel-containing systems outside the Active Reactor Core, on the ability to control the reactor. Include the magnitude and rate of reactivity addition associated with sudden reduced fuel salt flow out of the Active Reactor Core and the impact on the capability to control the reactor.

- $\quad$ TS that control important design features, LCOs, and SRs as discussed in Chapter 14 of this format and content guide. The applicant should justify these TS in this section of the SAR.

\subsubsection{Active Reactor Core Physics Parameters}

In this section, the applicant should discuss the core physics parameters and show the methods and analyses used to determine them. The information should include the following:

- $\quad$ Analysis methods and values for neutron lifetime and effective delayed neutron fraction. The applicant should describe the effects of reactor operating characteristics and fuel composition changes.

- $\quad$ Analysis methods, values, and signs for coefficients of reactivity (e.g., fuel temperature and moderator temperature, void, and power). The applicant should describe the effects of reactor operating characteristics and fuel composition changes. This analysis, along with the analysis in Chapter 13, should show that the net effect of reactivity coefficients is sufficiently negative to prevent or mitigate damaging reactor transients.

- $\quad$ The axial and radial distributions of neutron flux densities, justifications for the methods used, and comparisons with applicable measurements. The applicant should describe changes in flux densities with power level, fuel composition changes, core configurations, and Control Element configurations. The information on neutron flux density should include peak-to-average values for thermal-hydraulic analyses. The applicant should validate these calculations by comparing them with experimental measurements and other validated calculations.

- The analysis methods used to address the dynamic behavior of changes in void fraction because of fission product gas formation and the agglomeration and transport of bubbles to the fuel solution surface. The neutronic impacts of these phenomena should be discussed to demonstrate that they have no adverse effect on safe reactor operations.

- TS that control important design features, LCOs, and SRs as discussed in Chapter 14 of this format and content guide. The applicant should justify these TS in this section of the SAR.

\subsubsection{Operating Limits}

The applicant should present the following information on reactor operating limits: 
- Reactivity conditions, excess reactivity, and negative reactivity for combinations of Control Elements that are activated and analyzed for the limiting core and operating cores during the life of the reactor. The applicant should discuss operational and safety considerations for excess reactivity.

- $\quad$ Excess reactivity based on reactor temperature coefficients, poisons, fission gas formation, changes in void fraction, and fuel additions or removal operations. The applicant should justify the upper limit on excess reactivity to ensure safe reactor operation and shutdown.

- $\quad$ The amount of negative reactivity that must be available by Control Element action to ensure that the reactor can be shut down safely from any operating condition and maintained in a safe shutdown state. The analyses should assume that the most reactive Control Element is non-functional (i.e., one stuck Control Element), non-scrammable Control Elements are at their most reactive position, and normal electrical power is unavailable to the reactor. The applicant should discuss how the shutdown margin will be verified. The analyses should include all relevant uncertainties and error limits.

- $\quad$ The limiting core configuration that is possible with the planned fuel in this reactor. The limit should be imposed by the maximum neutron flux density and thermal power density compatible with heat removal capability and maintaining operational stability. The safety limits and limiting safety system settings for the reactor should be derived from this core configuration. The detailed analyses should be included in Section 4.6. Normal operating conditions and credible events, such as a stuck Control Element, should be considered.

- A transient analysis assuming that an instrumentation malfunction drives the most reactive Control Element out in a continuous ramp mode in its most reactive region. It should show that neither the reactor nor the Fuel System Boundary is damaged.

- $\quad$ The redundancy and diversity of Control Elements necessary to ensure reactor control for the considerations noted above.

- $\quad$ Stability definition with criteria for acceptable performance. The applicant should describe protection solutions to maintain power oscillations within operational or safety limits and might include operational limits on parameters such as power density.

- $\quad$ TS for safety limits, limiting safety system settings (LSSSs), LCOs, and SRs as discussed in Chapter 14 of this format and content guide. The applicant should justify these TS in this section of the SAR.

\subsection{Thermal-Hydraulic Design}

In this section, the applicant should present the information and analyses necessary to show that sufficient cooling capacity exists to prevent fuel overheating and loss of Fuel System Boundary integrity for all anticipated reactor operating conditions. The applicant should address the fuel salt flow conditions for which the reactor is designed and licensed, forced or natural-convection flow, or both. A detailed description of the analytical methods used in the thermal-hydraulic design should be provided. Computer codes that are used should be described in detail as to the name and type of code, the way it is used, and its validity based on experiments. Estimates of the accuracy of the analytical methods should be included. The information should include the following: 
- Various systems and approaches for removing heat from the core (e.g., heat exchangers, auxiliary passive heat removal systems, gas management [heat removal] system). The expected fraction of heat removed by each approach should be discussed. The ability of the combined systems and approaches to accommodate the varying power, from gas formation, changes in void fraction, and transport, during normal and transient operation should also be discussed.

- Hydraulic characteristics of the core, fuel salt/primary cooling heat exchanger number and arrangement and total system flow rates; fuel salt flow and pressures; pressure changes at piping exits and entrances; material compatibility and heat transfer between fuel salt and heat exchanger, to include plating or precipitation of material on the surfaces of the heat exchanger; natural circulation within the fuel salt; temperature profile along heat exchanger surfaces from entrance to exit; and frictional and buoyant forces. The applicant should address individual heat exchangers, as well as the core as a whole, for all flow conditions in the Primary Cooling System, including temperature variations and wave propagation caused by vibration and chemistry changes resulting from fuel salt to coolant salt breaches, if applicable. The transition from forced to natural convection flow in the heat exchangers should be calculated, and the applicant should prepare calculations for an event during which normal electrical power is lost and the core decay heat must be removed. The discussion should also describe the fission gas heat removal, any additional auxiliary cooling systems, and the effect that the loss of these systems would have on core coolability and decay heat removal.

- $\quad$ Thermal power density distribution in the fuel and heat fluxes into the fuel salt/primary cooling heat exchangers

- $\quad$ Calculations and the thermal-hydraulic methodology for the transfer of heat to the coolant salt. The applicant should take into account uncertainties in thermal-hydraulic and nuclear parameters and such engineering factors as heat exchange surface wall thickness and buildup of any layers of corrosion products both inside and exterior to the heat exchange surface. The calculations should be based on fuel measurements and procurement specifications, as well as operating history and conditions. The calculational methodology should be applicable to the thermal-hydraulic operating conditions, and the applicant should justify its use.

- $\quad$ Calculations and experimental measurements to determine the fuel salt conditions that ensure fuel salt temperature limits are not exceeded and Fuel System Boundary integrity is not lost. The applicant should calculate at least the limiting core configuration. The discussion should also examine the positive reactivity feedback characteristics of overcooling. Operating conditions should include steady fission power, shutdown decay heat, and the transients analyzed in Chapter 13. The applicant should take into account operational and fuel characteristics from the beginning to the end of fuel life.

- $\quad$ Thermal-hydraulic analysis considering the effects of partial or complete loss of flow in frozen piping caused by loss of heaters or overcooling. This analysis is necessary because fuel salts have high melting temperatures.

- $\quad$ For the core geometry and the fuel salt thermal-hydraulic characteristics (including flow instability), a discussion to establish the fuel heat removal conditions that ensure Fuel System Boundary integrity, solubility of fuel salt and fission products, temperature distributions, and fission gas retention capacity. The discussion should show correlations among these factors and justify their use in deriving SLs and LSSSs for the TS. 
- $\quad$ The design bases for the Primary Cooling System, Emergency Cooling System, fission gas treatment system, and other systems designed to maintain Fuel System Boundary integrity should also be discussed in Chapter 5 of the SAR. The analyses here and in Chapter 13 should describe reduction of cooling scenarios for forced-flow reactors. Natural-convection cooling that removes decay heat to ensure thermal stability should also be discussed. Flow blockages should be analyzed in Chapter 13.

- In the case of MSRs, the coolant salt flows through heat exchange surfaces in contact with the fuel salt; thus, the breach of a heat exchange surface should be analyzed in Chapter 13, as should the effects of mixing of fuel and coolant salts.

\subsection{Gas Management System}

In this section, the applicant should describe the design of the system for removing fission product gases from the core and cover gas of the MSR. The gas management system might also provide some reactor cooling; Section 4.6, Chapter 5, and Section 9.6 of the SAR should describe this aspect of its function. The applicant should describe the major components of the gas management system and their functions.

The essential functions of a gas management system are to remove volatile fission products (e.g., krypton, xenon, iodine) until ultimate discharge and provide venting of any pressure/density transients that could result in damage to the Vessel or the fuel salt/primary cooling heat exchanger and result in loss of the Fuel System Boundary. The applicant should describe the gas management system features that perform these duties in sufficient detail to demonstrate that the Active Reactor Core can be operated safely and in accordance with applicable environmental release criteria. This information should include the geometric dimensions of the major components and piping (including whether it is favorable geometry), materials of construction (including chemical compatibility with evolved gases), composition of any trap media/filters, pressure the equipment is designed to withstand, surge capacity for fission product storage, and any additional passive or active devices, such as alarms and pressure-relief devices, needed to perform the system's intended function.

The proper function of the gas management system, which is part of the Fission Product Barrier, is essential. Malfunction or failure of components in this system could cause excessive pressure that could have positive reactivity feedback to the fuel solution and operating instability. All of the process variables controlling the gas management system must be analyzed and appropriate limits assigned in the TS to avoid such consequences.

The technical rationale for this section is that the specific components in the gas management system can vary from one applicant to another; this system is designed to be general in nature. A system for trapping entrained uranium and holding fission products until they can be safely disposed of is essential. There would be essentially three classes of hazards to be considered: an inadvertent criticality outside the Active Reactor Core, a release of gaseous fission products, and an increase in the pressure in the free surface space above the core. The means of preventing these events must be described. One of these hazards, pressure increase, could potentially increase the density of the core and affect the power density. These potential events should be discussed in terms of reactor control. 


\subsection{References}

1. Corrosion Behavior of Reactor Materials in Fluoride Salt Mixtures, ORNL-TM-328, DeVan and Evans, 1962. In particular, Figure 9 explains the relationship between redox, temperature, and corrosion.

2. Compatibility Studies of Potential Molten-Salt Breeder Reactor Materials in Molten Fluoride Salts, ORNL-TM-5783, Keiser, 1977. Provides more detail about measured removal rates for long-term applications.

3. Stability Analysis of the Molten-Salt Reactor Experiment, ORNL-TM-1070, Ball and Kerlin, 1965. Explains the response of MSRE to oscillations.

4. Theoretical Dynamic Analysis of MSRE with ${ }^{233}$ U Fuel, ORNL-TM-2571, Steffy and Wood, 1969. Provides a good explanation of transient damping in MSRs.

5. Format and Content for Safety Analysis Reports for Research Reactors, American National Standards Institute/American Nuclear Society, ANSI/ANS-15.21-2012, ANS, LaGrange Park, Illinois, 2012.

6. The Development of Technical Specifications for Research Reactors, American National Standards Institute/American Nuclear Society, ANSI/ANS-15.1-R2013, ANS, LaGrange Park, Illinois, 2013.

\section{Appendix 4.1}

Regulatory Guide 2.1, "Shield Test Program for Evaluation of Installed Biological Shielding in Research and Training Reactors," has been replaced by Regulatory Guide 1.69, "Concrete Radiation Shields and Generic Shield Testing for Nuclear Power Plants," issued May 2009. 


\section{APPENDIX A. CHAPTER 4, "MOLTEN SALT REACTOR DESCRIPTION"-MSR ADAPTATION OF PART 2}

\section{MOLTEN SALT REACTOR DESCRIPTION (Part 2)}

Replace NUREG-1537, Part 2, Chapter 4, in its entirety with the following guidance.

NUREG-1537, Part 2, Chapter 4, of the standard review plan and acceptance criteria, as augmented by this ISG, is applicable to reviewing a description of the design and functional characteristics of the reactor for the licensing of a nonpower molten salt reactor (MSR) facility. Whenever the term MSR or reactor appears, it is understood to mean a nonpower reactor facility.

In this chapter of the SAR, the applicant should discuss and describe the principal features, operating characteristics, and parameters of the MSR. ${ }^{10}$ The analysis in this chapter should support the conclusion that the reactor design ensures adequate public safety through safe operation and shutdown under all credible operating conditions. Information in this chapter of the SAR should provide the bases for many systems, subsystems, and functions discussed elsewhere in the SAR and for many technical specifications (TS).

In following the instructions in this chapter for the MSR, it should be noted that the fuel salt performs the function of the fuel ${ }^{11}$ and coolant. In the following sections, any direct reference to a moderator applies to designs that might use a moderator. It should also be noted that no fuel cladding is used in the MSR design; consequently, the concept of Fission Product Barrier performed by the cladding is no longer valid. The cladding's role is now performed by the Fuel System Boundary, including the Vessel and the boundaries of any penetrations (Control Element channels, instrumentation systems thimbles, fuel salt/primary cooling heat exchangers) and fuel transfer pipes and tanks in and outside the MSR Vessel.

The following glossary contains terms often used when discussing an MSR.

Active Reactor Core: In an MSR, the Vessel region occupied by the fuel salt where the majority of prompt neutrons are generated and where most fissions occur. In an MSR, the core geometry might change with time as a result of changes in density and voiding of the solution. The core does not include the part of the fuel salt that can become entrained into the cover gas.

Coating: Intervening protective layer of material between the corrosive fuel salt and the structural container alloy. Multiple layer configurations are possible (ranging in thickness from $>1 \mathrm{~mm}$, similar to liners used in current LWRs, to $<500 \mathrm{~nm}$, which adhere to the underlying substrate). Also included are embedded coatings, which are chemically resistant material that is embedded into the surface of the structural alloy, allowing surface modification to be performed to the structure to enhance its corrosion resistance.

Control Element(s): Object(s) employed to interact with an MSR's neutron population to adjust reactivity. Control elements can act through fuel displacement, neutron absorption, neutron reflection, neutron spectral adjustment, or a combination of these methods. Control elements can be solids, liquids, or gases, and they can be passively or actively positioned.

\footnotetext{
${ }^{10}$ MSRs are a class of reactors in which a molten salt performs a significant function in the core.

${ }^{11}$ There are also salt-cooled reactor designs that propose using fixed-position, coated-particle ceramic fuel. The discussion in this chapter is focused on MSRs operating with liquid fuel.
} 
Emergency Cooling System: System that provides decay heat removal from the Reactor Fuel following an accident (e.g., a direct reactor auxiliary cooling system or a reactor vessel auxiliary cooling system).

Fission Product Barrier: Portion of the Fuel System Boundary in contact with fission products only (e.g., the gas management system boundary).

Fuel Barrier: Portion of the Fuel System Boundary in contact with the fuel salt (principally the Vessel, heat exchanger, control element thimbles, instrumentation thimbles, piping, tanks, and valves).

Fuel System Boundary: All structures that prevent the release of fuel, fission gas, or other fission products. For an MSR, this includes the Vessel, waste-handling tank, pumps, valves, and piping. (Essentially includes the Fission Product Barrier and the Fuel Barrier.)

Heat Dissipation System: Set of components or system(s) that interface with the Primary Cooling System to provide the principal means of transferring the heat from the core to the environment. The Heat Dissipation System might use a variety of coolants (e.g., salt, liquid metal, or water) but does not contain fuel.

Neutron Moderator: In an MSR, materials in or near the core that consist of light elements. Moderators are generally solid form.

Primary Cooling System: Directly interfaces with the Fuel System Boundary at the fuel salt/primary cooling system heat exchanger(s) to provide the principal means of removing heat from the fuel salt by transferring the heat to the Heat Dissipation System. The Primary Cooling System typically contains a salt but does not contain fuel.

Reactor Fuel: In an MSR, fuel salt which consists of fissionable and possibly fertile halide salts, fission products, and generally solvent halide salt(s).

Vessel: For an MSR, structure containing the Active Reactor Core. Other components might reside in the Vessel but outside the Active Reactor Core, such as heat exchangers in certain design configurations.

This chapter gives guidance for evaluating the SAR description of the reactor and how it functions, as well as the design features for ensuring that the reactor can be safely operated and shut down from any operating condition or accident assumed in the safety analysis. Information in this chapter of the SAR should provide the design bases for many systems and functions discussed in other chapters of the SAR and for many TS. The systems that should be discussed in this chapter of the SAR include the Active Reactor Core, Vessel, gas management system, and biological shield. The nuclear design of the reactor and the way systems work together should also be addressed. In this chapter the applicant should explain how the design and proper operation of an MSR make accidents extremely unlikely. This chapter of the SAR, along with the analysis in Chapter 13, "Accident Analyses," should demonstrate that even the consequences of the design-basis accident would not cause unacceptable risk to the health and safety of the public. 


\subsection{Summary Description}

This section of the SAR should contain a general overview of the reactor design and important characteristics of operation. The reviewer need not make any specific review findings for this section. The detailed discussions, evaluations, and analyses should appear in the following sections of the SAR.

This section should contain a brief discussion of the way the facility design principles achieve the principal safety considerations. For the items requested, this section should include summaries of the format and content guide and descriptive text, summary tables, drawings, and schematic diagrams.

\subsection{Active Reactor Core}

This section of the SAR should contain the design information on all components of the Active Reactor Core. The information should be presented in diagrams, drawings, tables of specifications, and text and analysis sufficient to give a clear understanding of the core components and how they constitute a functional MSR that could be operated and shut down safely.

By reviewing this section, the reviewer gains an overview of the Active Reactor Core design and assurance that the SAR describes a complete operable MSR core. Subsequent sections should contain a description and analysis of the specifications, operating characteristics, and safety features of the reactor components. Although cooling systems should be discussed in Chapter 5, "Molten Salt Reactor Coolant Systems," of the SAR, relevant information should also be presented or referenced in this chapter. The information in the following sections should address these systems and components:

- Reactor Fuel, including the use of the Vessel as Fuel Barrier and Fission Product Barrier

- $\quad$ Control Elements

- $\quad$ Neutron Moderator (if any) and neutron reflector

- $\quad$ Neutron startup source

- $\quad$ Vessel

- $\quad$ Gas management system

The information in the SAR for each core component and system should include the following:

- $\quad$ Design bases

- $\quad$ System or component description, including drawings, schematics, and specifications of principal components, including materials

- Operational analyses and safety considerations

- Instrumentation and control features not fully described in Chapter 7, "Instrumentation and Control Systems," of the SAR, as well as a reference to Chapter 7 
- $\quad$ TS requirements and their bases, including testing and surveillance, or a reference to Chapter 14, "Technical Specifications"

\subsubsection{Reactor Fuel}

\section{Areas of Review}

The information in the SAR should include a reference to the fuel development program and the operational and limiting characteristics of the specific fuel used in the reactor.

The design basis for an MSR should be the maintenance of Fuel System Boundary integrity under any conditions assumed in the safety analysis. Loss of integrity is defined as the escape of any fuel and fission products from the Fuel System Boundary. Since the fuel in an MSR is a liquid salt without cladding or encapsulation, the Fuel System Boundary is the interface surface between the fuel salt, including fission products, and any egress point. During operation, this interface includes the Vessel, the gas management system, the fuel salt/primary cooling system heat exchanger(s), the Control Element thimbles, and any pipes used for transferring fuel from and to the Active Reactor Core and tanks that store the radioactive fuel salt. Therefore, the fuel salt must be shown to be compatible with the materials of construction for the Fuel Barrier and the Coating (including fission products) for any normal or upset condition. The reviewer should be able to conclude that the applicant has included all information necessary to establish the limiting characteristics beyond which Fuel System Boundary integrity could be lost.

Within the context of the factors listed in Section 4.2 of this review plan, the information on, and analyses of, fuel should include the information requested in this section of the format and content guide. Sufficient information and analyses should support the limits for operational conditions. These limits should be selected to ensure the integrity of the Fuel Barrier. Analyses in this section of the SAR should address mechanical forces and stresses; corrosion and erosion of the Fuel Barrier, or collection of fission products, decay daughters, or fuel precipitates on the Fuel Barrier, whether caused by changes in salt chemistry (such as redox, density, pressure, and temperature) or from normal operation; hydraulic forces, including natural convection in the fuel salt; thermal changes and temperature gradients; and internal and external pressures production of fission gas, including pneumatic pressures related to fuel transfer. The analyses should also address radiation effects, including the maximum fission densities and fission rates that the fuel is designed to accommodate. Results from these analyses should form part of the design bases for other sections of the SAR, for the reactor safety limits, and for other fuel-related TS.

\section{Acceptance Criteria}

The acceptance criteria for information on Reactor Fuel include the following:

- $\quad$ The design bases for the fuel should be clearly presented, and the design considerations and functional description should ensure that fuel conforms to the bases. Maintaining Fuel System Boundary integrity should be the most important design objective.

- $\quad$ The chemical and physical characteristics of the fuel constituents, including the salt and any stabilizing additives, should be chosen for compatibility with each other and the anticipated environment, including interaction with the Fuel Barrier. Consideration should be given to fission product buildup in or precipitation from the homogeneous fuel salt. 
- $\quad$ Fuel enrichment should be consistent with the requirements of 10 CFR 50.64, "Limitations on the Use of Highly Enriched Uranium (HEU) in Domestic Non-Power Reactors."

- $\quad$ The fuel operating parameters should take into account characteristics that could limit Fuel Barrier integrity, such as heat capacity and conductivity, melting and softening temperatures of the Vessel, and cooling interface materials; corrosion and erosion caused by coolant or fuel salt; chemical compatibility of the fuel salt with the Fuel barrier; physical stresses from mechanical or hydraulic forces (internal pressures, vibration, and Bernoulli forces); fuel composition changes; radiation damage to the Fuel Barrier; and retention of fission products.

- $\quad$ The fuel design should include the nuclear features of the Active Reactor Core, such as structural materials with small neutron absorption cross sections and minimum impurities, neutron reflectors, and burnable poisons, if used.

- $\quad$ The various phenomena that result in changes to the initial fuel composition and properties should be considered. The submittal should include information on fission product gas formation; sparging gas if used; the transport, changes in void fraction, and removal of gas; associated redox changes, potential fuel and fission product precipitation, and the addition of fuel and salt, along with the reactivity implications of these items.

- $\quad$ The discussion of the fuel should include a summary of the fuel development, qualification, and production program.

- $\quad$ The applicant should propose TS as discussed in Chapter 14 of the format and content guide to ensure that the fuel meets the safety-related design requirements. The applicant should justify the proposed TS in this section of the SAR.

\section{Technical Rationale}

The parameters included in the technical review have been identified as important, based on experience with previous operating MSRs, as discussed in References 1 through 4.

\section{Review Procedures}

The reviewer should confirm that the information on the Reactor Fuel includes a description of the required characteristics. The safety-related parameters should become design bases for the reactor operating characteristics in other sections of this chapter, especially Section 4.6 on the thermal-hydraulic design of the core.

\section{Evaluation Findings}

This section of the SAR should contain sufficient information to support the following types of conclusions, which will be included in the NRC staff's safety evaluation report:

- The applicant has described in detail the fuel salt to be used in the reactor. The discussion includes the design limits (chemical and physical) and clearly gives the technological and safety-related bases for these limits.

- $\quad$ The applicant has discussed the constituents, materials, components, and preparation specifications for the fuel. Compliance with these specifications for all fuel used in the 
reactor will ensure uniform characteristics and compliance with design bases and safetyrelated requirements.

- $\quad$ The applicant has referred to the fuel development program under which all fuel characteristics and parameters that are important to the safe operation of the reactor were investigated. The design limits are clearly identified for use in design bases to support TS.

- Information on the design and development program for the fuel offers reasonable assurance that the fuel can function safely in the reactor without adversely affecting the health and safety of the public.

\subsubsection{Control Elements}

\section{Areas of Review}

The Control Elements in an MSR are designed to change reactivity by changing the amount of neutron absorber (or fuel) or reflection in or near the Active Reactor Core. Depending on their function, Control Elements can be designated as regulating, safety, shim, or transient rods. To trip the reactor, the negative reactivity of the Control Elements is usually added passively and quickly. Because the Control Elements serve a dual function (control and safety), control and safety systems for nonpower reactors are usually not completely separable. In nonpower reactors, a reactor trip does not challenge the safety of the reactor or cause any undue strain on any systems or components associated with the reactor.

This section of the format and content guide discusses the areas of review.

\section{Acceptance Criteria}

The acceptance criteria for information on Control Elements include the following:

- $\quad$ The Control Elements, blades, followers, movable reflectors (if used), and support systems should be designed with adequate margin to withstand all anticipated stresses and challenges from mechanical, hydraulic, and thermal forces and the effects of their chemical and radiation environment.

- $\quad$ The Control Elements should be sufficient in number and reactivity worth to comply with the "single stuck rod" criterion; that is, it should be possible to shut down the reactor and comply with the requirement of minimum shutdown margin with the highest worth scrammable Control Element fails to insert negative reactivity. The Control Elements should also be sufficient to control the reactor in all designed operating modes and to shut down the reactor safely from any operational condition. The design bases for redundancy and diversity should ensure these functions.

- $\quad$ The Control Elements should be designed for rapid, fail-safe shutdown of the reactor from any operating condition. The discussion should address conditions under which normal electrical power is lost.

- $\quad$ The Control Elements should be designed so that tripping them does not challenge their integrity or operation or the integrity or operation of other reactor systems. 
- $\quad$ The Control Element design should ensure that positioning is reproducible and that a readout of positions is available for all reactor operating conditions.

- $\quad$ The drive and control systems for each Control Element should be independent from other Control Elements to prevent a malfunction in one from affecting the activation of any other.

- $\quad$ The drive speeds and scram times of the Control Elements should be consistent with reactor kinetics requirements, considering mechanical friction, hydraulic resistance, and the electrical or magnetic system.

- $\quad$ The Control Elements should allow replacement and inspection, as required by operational requirements and the TS.

- The action of the Control Element (manual or automatic) should be such that it does not affect the stability of the core, but a return to a stable state following small perturbations (including physical ones from fission product gas formation, sparging gas if used, and changes in void fraction), if the core is designed within an acceptable power density limit.

- $\quad$ TS should be proposed according to the guidance in Chapter 14 of the format and content guide, which describes important design aspects and proposes limiting conditions for operations (LCOs) and surveillance requirements, and they should be justified in this section 4.2.2 of the SAR.

\section{Review Procedures}

The reviewer should confirm that the design bases for the Control Elements define all essential characteristics and that the applicant has addressed them completely.

\section{Evaluation Findings}

This section of the SAR should contain sufficient information to support the following types of conclusions, which will be included in the staff's safety evaluation report:

- $\quad$ The applicant has described the control and safety element systems for the reactor and included a discussion of the design bases, which are derived from the planned operational characteristics of the reactor. All functional and safety-related design bases can be achieved by the Control Elements designs.

- $\quad$ The applicant has included information on the materials, components, and fabrication specifications of the Control Element systems. These descriptions offer reasonable assurance that the Control Elements conform to the design bases and can control and shut down the reactor safely from any operating condition.

- Information on scram design for the Control Elements has been compared with designs at other nonpower reactors having similar operating characteristics. Reasonable assurance exists that the reactor trip features designed for this facility will perform as necessary to ensure Fuel System Boundary integrity and to protect the health and safety of the public.

- $\quad$ The Control Element design includes reactivity worths that can control the excess reactivity planned for the reactor, including ensuring an acceptable shutdown reactivity and margin, as defined and specified in the TS. 
- $\quad$ Changes in reactivity caused by Control Element dynamic characteristics are acceptable. The staff evaluations include maximum scram times and maximum rates of insertion of positive reactivity for normal and ramp insertions caused by system malfunctions.

- $\quad$ The applicant has justified appropriate design limits, LCOs, and surveillance requirements for the Control Elements and included them in the TS.

\subsubsection{Neutron Moderator and Neutron Reflector}

\section{Areas of Review}

In this section of the SAR, the applicant should describe Neutron Moderators (if applicable) and reflectors and their special features. The information pertinent to this section, therefore, applies to any moderator that might be added to the MHR design. The reflectors are chosen primarily for favorable nuclear properties and physical characteristics. Section 4.2.1 of the SAR should contain a description of the relationship of all moderators (if applicable) to the core. Buildup of contaminating radioactive material in the moderator (if applicable) or reflector during reactor operation should be discussed in Chapter 1, "Radiation Protection Program and Waste Management," of the SAR.

Areas of review should include the following:
- Geometry
- Materials
- $\quad$ Compatibility with the operational environment
- $\quad$ Structural designs
- $\quad$ Response to radiation heating and damage
- $\quad$ Capability to be moved and replaced, if necessary
- $\quad$ Provisions for cooling

Section 4.5 of the SAR should discuss the nuclear characteristics of the moderator.

\section{Acceptance Criteria}

The acceptance criteria for information on Neutron Moderators (if applicable) and reflectors include the following:

- $\quad$ The nonnuclear design bases, such as reflector encapsulations, should be clearly presented, and the nuclear bases should be briefly summarized. Nonnuclear design considerations should ensure that the moderator (if applicable) and reflector can provide the necessary nuclear functions.

- $\quad$ The design should ensure that the moderator (if applicable) and reflector are compatible with their chemical, thermal, mechanical, and radiation environments.

- $\quad$ The design should allow for dimensional changes from radiation damage and thermal expansion to avoid malfunctions of the moderator (if applicable) or reflector. 
- $\quad$ The design should provide for removal or replacement of moderator (if applicable) or reflector components and systems, if required by operational considerations.

- $\quad$ TS, if required, should be proposed according to the guidance in Chapter 14 of the format and content guide, which describes important design aspects and proposes LCOs and surveillance requirements. The proposed TS should be justified in this section of the SAR.

\section{Review Procedures}

The reviewer should confirm that the information on the Neutron Moderator (if applicable) and reflector completely describes the required systems. The bases for the nuclear characteristics should appear in Section 4.5 of the SAR.

\section{Evaluation Findings}

This section of the SAR should contain sufficient information to support the following types of conclusions, which will appear in the staff's safety evaluation report:

- $\quad$ The moderator (if applicable) and reflector are integral constituents of an Active Reactor Core; the staff's evaluation of the nuclear features appears in Section 4.5. The designs take into account interactions between the moderator (if applicable) or reflector and the reactor environment. Reasonable assurance exists that degradation rates of the moderator (if applicable) or reflector will not affect safe reactor operation, prevent safe reactor shutdown, or cause uncontrolled release of radioactive material to the unrestricted environment.

- $\quad$ Moderators (if applicable) or reflectors are clad in [insert name of cladding material] if they are located in an environment where fuel salt infiltration could cause changes in neutron scattering and absorption, thereby changing core reactivity. Reasonable assurance exists that leakage will not occur. In the unlikely event fuel salt infiltration occurs, the applicant has shown that this infiltration will not interfere with safe reactor operation or prevent safe reactor shutdown.

- $\quad$ The moderator (if applicable) or reflector is composed of materials incorporated into a sound structure that can retain size and shape and support all projected physical forces and weights. Therefore, no unplanned changes to the moderator or reflector would occur that would interfere with safe reactor operation or prevent safe reactor shutdown.

- $\quad$ The applicant has justified appropriate design limits, LCOs, and surveillance requirements for the moderator and reflector and included them in the TS.

\subsubsection{Neutron Startup Source}

\section{Areas of Review}

Each nuclear reactor should contain a neutron startup source that ensures the presence of neutrons during all changes in reactivity. This is especially important when starting the reactor from a shutdown condition. Therefore, the reviewer should evaluate the function and reliability of the source system. 
Areas of review should include the following:

- Type of nuclear reaction

- $\quad$ Energy spectra of neutrons

- $\quad$ Source strength

- Interaction of the source and holder, while in use, with the chemical, thermal, and radiation environment

- Design features that ensure the function, integrity, and availability of the source

- TS

\section{Acceptance Criteria}

Acceptance criteria for information on the neutron startup source include the following:

- $\quad$ The source and source holder should be constructed of materials that will withstand the environment in the Active Reactor Core and during storage, if applicable, with no significant degradation.

- $\quad$ The type of neutron-emitting reaction in the source should be comparable to that at other licensed reactors, or test data should be presented in this section of the SAR to justify use of the source.

- $\quad$ The natural radioactive decay rate of the source should be slow enough to prevent significant decay over a 24-hour period or between reactor operations.

- $\quad$ The design should allow easy replacement of the source and its holder and a source check or calibration.

- Neutron and gamma radiation from the reactor during normal operation should not cause heating, fissioning, or radiation damage to the source materials or the holder.

- If the source is regenerated by reactor operation, the design and analyses should demonstrate its capability to function as a reliable neutron startup source in the reactor environment.

- $\quad \mathrm{TS}$, if required, should be proposed according to the guidance in Chapter 14 of the format and content guide, which proposes LCOs and surveillance requirements, and should be justified in this section of the SAR.

\section{Review Procedures}

The reviewer should confirm that the information on the neutron startup source and its holder includes a complete description of the components and functions. In conjunction with Chapter 7 of the SAR, the information should demonstrate the minimum source characteristics that will produce the required output signals on the startup instrumentation.

\section{Evaluation Findings}

This section of the SAR should contain sufficient information to support the following types of conclusions, which will be included in the staff's safety evaluation report: 
- $\quad$ The design of the neutron startup source is of a type (i.e., neutron-emitting reaction) that has been used reliably in similar reactors licensed by the NRC (or the design has been fully described and analyzed). The staff concludes that this type of source is acceptable for this reactor.

- $\quad$ The source will not degrade in the radiation environment during reactor operation. Either the levels of external radiation are not significant or the source will be retracted while the reactor is at high power to limit the exposure.

- Because of the source holder design and fabrication, reactor neutron absorption is low, and radiation damage is negligible in the environment of use. When radiation heating occurs, the holder temperature does not increase significantly above the ambient temperature.

- $\quad$ The source strength produces an acceptable count rate on the reactor startup instrumentation and allows for a monitored startup of the reactor under all operating conditions.

- $\quad$ The applicant has justified appropriate LCOs and surveillance requirements for the source and included them in the TS.

- $\quad$ The source and holder operate safely and reliably.

\subsubsection{Reactor Internals Support Structures}

\section{Areas of Review}

An MSR Active Reactor Core is composed of the homogeneous fuel salt and off-gas inside a Vessel; the core does not require a support structure beyond the MSR Vessel. However, all other Active Reactor Core components must be secured firmly and accurately because the capability to maintain a controlled chain reaction depends on the relative positions of the components. Controlling reactor operations safely and reliably depends on the capability to locate components and reproduce responses of instrument and control systems, including nuclear detectors and Control Elements. Predictable Fuel Barrier integrity depends on stable and reproducible Control Element action and fuel salt flow patterns. Generally, the Control Elements of nonpower reactors are suspended from a superstructure, which allows gravity to rapidly change core reactivity to shut down the reactor.

Areas of review include the design of the support structure for the core components and Vessel, including a demonstration that the design loads and forces have adequate margin compared with all expected loads and hydraulic forces and that relative positions of components can be maintained within tolerances.

This section of the format and content guide discusses additional areas of review.

\section{Acceptance Criteria}

Acceptance criteria for information on the core support structure include the following:

- $\quad$ The design should show that the support structure will hold the weight of all core-related components with adequate margin. 
- $\quad$ The design should show that the support structure will withstand all hydraulic forces from anticipated flow with negligible deflection or motion with adequate margin.

- The design should consider the methods by which core components (e.g., reflector pieces, Control Elements, non-coolant moderator, any associated cooling systems, and the fuel transport pipe) are attached to the core support structure. The information should include tolerances for motion and reproducible positioning. These tolerances should ensure that variations will not cause reactivity design bases, cooling design bases, safety limits, or LCOs in the TS to be exceeded.

- The design should account for the effect of the local environment on the material of the support structure. The impact of radiation damage, mechanical stresses, chemical compatibility with the fuel salt and core components, and reactivity effects should not degrade the performance of the supports sufficiently to prevent safe reactor operation for the design life of the reactor.

- $\quad$ The design should show that stresses or forces from reactor components other than the core could not cause malfunctions, interfere with safe reactor operation or shutdown, or cause other core-related components to malfunction.

- $\quad$ The core of an MSR could vary in dimension, based on the purpose of the facility. Fuel could be transferred to and from the core during planned operations; consequently, there are devices to ensure that such operations do not occur inadvertently. The design for a changing core configuration should contain features such as position tolerances to ensure safe and reliable reactor operation within all design limits, including reactivity and cooling capability. The description should include the interlocks that keep the Active Reactor Core configuration from changing while the reactor is critical or while forced cooling is required, if applicable. The design should show how the reactor would be shut down if unwanted action occurs.

- $\quad$ TS, if required, should be proposed according to the guidance in Chapter 14 of the format and content guide, which proposes LCOs and surveillance requirements, and should be justified in this section of the SAR.

\section{Review Procedures}

The reviewer should confirm that the design bases define a complete support system.

\section{Evaluation Findings}

This section of the SAR should contain sufficient information to support the following types of conclusions, which will appear in the staff's safety evaluation report:

- $\quad$ The applicant has described the support system for the Active Reactor Core, including the design bases, which are derived from the planned operational characteristics of the reactor and the core design. All functional and safety-related design bases can be achieved by the design.

- The support structure includes acceptable guides and supports for other essential core components, such as Control Elements, nuclear detectors, and neutron reflectors.

- $\quad$ The support structure provides sufficient heat removal to conform to the design criteria and to prevent loss of Fuel System Boundary integrity from overheating. 
- $\quad$ The support structure is composed of materials shown to be resistant to radiation damage, fuel salt erosion and corrosion, thermal softening or yielding, and excessive neutron absorption.

- $\quad$ The core support structure is designed to ensure a stable and reproducible core configuration for all anticipated conditions (e.g., reactor trips, fuel salt flow change, and core motion) through the reactor life cycle.

- The applicant has justified appropriate LCOs and surveillance requirements for the core support structure and included them in the TS.

\subsection{Vessel}

\section{Areas of Review}

The Vessel of an MSR is an essential part of the Fuel System Boundary and is the primary Fuel Barrier (including fission products). The Vessel can also provide some support for components and systems mounted to the core supports.

The areas of review are the design bases of the Vessel and the design details needed to achieve those bases. This section of the format and content guide discusses the information that the applicant should submit for review.

\section{Acceptance Criteria}

The acceptance criteria for information on the Vessel include the following:

- The Vessel dimensions should include thickness and structural supports, and fabrication methods should be discussed. The Vessel should be designed with adequate margin to withstand all mechanical and hydraulic forces and stresses to which it could be subjected during its lifetime.

- The construction materials and Vessel treatment should resist chemical interaction with the fuel salt and be chemically compatible with other reactor components in the Fuel System Boundary. The compatibility between the Vessel material and fuel salt should be addressed to prevent fuel salt leakage.

- $\quad$ The dimensions of the Vessel and the materials used to fabricate it, as well as the position of the Active Reactor Core with respect to the Vessel, should ensure that radiation damage to the Vessel is minimized so that the Vessel will remain intact for its projected lifetime.

- $\quad$ The construction materials and Vessel treatment should be appropriate for preventing fuel salt from corroding the Vessel interior.

- $\quad$ A plan should be in place to assess irradiation of and chemical damage to the Vessel materials. Remedies for damage or a replacement plan should be discussed.

- $\quad$ All penetrations and attachments to the Vessel below the fuel salt level should be designed to avoid malfunction and unintended loss of fuel salt.

- $\quad \mathrm{TS}$, if required, should be proposed according to the guidance in Chapter 14 of the format and content guide, which proposes LCOs and surveillance requirements, and should be justified in this section of the SAR. 


\section{Technical Rationale}

Fuel salt chemistry has been shown to affect corrosion and result in possible loss of Vessel integrity, based on experience from operation of previous reactors, as described in References 1 through 4.

\section{Review Procedures}

The reviewer should confirm that the design bases describe the requirements for the Vessel and that the detailed design is consistent with the design bases and acceptance criteria for the Vessel.

\section{Evaluation Findings}

This section of the SAR should contain sufficient information to support the following types of conclusions, which will appear in the staff's safety evaluation report:

- Information has been provided on gas composition (sparging and fission gases) and gas handling.

- $\quad$ The Vessel system can withstand all anticipated mechanical and hydraulic forces, stresses, and irradiation damage effects to prevent loss of integrity, which could lead to a loss of fuel salt or fission products or other malfunctions that could interfere with safe reactor operation or shutdown.

- $\quad$ The penetrations and attachments to the Vessel are designed to ensure safe reactor operation. Safety and design considerations of any penetrations below the fuel salt level include analyses of potential malfunction and loss of fuel salt. The applicant discusses credible fuel spill and leak scenarios in Chapter 13 of the SAR, Section 13.1.4.

- $\quad$ The construction materials, treatment, and methods of attaching penetrations and components are designed to prevent chemical interactions among the Vessel and the fuel salt and other components.

- $\quad$ The inner surfaces of the Vessel are designed and treated to avoid corrosion in locations that are inaccessible for the life of the Vessel. Vessel surfaces will be inspected in accessible locations.

- $\quad$ The applicant has considered the possibility that fuel salt might leak into unrestricted areas, including groundwater, and has included precautions to avoid the uncontrolled release of radioactive material.

- Design considerations include the shape and dimensions of the Vessel to ensure sufficient radiation shielding to protect personnel and components. Exposures have been analyzed, and acceptable shielding factors are included in the Vessel design.

- $\quad$ The applicant has justified appropriate LCOs and surveillance requirements for the Vessel and included them in the TS.

- $\quad$ The design features of the Vessel offer reasonable assurance of its reliability and integrity for its anticipated life. The design of the Vessel is acceptable to avoid undue risk to the health and safety of the public. 


\subsection{Biological Shield}

\section{Areas of Review}

The radiation shields around nonpower reactors are called biological shields and are designed to protect personnel and reduce radiation exposures to reactor components and other equipment. The principal design and safety objective is to protect employees and the public. The second design objective is to make the shield as thin as possible, consistent with acceptable protection factors. In some MSRs, fuel salt might need to be transported to locations outside the Vessel as part of normal operations, and this should be addressed in the shield design. Traditional methods of improving protection factors without increasing shield thickness are to use materials with higher density, higher atomic numbers for gamma rays, and higher hydrogen concentration for neutrons. The optimum shield design should consider all of these.

This section of the format and content guide discusses areas of review.

\section{Acceptance Criteria}

The acceptance criteria for information on the biological shields include the following:

- $\quad$ The principal objective of the shield design should be to ensure that the projected radiation dose rates and accumulated doses in occupied areas do not exceed the limits of 10 CFR Part 20, "Standards for Protection Against Radiation," and the guidelines of the facility's ALARA (as-low-as-reasonably-achievable) program discussed in Chapter 11 of the SAR.

- $\quad$ The shield design should address potential damage from radiation heating and induced radioactivity in reactor components and shields. The design should limit heating and induced radioactivity to levels that could not cause significant risk of failure.

- $\quad$ The solid shielding materials should be apportioned to ensure protection from all applicable radiation and all conditions of operation.

- $\quad$ Shielding materials should be based on demonstrated effectiveness at other nonpower reactors with similar operating characteristics, and the calculational models and assumptions should be justified by similar comparisons. New shielding materials should be justified by calculations, development testing, and the biological shield test program during facility startup.

- The analyses should include specific investigation of the possibility of radiation streaming or leaking from shield penetrations, inserts, and other places where materials of different density and atomic number meet. Any such streaming or leakage should not exceed the stated limits.

- $\quad$ Supports and structures should ensure shield integrity, and quality-control methods should ensure that fabrication and construction of the shield exceed the requirements for similar industrial structures.

- $\quad \mathrm{TS}$, if required, should be proposed according to the guidance in Chapter 14 of the format and content guide, which proposes LCOs and surveillance requirements. The applicant should justify the proposed TS in this section of the SAR. 


\section{Review Procedures}

The reviewer should confirm that the objectives of the shield design bases are sufficient to protect the health and safety of employees and the public and that the design achieves the design bases. The reviewer should compare design features, materials, and calculational models with those of similar nonpower reactors that have operated acceptably.

\section{Evaluation Findings}

This section of the SAR should contain sufficient information to support the following types of conclusions, which will be included in the staff's safety evaluation report:

- $\quad$ The analysis in the SAR offers reasonable assurance that the shield designs will limit exposures from the reactor and reactor-related sources of radiation so as not to exceed the limits of 10 CFR Part 20 and the guidelines of the facility's ALARA program.

- $\quad$ The design offers reasonable assurance that the shield can be successfully installed with no radiation streaming or other leakage that would exceed the limits of 10 CFR Part 20 and the guidelines of the facility's ALARA program.

- $\quad$ Reactor components are sufficiently shielded to avoid significant radiation-related degradation or malfunction.

- $\quad$ The applicant has justified appropriate LCOs and surveillance requirements for the shield and included them in the TS.

\subsection{Nuclear Design}

In this section of the SAR, the applicant should show how the systems described in this chapter function together to form a nuclear reactor that can be operated and shut down safely from any operating condition. The analyses should address all possible operating conditions throughout the reactor's anticipated life cycle. Because the information in this section describes the characteristics necessary to ensure safe and reliable operation, it will determine the design bases for most other chapters of the SAR and the TS. The text, drawings, and tables should completely describe the reactor's operating characteristics and safety features.

\subsubsection{Normal Operating Conditions}

\section{Areas of Review}

In this section of the SAR, the applicant should discuss the configuration for a functional reactor that can be operated safely.

This section of the format and content guide discusses the areas of review.

\section{Acceptance Criteria}

The acceptance criteria for information on normal operating conditions include the following:

- $\quad$ The information should show a complete, operable Active Reactor Core. Control Elements should be sufficiently redundant and diverse to control all proposed excess 
reactivity safely and to safely shut down the reactor and maintain it in a shutdown condition. Reactivity analyses should include individual and total Control Element effects.

- The information should describe anticipated power oscillations and their effects on safety-related equipment and systems. These oscillations should be shown to be selfdamping and controllable.

- $\quad$ Anticipated fuel salt composition evolution should account for uranium depletion; actinide generation and depletion (including fissile material); fission product buildup; changes in fuel salt chemical stability caused by changes in redox, temperature, pressure, density, and specific heat capacity; poisons, both from fission products and those added by design; and changes to fuel salt composition from online fuel salt polishing or processing and changes to fuel salt composition from online addition or removal of fuel salt, for the life of the reactor. The information should also include an analysis of the total fuel salt volume as a function of fuel composition changes.

- $\quad$ The analyses should show initial and changing reactivity conditions, Control Element reactivity worths, and reactivity worths of reflector units, as well as in-core components for all anticipated configurations. There should be a discussion of administrative and physical constraints that would prevent inadvertent reactivity changes that could suddenly introduce sufficient reactivity to cause prompt criticality or an analyzed safe amount, whichever was larger. These analyses should address movement, overfilling of fuel, and voiding of core components, including fission gas generation.

- $\quad$ The reactor kinetic parameters and behavior should be shown, along with the dynamic reactivity changes caused by the instrumentation and control systems. Analyses should prove that the control systems will prevent nuclear transients from causing the loss of Fuel System Boundary integrity or an uncontrolled addition of reactivity (e.g., the reactivity control system shall be designed with appropriate limits on the rate and amount of reactivity increase that could occur during a reactivity insertion accident so as to prevent compromise of the Fuel System Boundary).

- $\quad$ The information should include the magnitude and impact of the distribution of delayed neutrons, in fuel-containing systems outside the Active Reactor Core, on the ability to control the reactor. The magnitude and rate of reactivity addition associated with sudden reduced fuel salt flow out of the Active Reactor Core and the impact on the ability to control of the reactor should also be included.

- $\quad$ The information should include calculated core reactivities for possible and planned configurations of the Control Elements. This should include the reactivity impacts of fission gas, sparging gas, void formation and collapse, fission product gas removal, fuel salt polishing or processing, and fuel salt addition/removal. If only one core configuration will be used over the life of the reactor, the applicant should clearly indicate this. The limiting core configuration during reactor life should be indicated. This information should be used for the analyses in Section 4.6 of the SAR. The information should also include reactivities for fuel salt storage and handling outside the reactor, fuel transport to and from the core, and the effects of core recycling after fuel salt cleanup operations (if any).

- $\quad$ TS, if required, should be proposed according to the guidance in Chapter 14 of the format and content guide, which proposes LCOs and surveillance requirements, and should be justified in this section of the SAR. 


\section{Technical Rationale}

Power oscillations in MSRs are expected and usually are self-limiting because of the large negative reactivity feedback coefficients. It is necessary to ensure that oscillations are bounded for proper operation of the reactor, based on the operation of previous MSRs found in References 1 through 4.

\section{Review Procedures}

The reviewer should confirm that a complete, operable core has been analyzed.

\section{Evaluation Findings}

This section of the SAR should contain sufficient information to support the following types of conclusions, which should appear in the staff's safety evaluation report:

- $\quad$ The applicant has described the proposed initial core configuration and analyzed all reactivity conditions. These analyses also include other possible core configurations planned during the life of the reactor. The assumptions and methods used have been justified and validated.

- $\quad$ The analyses include reactivity and geometry changes resulting from fuel composition changes; fissile material buildup; the buildup and removal of fission products, both in solution and in the gas management system; fuel salt polishing or processing; fuel salt addition or removal; and the use of poisons, as applicable.

- $\quad$ The reactivity analyses include the reactivity values for the components that impact reactivity such as control elements, neutron reflector and non-coolant moderator if applicable. The assumptions and methods have been justified.

- The analyses address the steady-power operation and kinetic behavior of the reactor and show that the dynamic response of the Control Elements and instrumentation is designed to prevent reactor transients that cause the reactor to exceed operating limits. The analyses address the effect of distributed delayed neutrons associated with fuel outside the Active Reactor Core and the impact on the ability to control the reactor. The analyses also indicate the magnitude and rate of reactivity addition associated with a rapid reduction or total loss of fuel salt flow. This event should be discussed in chapter 13 of the SAR

- $\quad$ The analyses show that any in-core components that could be flooded or voided could not cause reactor transients beyond the capabilities of the instrumentation and control systems to prevent Fuel System Boundary damage. This includes any impacts on reactivity associated with failures associated with pneumatic fuel transfer.

- $\quad$ The analyses address a limiting core that is the minimum size possible with the planned fuel. The applicant uses it in Section 4.6 of the SAR to determine the limiting thermalhydraulic characteristics for the reactor.

- The analyses and information in this section describe an Active Reactor Core that could be designed, built, and operated without unacceptable risk to the health and safety of the public. 
- $\quad$ The applicant has justified appropriate LCOs and surveillance requirements for minimal operating conditions and included them in the TS. The applicant has also justified the proposed TS.

\subsubsection{Active Reactor Core Physics Parameters}

In this section of the SAR, the applicant should present information on core physics parameters that determine reactor operating characteristics and are influenced by the reactor design.

\section{Areas of Review}

Areas of review should include the design features of the Active Reactor Core that determine the operating characteristics and analytical methods for important contributing parameters. The results presented in this section of the SAR should be used in other sections of this chapter.

This section of the format and content guide further discusses the areas of review.

\section{Acceptance Criteria}

The acceptance criteria for information on Active Reactor Core physics parameters include the following:

- $\quad$ The calculational assumptions and methods should be justified and traceable to their development and validation, and the results should be compared with calculations of similar facilities and previous experimental measurements. The ranges of validity and accuracy should be stated and justified.

- Uncertainties in the analyses should be provided and justified.

- $\quad$ Methods used to analyze neutron lifetime, effective delayed neutron fraction (accounting for distributed delayed neutrons), and reactor periods should be presented, and the results should be justified. Comparisons should be made with similar reactor facilities. The results should agree within the estimates of accuracy for the methods.

- Net coefficients of reactivity (temperature, void, and power) should be negative over the significant portion of the operating ranges of the reactor. The results should include estimates of accuracy. If any parameter is not negative within the error limits over the credible range of reactor operation, the combination of the reactivity coefficients should be analyzed and shown to be sufficient to prevent reactor damage and risk to the public from reactor transients, as discussed in Chapter 13 of the SAR.

- $\quad$ Changes in feedback coefficients with core configurations, power level, and fuel composition changes should not change the conclusions about reactor protection and safety, nor should they void the validity of the analyses of normal reactor operations.

- The methods and assumptions for calculating the various neutron flux densities should be validated by comparisons with results for similar reactors or previous experimental measurements. Uncertainties and ranges of accuracy should be given for other analyses requiring neutron flux densities, such as fuel composition changes, thermal power densities, fission gas production, Control Element reactivity worths, and reactivity coefficients. This should include a description of the method of calculating and verifying the composition changes and the fuel composition after any isotope removal. It should 
also include methods to analyze fission gas evolution and the generation of void spaces or collapse of voids and predict their reactivity effects.

- $\quad \mathrm{TS}$, if required, should be proposed according to the guidance in Chapter 14 of the format and content guide, which proposes LCOs and surveillance requirements, and should be justified in this section of the SAR.

\section{Review Procedures}

The reviewer should confirm that generally accepted and validated methods have been used for the calculations, evaluate the dependence of the calculational results on reactor design features and parameters, review the agreement of the methods and results of the analyses with the acceptance criteria, and consider the derivation and adequacy of uncertainties and errors.

\section{Evaluation Findings}

This section of the SAR should contain sufficient information to support the following types of conclusions, which should appear in the staff's safety evaluation report:

- $\quad$ The analyses of neutron lifetime, effective delayed neutron fraction, and coefficients of reactivity have been completed using methods validated at similar reactors and experimental measurements.

- $\quad$ The effects of fuel composition changes and reactor operating characteristics for the life of the reactor are considered in the analyses of the Active Reactor Core physics parameters.

- $\quad$ The numerical values for the Active Reactor Core physics parameters depend on features of the reactor design, and the information given is acceptable for use in the analyses of reactor operation.

- $\quad$ The applicant has justified appropriate LCOs and surveillance requirements for the Active Reactor Core physics parameters and has included them in the TS. The applicant has also justified the TS.

\subsubsection{Operating Limits}

Areas of Review

In this section of the SAR, the applicant should present the nuclear design features necessary to ensure safe operation of the Active Reactor Core and safe shutdown from any operating condition. The information should demonstrate a balance between fuel loading, Control Element worths, and number of Control Elements. The applicant should discuss and analyze potential accident scenarios, as distinct from normal operation, in Chapter 13 of the SAR.

This section of the format and content guide discusses the areas of review.

\section{Acceptance Criteria}

The acceptance criteria for information on operating limits include the following: 
- $\quad$ All operational requirements for excess reactivity should be stated, analyzed, and discussed. These could pertain to at least the following:

- Temperature coefficients of reactivity

- $\quad$ Fuel composition changes between reloads or shutdowns

- $\quad$ Void coefficients

- $\quad$ Fission product poison (e.g., samarium and or dissolved xenon [if applicable])

- $\quad$ Overall power coefficient of reactivity if not accounted for in the items listed previously

- $\quad$ Fuel processing/cleanup, handling, and reuse

- $\quad$ Fuel salt flow rate

- $\quad$ Experiments

- $\quad$ Credible inadvertent insertion of excess reactivity should not damage the reactor or Fuel System Boundary; this event should be analyzed in Sections 4.5 and 4.6 and Chapter 13 of the SAR.

- $\quad$ The minimum amount of total Control Element reactivity worth to ensure reactor subcriticality should be stated.

- $\quad$ A transient analysis should be performed that assumes that an instrumentation malfunction drives the most reactive Control Element out in a continuous ramp mode in its most reactive region. The analysis should show that the reactor would not be damaged and that Fuel System Boundary integrity would not be lost. Chapter 13 of the SAR should analyze reactivity additions under accident conditions.

- $\quad$ An analysis should be performed that examines reactivity, assuming that the reactor is operating under its maximum licensed conditions, normal electrical power is lost, and the Control Element of maximum reactivity worth and any non-scrammable Control Elements remain fully withdrawn. The analysis should show how much negative reactivity must be available in the remaining scrammable Control Elements so that, without operator intervention, the reactor can be shut down safely and remain subcritical without risk of Fuel System Boundary damage, even after temperature equilibrium is attained and all transient poisons, such as xenon, are reduced, with consideration for the most reactive core loading.

- $\quad$ On the basis of analysis, the applicant should justify a minimum negative reactivity (shutdown margin) that will ensure the safe shutdown of the reactor. This discussion should address the methods and the accuracy with which this negative reactivity can be determined to ensure its availability.

- $\quad$ The core configuration with the highest power density possible for the planned fuel should be analyzed as a basis for safety limits and limiting safety system settings (LSSSs) in the thermal-hydraulic analyses. The core configuration should be compared with other configurations to ensure that a limiting configuration is established for steady power.

- $\quad$ The effects of fuel salt surface phenomena on reactivity should be considered, if applicable. 
- $\quad$ Analysis should show that power oscillations will not exceed the operational or safety limits and might include operational limits on parameters such as power density.

- $\quad$ The applicant should propose and justify TS for safety limits, LSSSs, LCOs, and surveillance requirements, as discussed in Chapter 14 of the format and content guide.

\section{Review Procedures}

The reviewer should confirm that the methods and assumptions used in this section of the SAR have been justified and are consistent with those in other sections of this chapter.

\section{Evaluation Findings}

This section of the SAR should contain sufficient information to support the following types of conclusions, which will appear in the staff's safety evaluation report:

- $\quad$ The applicant has discussed and justified all excess reactivity factors needed to ensure a readily operable reactor. The applicant has also considered the design features of the control systems that ensure that this amount of excess reactivity is fully controlled under normal operating conditions.

- The discussion of limits on excess reactivity shows that a credible rapid activation of the most reactive Control Element or other credible failure that would add reactivity to the reactor would not lead to loss of Fuel System Boundary integrity. Therefore, the information demonstrates that the proposed amount of reactivity is available for normal operations but that it would not cause unacceptable risk to the public from a transient.

- $\quad$ The definition of the shutdown margin is negative reactivity obtainable by Control Elements to ensure reactor shutdown from any reactor condition, including a loss of normal electrical power. With the assumption that the most reactive Control Element is inadvertently stuck in its fully withdrawn position, and non-scrammable Control Elements are in the position of maximum reactivity addition, the analysis derives the minimum negative reactivity necessary to ensure safe reactor shutdown. The applicant proposes a shutdown margin of [ $x x$-reviewer should insert the margin specified in the $S A R]$ in the TS that ensures adequate public safety. The applicant has justified this value; it is readily measurable and is acceptable.

- $\quad$ The SAR contains calculations of the peak thermal power density achievable with any core configuration. This value is used in the calculations in the thermal-hydraulic section of the SAR to derive reactor safety limits and LSSSs, which are acceptable.

\subsection{Thermal-Hydraulic Design}

\section{Areas of Review}

The information in this section should enable the reviewer to determine the limits on the cooling conditions necessary to ensure that Fuel System Boundary integrity will not be lost under any reactor conditions, including accidents.

Since the fuel salt is free to move in a liquid form, the temperature within the fuel can more readily equalize; however, the power shape might still cause some hot spots, which could have 
adverse safety impacts in terms of instability and/or fuel and fission product precipitation, a potential that the applicant's safety analysis should address. Because some of the factors in the thermal-hydraulic design are based on experimental measurements and correlations that are a function of fuel salt conditions, the analyses should confirm that the values of such parameters are applicable to the reactor conditions analyzed.

The MSR design might contain a flow loop that circulates fission gases and a sparing gas. The reviewer needs to determine the constituents in the bubbly mixture and cover gas. The reviewer should also ensure that any sources and sinks of energy in the flow loop are within the design capacities of any heat exchangers in the loop.

This section of the format and content guide discusses the areas of review.

\section{Acceptance Criteria}

The acceptance criteria for information on thermal-hydraulic design include the following:

- $\quad$ The applicant should propose criteria and safety limits based on the criteria for acceptable safe operation of the reactor, thus ensuring Fuel System Boundary integrity under all analyzed conditions. The discussion should include the consequences of these conditions and justification for the alternatives selected. It should also include the limiting power density to offset the onset of instability following perturbation to the system (including from fission gas generation).

- $\quad$ Safety limits, as discussed in Chapter 14 of the format and content guide, should be derived from the analyses described previously, the analyses in Section 4.5.3 of the SAR, and any other necessary conditions to ensure adequate public safety. The safety limits should include consideration of the effects of uncertainties or tolerances and should be included in the TS.

- LSSSs, as discussed in Chapter 14 of the format and content guide of the SAR, should be derived from the analyses described previously, the analyses in Section 4.5.3 of the SAR, and any other necessary conditions to ensure adequate public safety. These settings should be chosen to maintain Fuel System Boundary integrity when safety system protective actions are initiated at the LSSSs.

- A forced-flow reactor should be capable of switching to natural-convection flow without jeopardizing safe reactor shutdown. Loss of normal electrical power should not change this criterion. These limits should be based on the thermal-hydraulic analyses and appear in the TS.

- $\quad$ For MSRs, changes in the redox of the fuel salt could result in fuel or fission product plate-out or precipitation; this should be considered in the thermal-hydraulic design.

- $\quad$ The gas treatment system will contain fission product gas. In addition there might be storage or drain systems and associated piping that contain fuel salt. Since these form part of the Fuel System Boundary, this section should consider any associated cooling systems and show their ability to maintain their functions and Fuel System Boundary integrity under normal and abnormal operations. Fuel salts have high melting temperatures; thus, the thermal-hydraulic analysis should consider the effects of partial or complete loss of flow in some piping as a result of freezing from loss of heaters. In addition the thermal-hydraulic needs to address the possible effects of overcooling. 


\section{Technical Rationale}

Previous experience with MSRs has indicated the importance of the interrelationship between the temperature of the fuel salt and redox.

\section{Review Procedures}

The reviewer should confirm that the thermal-hydraulic analyses for the reactor are complete and address all issues that affect key parameters (e.g., flow, temperature, pressure, power density, redox, and peaking). The basic approach is an audit of the SAR analyses, but the reviewer may also perform independent calculations to confirm SAR results or methods.

\section{Evaluation Findings}

This section of the SAR should contain sufficient information to support the following types of conclusions, which will appear in the staff's safety evaluation report:

- $\quad$ The information in the SAR includes the thermal-hydraulic analyses for the reactor. This includes fission gas generation, changes in void fraction including void collapse, and phenomena that could affect stability on the fuel salt surface. The applicant has justified the assumptions and methods and validated their results.

- $\quad$ All necessary information on the fuel salt hydraulics and thermal conditions of the fuel salt is specified for this reactor. The analysis has considered the various approaches and systems for heat removal, such as the gas management system, fuel transfer piping and drain or storage tanks containing radioactive fuel. The analyses give the limiting conditions of the features that ensure Fuel System Boundary integrity.

- $\quad$ Safety limits and LSSSs are derived from the thermal-hydraulic analyses. The values have been justified and appear in the TS. The thermal-hydraulic analyses on which these parameters are based ensure that overheating or overcooling during any operation or credible event will cause neither a loss of Fuel System Boundary integrity and unacceptable radiological risk to the health and safety of the public nor fuel or fission product plate-out or precipitation that could lead to a loss of Fission Product Barrier integrity. The analysis includes methods for calculating the induced natural convection within the homogeneous fuel salt.

\subsection{Gas Management System}

\section{Areas of Review}

This section of the SAR should contain the design information on all components of the gas management system. The design information should be presented in drawings, diagrams, text, and analysis in sufficient detail for the staff to understand the flow of evolved gases and fission products from their generation in the Active Reactor Core to their ultimate release. Using this information, the staff should determine whether there is reasonable assurance that the gas management system can contain hazardous chemicals and volatile fission products until they can be released safely, in accordance with environmental release criteria, and can withstand any pressure transients within the reactor system. 
In evaluating the analysis demonstrating these capabilities, the staff should ensure that these criteria can be met for the maximum power density that is considered credible during power oscillations. The applicant should justify the maximum fission product generation rates during power oscillations.

This section of the format and content guide discusses the areas of review.

\section{Technical Rationale}

Areas of review, acceptance criteria, and evaluation findings are all dictated by the following hazards: an inadvertent criticality outside the Active Reactor Core, a release of gaseous fission products, and an increase in the pressure in the headspace over the core. Although the reactor will operate in a steady-state mode, power oscillations could be possible. Therefore, the design must be sufficiently robust to sustain fission product, heat generation, and pressures that will occur at peak power.

\section{Acceptance Criteria}

The design of the gas management system should be found acceptable if it meets the following acceptance criteria:

- $\quad$ The geometry of all equipment and piping should be favorable (e.g., subcritical when filled with optimally moderated fuel salt).

- If any portions of the equipment or piping are not in a favorable geometry, the applicant's analysis should demonstrate that no single failure can result in a criticality outside the core.

- Monitoring should be provided periodically for the long-term accumulation of fissionable material in the system.

- The construction materials must be compatible with the chemical environment such that corrosion cannot lead to a loss of confinement.

- $\quad$ The maximum pressure resulting from heat from fission gases must not exceed the design pressure for the system, unless redundant pressure relief features are described.

- $\quad$ The maximum release of fission gases must not exceed applicable regulatory criteria.

- $\quad$ The maximum release of hazardous chemicals must not exceed applicable regulatory criteria (this should include any potential effect on workers in the production facility).

- Monitoring should be provided for concentrations of hazardous chemicals and fission products to detect buildup and leaks.

Chapter 5 contains acceptance criteria for any credited cooling function of the gas management system.

\section{Technical Rationale}

Most of these are events can result in release pathways through the loss of confinement (e.g., by corrosion or overpressurization). The exception to this is criticality, which will result in the generation of more fission products (although they will be small compared with those generated during normal reactor operations). Criticality should not be allowed outside the Vessel because 
there are no means to control it or adequately protect personnel outside such an environment. Ideally, all equipment that is connected to the Vessel should have favorable geometry (i.e., the contained SNM will always have a subcritical multiplication factor). Maintaining aerosolized fuel within the Active Reactor Core (ideally) or the favorable geometry part of the gas management system (as an anticipated upset) is crucial.

\section{Review Procedures}

The reviewer should confirm that the design of the gas management system and the associated analysis are sufficient to provide reasonable assurance of safe operation of the reactor and compliance with all applicable chemical and radiological release criteria.

\section{Evaluation Findings}

This section of the SAR should contain sufficient information to support the following types of conclusions, which will be included in the staff's safety evaluation report:

- The applicant has described the system in sufficient detail to prevent criticality outside the Vessel, caused by the entrainment of uranium in the gas, slow accumulation over time, or backflow of fuel salt from the Vessel.

- $\quad$ The applicant has designed the system to withstand the maximum pressure that could occur during credible power oscillations, so as to avoid breaching confinement and exceeding applicable regulatory limits.

- $\quad$ The applicant has designed the system to allow for control of the reactor during possible increases in pressure (e.g., pneumatic fuel transfer system).

- $\quad$ The applicant has designed the system to be compatible with the chemical environment to which it will be exposed, avoiding corrosion that could result in a release of hazardous chemicals or fission products exceeding applicable regulatory limits.

- $\quad$ The applicant has designed sufficient surge capacity to contain hazardous chemicals and allow for the decay of fission products until they can be released in accordance with applicable regulatory limits.

\section{Technical Rationale}

These conclusions are driven by the consideration of hazards discussed previously.

\subsection{References}

1. Corrosion Behavior of Reactor Materials in Fluoride Salt Mixtures, ORNL-TM-328, DeVan and Evans, 1962. In particular, Figure 9 explains the relationship between redox, temperature, and corrosion.

2. Compatibility Studies of Potential Molten-Salt Breeder Reactor Materials in Molten Fluoride Salts, ORNL-TM-5783, Keiser, 1977. Goes into more detail about measured removal rates for long-term applications.

3. Stability Analysis of the Molten-Salt Reactor Experiment, ORNL-TM-1070, Ball and Kerlin, 1965. Explains the response of MSRE to oscillations. 
4. Theoretical Dynamic Analysis of MSRE with ${ }^{233} U$ Fuel, ORNL-TM-2571, Steffy and Wood, 1969. Also provides a good explanation of transient damping in MSRs.

5. The Development of Technical Specifications for Research Reactors, American National Standards Institute/American Nuclear Society, ANSI/ANS-15.1-R2013, ANS, LaGrange Park, Illinois, 2013. 
A-44 
APPENDIX B. CHAPTER 5, "MOLTEN SALT REACTOR COOLING SYSTEMS"-MSR ADAPTATION 



\section{APPENDIX B. CHAPTER 5, "MOLTEN SALT REACTOR COOLING SYSTEMS”-MSR ADAPTATION OF PART 1}

\section{MOLTEN SALT REACTOR COOLING SYSTEMS (Part 1)}

Replace NUREG-1537, Part 1, Chapter 5, in its entirety with the following guidance.

NUREG-1537, Part 1, Chapter 5, of the format and content guide, as augmented by this ISG, is applicable to providing a description of the cooling systems for the licensing of a nonpower molten salt reactor (MSR) facility. Whenever the term MSR or reactor appears, it is understood to mean a nonpower reactor facility.

In this chapter of the SAR, the applicant should give the design bases, descriptions, and functional analyses of the MSR cooling systems. ${ }^{12}$ The principal purpose of the cooling systems is to safely remove the fission and decay heat from the liquid fuel ${ }^{13}$ and dissipate it to the environment. The discussions should include all significant heat sources in the reactor and should show how the heat is safely removed and transferred to the environment.

The following glossary contains terms often used when discussing an MSR.

Active Reactor Core: In an MSR, the Vessel region occupied by the fuel salt where the majority of prompt neutrons are generated and where most fissions occur. In an MSR, the core geometry might change with time as a result of changes in density and voiding of the solution. The core does not include the part of the fuel salt that can become entrained into the cover gas.

Coating: Intervening protective layer of material between the corrosive fuel salt and the structural container alloy. Multiple layer configurations are possible (ranging in thickness from $>1 \mathrm{~mm}$, similar to liners used in current LWRs, to $<500 \mathrm{~nm}$, which adhere to the underlying substrate). Also included are embedded coatings, which are chemically resistant material that is embedded into the surface of the structural alloy, allowing surface modification to be performed to the structure to enhance its corrosion resistance.

Control Element(s): Object(s) employed to interact with an MSR's neutron population to adjust reactivity. Control elements can act through fuel displacement, neutron absorption, neutron reflection, neutron spectral adjustment, or a combination of these methods. Control elements can be solids, liquids, or gases, and they can be passively or actively positioned.

Emergency Cooling System: System that provides decay heat removal from the Reactor Fuel following an accident (e.g., a direct reactor auxiliary cooling system or a reactor vessel auxiliary cooling system).

\footnotetext{
${ }^{12}$ MSRs are a class of reactors in which a molten salt performs a significant function in the core.

13 There are also salt-cooled reactor designs that propose using fixed-position, coated-particle ceramic fuel. The discussion in this chapter is focused on MSRs operating with liquid fuel.
} 
Fission Product Barrier: Portion of the Fuel System Boundary in contact with fission products only (e.g., the gas management system boundary).

Fuel Barrier: Portion of the Fuel System Boundary in contact with the fuel salt (principally the Vessel, heat exchanger, control element thimbles, instrumentation thimbles, piping, tanks, and valves).

Fuel System Boundary: All structures that prevent the release of fuel, fission gas, or other fission products. For an MSR, this includes the Vessel, waste-handling tank, pumps, valves, and piping. (Essentially includes the Fission Product Barrier and the Fuel Barrier.)

Heat Dissipation System: Set of components or system(s) that interface with the Primary Cooling System to provide the principal means of transferring the heat from the core to the environment. The Heat Dissipation System might use a variety of coolants (e.g., salt, liquid metal, or water) but does not contain fuel.

Neutron Moderator: In an MSR, materials in or near the core that consist of light elements. Moderators are generally solid form.

Primary Cooling System: Directly interfaces with the Fuel System Boundary at the fuel salt/primary cooling system heat exchanger(s) to provide the principal means of removing heat from the fuel salt by transferring the heat to the Heat Dissipation System. The Primary Cooling System typically contains a salt but does not contain fuel.

Reactor Fuel: In an MSR, fuel salt which consists of fissionable and possibly fertile halide salts, fission products, and generally solvent halide salt(s).

Vessel: For an MSR, structure containing the Active Reactor Core. Other components might reside in the Vessel but outside the Active Reactor Core, such as heat exchangers in certain design configurations.

The class of MSRs discussed in this chapter use liquid fuel rather than solid heterogeneous fuel. The homogeneous Reactor Fuel (fuel salt) is contained within the Fuel System Boundary. Reactor Fuel can typically be added online, and fission products can be removed from the fuel salt online through a fuel salt cleanup system and gas management system. Under normal operation, the fuel salt moves through the Active Reactor Core where it is brought into a critical configuration and heat is added to the fuel salt as discussed in Chapter 4, "Molten Salt Reactor Description," of the SAR. Subsequently, the fuel salt continues through a fuel salt/primary cooling heat exchanger where heat is transferred from the fuel salt to the Primary Cooling System containing a compatible non-fuel salt (coolant salt). The fuel salt then returns to the Active Reactor Core. The coolant salt passes heat to the Heat Dissipation System through subsequent system interfaces. The subsystems can be forced convection or natural thermal convection. In this chapter, an MSR applicant should describe and discuss all systems that remove and dispose of heat from the Reactor Fuel, as well as major components. 
Heat from the fuel salt is normally transferred through one or more fuel salt/primary cooling heat exchangers to the Primary Cooling System. On reactor shutdown, decay heat can be removed through an auxiliary heat exchanger instead of the fuel salt/ coolant salt heat exchanger. Some nonpower MSR designs might be capable of dissipating decay heat in the natural convection mode. Other MSR designs might use a fuel salt drain tank or other irradiated fuel salt storage tanks to allow for safe storage of the fuel salt in the event of a design-basis accident or for maintenance. Decay heat in a fuel salt drain tank is cooled separately and is discussed as a separate system. Supplemental cooling systems might also be necessary to remove heat from the cover gas space above the core and from a fuel salt cleanup system. The design of the MSR cooling systems is based on selecting among interdependent parameters, including thermal power level, research capability, available fuel type, Active Reactor Core physics requirements, and radiation shielding.

If the MSR is designed to operate at such low power levels that no significant temperature increases will occur during normal operation, an engineered cooling system for heat removal is not required. For those reactors, the applicant should, in Chapter 4 of the SAR, discuss the disposition of the heat produced, estimate potential temperature increases during operation, and justify why an engineered cooling system for heat removal is not required. In this chapter, the applicant should summarize those considerations and conclusions.

For all other nonpower MSRs, the applicant should describe and discuss in this chapter systems to remove and dispose of the waste heat. The design bases of the MSR cooling systems for the full range of normal operation should be based on ensuring acceptable reactor conditions established in Chapter 4 of the SAR. The design bases of any features of the core cooling system designed to respond to potential accidents or to mitigate the consequences of potential accidents should be derived from the analyses in Chapter 13, "Accident Analyses," of the SAR. These features, such as an auxiliary heat exchanger or a fuel salt drain tank, should be summarized in this chapter and discussed in detail in Chapter 6, "Engineered Safety Features," of the SAR. In this chapter, the applicant should discuss and reference the technical specifications (TS) where analyses are used as the basis for a requirement.

In this chapter, the applicant should describe all auxiliary and subsystems that use and contribute to the heat load of the fuel salt, Primary Cooling System, or Heat Dissipation System. Any auxiliary systems using cooling systems from other sources should be discussed in Chapter 9, "Auxiliary Systems," of the SAR.

\subsection{Summary Description}

In this section, the applicant should briefly describe the reactor cooling systems and supplementary core heat removal pathways, summarizing the principal features. Information should include the following:

- $\quad$ Summary of the Fuel System Boundary emphasizing heat transfer mechanisms (a description of the Fuel System Boundary is provided in Chapter 4).

- $\quad$ Type of fuel salt flow: forced convection, natural convection, or both. 
- $\quad$ Type of Primary Cooling System, if one is present, and the method of heat transfer.

- Type of Heat Dissipation System, if one is present, and the method of heat transfer to the environment.

- Description of the capability to provide sufficient heat removal to support continuous operation at full licensed power.

- Description of any supplementary methods of removing core decay heat.

- Description of special or facility-unique features.

For an MSR, the applicant should provide additional information in this section on the core cooling systems unique to the principal features of MSRs, including supplementary core heat removal pathways. If the core cooling system is not the sole means of heat removal and the core heat removal is partitioned between supplementing pathways (such as a gas management system above the core or a fuel salt cleanup system), these additional pathways should be mentioned. The energy partitioning should be given. These other means of heat transport from the core should be summarized, including the corresponding amount of heat transported from the core and the fraction of total core heat removed.

\subsection{Fuel Salt Heat Transport}

The basic requirements and design bases of the fuel salt and the Fuel System Boundary are to maintain reactor facility conditions within the range of design conditions and accident analyses assumptions derived from other chapters of the SAR, especially Chapters 4 and 13. The applicant should show the interrelationships among all SAR chapters and the way heat transport is provided for the fuel salt. The following information should be included:

- $\quad$ Design bases and functional requirements of the Fuel System Boundary.

- $\quad$ Schematic and flow diagrams of the Fuel System Boundary, showing such essential components as the heat source (Active Reactor Core), heat sinks (heat exchangers), drain tank, gas management system, pumps, piping, valves, control and safety instrumentation, interlocks, and other related subsystems.

- $\quad$ Tables of allowable ranges of important design and operating parameters and specifications for the fuel salt and the Fuel System Boundary and its components, including:

- Materials and Coatings

- $\quad$ Fuel salt flow rates

- Inlet and outlet temperatures and pressures throughout the system

- $\quad$ Elevation of components and fuel salt levels relative to the Vessel

- Construction materials of components

- $\quad$ Fabrication specifications of safety-related components 
- $\quad$ Fuel salt chemistry and composition control limits

- $\quad$ Fuel salt quality requirements for operation and shutdown conditions, including redox and conductivity at a minimum

- $\quad$ Key parameters of interfacing components and systems

- $\quad$ Discussions and analyses keyed to drawings showing how the Fuel System Boundary provides the necessary cooling for all heat loads and all potential reactor conditions analyzed in the thermal-hydraulics section of Chapters 4 and 13, including the following:

- Removal of heat from the fuel salt by forced-convection or natural-convection cooling, or both for those reactors licensed to operate in both modes. Discussion and analyses of the effect of the size, shape, and structural features of the Fuel System Boundary on cooling characteristics.

- Transfer of heat from the fuel salt to the Primary Cooling System for all reactor conditions. This discussion should include any heat exchanger design and operating conditions. Some MSRs might have only a Fuel System Boundary that functions as a heat reservoir. For such systems, the analyses should include any factors that limit continuous operation, such as fuel salt temperature and the proposed TS that ensure operation within the analyzed limits.

- Safe reactor shutdown, including passive or fail-safe transition from forced- to natural-convection cooling and removal of decay heat from the fuel. This discussion should include the methods of decay heat removal in the event of loss of off-site electrical power. The discussion should also include any use of an auxiliary heat exchanger or a drain tank for accident mitigation and decay heat removal. Emergency Cooling System (ECS) features, such as an auxiliary heat exchanger or a fuel salt drain tank, should be summarized in this chapter and discussed in detail in Chapter 6 of the SAR. If applicable, subsection 5.8 of the SAR specifically addresses operation of a fuel salt drain tank.

- Locations, designs, and functions of such essential components as heat exchangers, drains, drain tanks, cover gas space, syphon-breaks, pumps, isolation valves, and check valves. These components ensure that the Fuel System Boundary is operable and that uncontrolled loss or discharge of contaminated salt from the Fuel System Boundary does not occur. Radiological effects of potential fuel salt releases should be analyzed primarily in Chapter 11, "Radiological Protection Program and Waste Management."

- Discussion of the control and safety instrumentation, including location and functions of sensors and readout devices. The scram or interlock functions that prevent safety limits from being exceeded should be shown and discussed, including the related TS.

- Description and function of any special features of the Fuel System Boundary. 
- $\quad$ Brief description and functions of special features or components of the Fuel System Boundary that affect or limit personnel radiation exposures from fission product gases, soluble fission products, nonsoluble fission products, delayed neutrons, tritium, and radioactive contaminants.

- Description of radiation monitors or detectors incorporated into the Fuel System Boundary and discussion of their functions.

- $\quad$ Brief discussion and references to detailed discussions in later sections of auxiliary systems using fuel salt, such as fuel salt cleanup, salt makeup, emergency cooling, experiment cooling, and experimental facility cooling. The direct effect of these auxiliary systems on the design and functioning of the Fuel System Boundary should be discussed.

- Discussion of leak detection and allowable leakage limits, if any.

- $\quad$ Discussion of normal fuel salt radiation concentration limits, including sampling frequency, isotopes of interest, and actions to be taken if limits are exceeded.

- $\quad$ Discussion of TS requirements for parameters of the Fuel System Boundary, including the bases and surveillance requirements

\subsection{Cooling Systems}

Most MSRs include a Primary Cooling System that interfaces directly with the fuel salt through the fuel salt/primary cooling heat exchanger(s). The Primary Cooling System is detailed in Subsection 5.3.1. Heat is transferred from the Primary Cooling System to the environment through a Heat Dissipation System. The Heat Dissipation System is detailed in Subsection 5.3.2.

\subsubsection{Primary Cooling System}

In this section, the applicant should give information about those MSRs that include a Primary Cooling System. For other MSRs, the applicant should state that a Primary Cooling System is not needed and should justify that conclusion. The applicant should provide the following information:

- The design bases and functional requirements of the Primary Cooling System, including whether the system is designed for continuous full-power reactor operation.

- $\quad$ Schematic and flow diagrams of the Primary Cooling System, showing such essentials as how the fuel salt/primary cooling heat exchanger connects the Fuel System Boundary (i.e., the heat source) to the Primary Cooling System, pumps, piping, valves, control and safety instrumentation, and interlocks and how the Primary Cooling System interfaces with the Heat Dissipation System for ultimate release of the heat.

- $\quad$ Tables of the range of important design and operating parameters and specifications of the Primary Cooling System, including the following:

- Coolant salt materials and their source

- Coolant salt flow rates 
- Location of Primary Cooling System in relation to the reactor and heat exchangers

- Construction materials and fabrication specifications of components

Primary cooling system salt chemistry and composition control limits

Specifications and limitations on coolant salt quality and corrosion of the Primary

Cooling System components, including the environmental effects of the use of

Primary Cooling System salt chemicals

- Discussion and functional analyses keyed to the drawings showing how the Primary

Cooling System provides the necessary heat transfer for all potential Fuel System

Boundary conditions. These discussions should address the following:

Inlet and outlet temperatures and pressures throughout the Primary Cooling System, including the pressure differential between the fuel salt and Primary Cooling System in the fuel salt/primary cooling heat exchanger. The applicant should discuss how the pressure in the Primary Cooling System is maintained above that in the Fuel System Boundary for all operating conditions, or analyze the radiological effect of leakage of fuel salt into the Primary Cooling System. Isolation of the fuel salt/primary cooling heat exchanger during shutdown periods is an acceptable method to control potential fuel salt-to-Primary Cooling System leakage if Primary Cooling System pressure is lower than Fuel System Boundary pressure only during periods of system shutdown. The applicant does not need to perform an analysis of fuel salt-to-Primary Cooling System leakage if Primary Cooling System pressure is lower than Fuel System Boundary pressure for only short periods for system testing or repair. If the transfer of fuel salt into the Primary Cooling System is caused by an abrupt event, such as a heat exchange surface rupture, the analysis should be given in Chapter 13 and summarized here.

Control of heat removal from the Primary Cooling System necessary to maintain fuel temperatures in the Fuel System Boundary within the limits derived in the thermal-hydraulics analyses in Chapters 4 and 13 of the SAR.

Transfer of heat from the fuel salt/primary cooling heat exchangers to the Heat Dissipation System when the Fuel System Boundary operates in all anticipated and licensed modes, including forced-convection flow and natural-convection flow, as applicable.

- Safe reactor shutdown and removal and dissipation of decay heat, including evaluation of the fuel salt system change from forced-convection flow to naturalconvection flow if forced convection flow is an allowed mode of operation.

- $\quad$ Response of the Primary Cooling System to the loss of fuel salt, including dumping the fuel salt into a fuel salt drain tank, if applicable.

Locations, designs, and functions of such essential components as drains, sumps, pumps, makeup salt, and check valves that ensure fuel salt is not inadvertently transferred to the Primary Cooling System and released to the environment. 
- Discussion of control and safety instrumentation, including locations and functions of sensors and readout devices and interlocks or safety capabilities.

- $\quad$ Brief description and functions of special features or components of the Primary Cooling System that affect or limit personnel radiation exposures from neutron activation of coolant salts and contaminants, and fission product leakage through heat exchange surfaces.

- Descriptions of functions of any radiation monitors or detectors incorporated into the Primary Cooling System. Discussion of surveillance to measure Primary Cooling System activity including frequency, action levels, and action to be taken.

- $\quad$ Brief comments and reference to detailed discussion in other sections of auxiliary cooling systems that transfer heat to the Primary Cooling System.

- Discussion of TS requirements, as appropriate, for the Primary Cooling System, including the bases and surveillance requirements.

The Primary Cooling System can also include a salt drain tank to provide for system maintenance. Any required cooling system for a coolant salt drain tank is discussed in Chapter 9 of the SAR.

The applicant should provide the following information about Primary Cooling System salt drain tanks:

- $\quad$ Design bases and functional requirements of all Primary Cooling System salt drain tanks.

- $\quad$ Schematic and flow diagrams of Primary Cooling System salt drain tanks, showing such essentials as how the drain tank connects to the respective coolant salt system, pumps, piping, valves, control and safety instrumentation, and interlocks.

- Locations and functions of control instrumentation, including sensors, readout displays, and interlocks.

- $\quad$ Discussion of any TS requirements, including the bases and surveillance requirements.

\subsubsection{Heat Dissipation System}

In this section, the applicant should give information about those MSRs that include a Heat Dissipation System. For other MSRs, the applicant should state that a Heat Dissipation System is not needed and should justify that conclusion. The applicant should provide the following information:

- $\quad$ The design bases and functional requirements of the Heat Dissipation System, including whether the system is designed for continuous full-power reactor operation.

- $\quad$ Schematic and flow diagrams of the Heat Dissipation System, showing essentials such as how the primary cooling/heat dissipation heat exchanger(s) connect the Primary Cooling System to the Heat Dissipation System, pumps, piping, valves, control and safety 
instrumentation, interlocks, and interface with the environment for ultimate release of the heat.

- $\quad$ Tables showing the range of important design and operating parameters and specifications of the Heat Dissipation System, including the following:

Coolant materials and their source.

Coolant flow rates.

Type of Heat Dissipation System, such as cooling tower, refrigerator, radiator, or body of water.

- Location of Heat Dissipation System in relation to the Primary Cooling System.

- Construction materials and fabrication specifications of components.

- $\quad$ Heat Dissipation System specifications related to environmental factors (e.g., temperature and humidity).

- Heat Dissipation System chemistry and composition control limits.

- Specifications and limitations on coolant quality and corrosion of the Heat Dissipation System components, including the environmental effects of the use of system chemicals.

- Discussion and functional analyses keyed to the drawings showing how the Heat Dissipation System provides the necessary cooling for all potential reactor conditions. These discussions should address the following:

Inlet and outlet temperatures and pressures throughout the Heat Dissipation System, including the pressure differential between the Primary Cooling System and Heat Dissipation System in all system heat exchangers.

- $\quad$ Control of heat removal from the Heat Dissipation System necessary to maintain fuel salt temperatures in the Fuel System Boundary within the limits derived in the thermal-hydraulics analyses in Chapters 4 and 13 of the SAR.

- Removal of heat from the Heat Dissipation System heat exchangers and release to the environment when the Fuel System Boundary operates in all anticipated and licensed modes, including forced-convection flow and natural-convection flow, as applicable.

- $\quad$ Safe reactor shutdown and removal and dissipation of decay heat, including evaluation of the Fuel System Boundary change from forced-convection flow to natural-convection flow if forced-convection flow is an allowed mode of operation.

- $\quad$ Response of the Heat Dissipation System to the loss of fuel salt (or Primary Cooling System salt), including dumping the fuel salt into a fuel salt drain tank (or Primary Cooling System salt into a drain tank), if applicable. 
- Discussion of control and safety instrumentation, including locations and functions of sensors and readout devices and interlocks or safety capabilities.

- $\quad$ Brief description and functions of special features or components of the Heat Dissipation System that affect or limit personnel radiation exposures from neutron activation of coolants and contaminants, and fission product leakage through heat exchange surfaces.

- Descriptions of functions of any radiation monitors or detectors incorporated into the Heat Dissipation System. Discussion of surveillance to measure Heat Dissipation System coolant activity including frequency, action levels, and action to be taken.

- $\quad$ Brief comments and reference to detailed discussion in other sections of auxiliary cooling systems that transfer heat to the Heat Dissipation System.

- Discussion of TS requirements, as appropriate, for the Heat Dissipation System, including the bases and surveillance requirements.

The Heat Dissipation System might include coolant drain tank(s) to provide for system maintenance. Any required cooling system for a coolant drain tank is discussed in Chapter 9 of the SAR.

The applicant should provide the following information about Heat Dissipation System drain tanks:

- Design bases and functional requirements of all Heat Dissipation System drain tanks.

- $\quad$ Schematic and flow diagrams of Heat Dissipation System drain tanks, showing such essentials as how the drain tank connects to the respective coolant system, pumps, piping, valves, control and safety instrumentation, and interlocks.

- Locations and functions of control instrumentation, including sensors, readout displays, and interlocks.

- Discussion of any TS requirements, including the bases and surveillance requirements.

\subsection{Fuel Salt Cleanup System}

In MSRs evaluated under this chapter, fission products are generated and entrained in the fuel salt because there is no fuel cladding. Gaseous fission products, such as xenon and krypton, bubble off continuously and are typically removed from the cover gas space through a gas management system without any significant impact on reactor operation. The gas management system is discussed in Chapter 4 and Chapter 11 of the SAR. Gas management system cooling is discussed in Chapter 9 of the SAR. Soluble and nonsoluble fission products remain in the fuel salt. Therefore, the fuel salt in the nonpower MSR will become highly radioactive. Nonsoluble fission products tend to plate out on reactor surfaces. The soluble fission products can be removed from the fuel salt by chemical processing, polishing, or filtration (operated in batch mode or continuously). The radiological controls for the fuel salt cleanup system are discussed in Chapter 11 of the SAR. Cooling for the filtering system or chemical processing loop is discussed in Chapter 9 of the SAR. In some nonpower MSR designs, the filtering system or chemical 
processing loop can also be used to add additional fuel to the fuel salt. Fuel handling is discussed in Chapter 9 of the SAR; if appropriate, fuel addition is summarized here. The purity of the fuel salt should be maintained as high as reasonably possible for the following reasons:

- To limit radioactivity levels in the fuel salt

- $\quad$ To limit the chemical corrosion of the Fuel System Boundary

- $\quad$ To limit the concentrations of particulate and dissolved contaminants that could be made radioactive by neutron irradiation

- $\quad$ To maintain the thermal-dynamic properties of the fuel salt within the operational limits established for the fuel

The applicant should provide the following information:

- $\quad$ The design bases and functional requirements of the fuel salt cleanup system. The design bases should be consistent with the discussions in Chapter 4 of the SAR. Any recommendations from the fuel vendor should also be addressed.

- $\quad$ Schematic drawings and flow diagrams of the fuel salt cleanup loop.

- $\quad$ Table of specifications for the cleanup system demonstrating that it is designed for the volume and throughput of the fuel salt.

- Locations and functions of control and monitoring instrumentation, including sensors, recorders, and meters. The discussion of monitors should include methods for continuously assessing fuel salt quality and effectiveness of the cleanup system.

- Locations and functional designs of cleanup system components such as branch points, pumps, valves, filters, and demineralizers.

- Interface with any liquid fuel addition system components as discussed in Chapter 9 of the SAR.

- Discussion of schedules and methods for replacing or regenerating cleanup system components and disposing of resultant radioactivity to ensure that radiation exposures do not exceed the limits discussed in Chapter 11 of the SAR.

- $\quad$ Summary of methods for predicting, monitoring, and shielding radioactivity deposited in cleanup system components from routine operations. The detailed discussion should be in Chapter 11 of the SAR.

- Summary of methods for predicting and limiting exposures of personnel in the event of inadvertent release of excess radioactivity in the fuel salt system and deposition in cleanup system components. The detailed discussion should be in Chapter 13 of the SAR.

- $\quad$ Summary of methods for preventing an inadvertent criticality outside the Active Reactor Core in the fuel salt cleanup system (e.g., subcritical when filled with optimally moderated fuel salt). 
- Provisions in the design and operation of the cleanup system to avoid malfunctions that could lead to significant loss of fuel salt and fission products, which could cause radiological exposure of personnel or release to the unrestricted environment to exceed the requirements in 10 CFR Part 20 and the facility ALARA (as-low-as-is-reasonablyachievable) program guidelines.

- $\quad$ Discussion of TS requirements for the fuel salt cleanup system, including the bases and surveillance requirements.

\subsection{Salt Makeup Systems}

During MSR operation, there might be a need for salt to be replaced or replenished in the fuel salt system or the Primary Cooling System. Salt can be lost because of operational activities or there might be a need to adjust the fuel salt composition. If applicable, salt makeup for the fuel salt is detailed in Subsection 5.5.1. If applicable, Primary Cooling System salt makeup is detailed in Subsection 5.5.2.

\subsubsection{Fuel Salt Makeup System}

MSR designs should include a system or a procedure that meets the projected needs for salt makeup in the Reactor Fuel. The makeup salt system need not be designed to provide a rapid, total replacement of the fuel salt inventory, but it should be able to maintain the minimum acceptable fuel salt quantity and quality for reactor operation.

The applicant should provide the following information:

- $\quad$ The design bases for the fuel salt makeup system that account for all activities that could cause a decrease in the generally solvent halide salt(s) in the Reactor Fuel. Although a required Emergency Cooling System need not be a part of the fuel salt makeup system, if it exists, it should be discussed in Chapter 6 of the SAR.

- $\quad$ Schematic diagrams and functional discussions that show the source of salt, the methods of addition to the fuel salt, and the requirements for pretreatment before addition.

- Locations and functions of control instrumentation, including sensors, readout displays, and interlocks. Methods should be discussed for tracking additions of makeup salt to detect significant changes that might indicate leaks or other malfunction of the Fuel System Boundary.

- $\quad$ Interface with any liquid fuel addition system components as discussed in Chapter 9 of the SAR, including a summary of methods for preventing an inadvertent criticality outside the Active Reactor Core in the fuel salt makeup system (e.g., subcritical when filled with optimally moderated fuel salt).

- $\quad$ Discussion of safety systems and administrative controls to ensure that the system or procedures for adding makeup salt will not lead to significant loss of fuel salt.

- $\quad$ Discussion of TS requirements for the fuel salt makeup system, including the bases and surveillance requirements. 


\subsubsection{Primary Cooling Makeup System}

MSR designs should include a system or a procedure that meets the projected needs for Primary Cooling System salt makeup. The primary cooling makeup system need not be designed to provide a rapid, total replacement of the cooling salt inventory, but it should be able to maintain the minimum acceptable cooling salt quantity and quality for Primary Cooling System operation.

The applicant should provide the following information:

- $\quad$ The design bases for the primary cooling makeup system that account for all activities that could cause a decrease in the cooling salt.

- Schematic diagrams and functional discussions that show the source of salt, methods of addition to the cooling salt, and requirements for pretreatment before addition.

- Locations and functions of control instrumentation, including sensors, readout displays, and interlocks. Methods should be discussed for tracking additions of makeup salt to detect significant changes that might indicate leaks or other malfunction of the Primary Cooling System Boundary.

- Discussion of TS requirements for the primary cooling makeup system, including the bases and surveillance requirements.

\subsection{MSR ${ }^{16} \mathrm{~N}$ Control System}

As a high-energy beta and gamma emitter with a 7-second half-life, ${ }^{16} \mathrm{~N}$ is a significant concern in water-cooled, water-moderated reactors. MSRs with fluoride-based salts will also generate ${ }^{16} \mathrm{~N}$. However, with operation, the MSR fuel salt becomes highly radioactive because of the presence of fission products and actinides. Therefore, the ${ }^{16} \mathrm{~N}$ formed in fluoride-based fuel salts is not an isolated radiological concern, and a separate ${ }^{16} \mathrm{~N}$ control system is not expected to be necessary for MSRs.

\subsection{Auxiliary Cooling Systems}

In addition to the systems discussed previously that are associated with the fuel salt or Primary Cooling System, other auxiliary cooling systems might require the use of fuel salt or primary cooling salt and could affect the operation or safety of the reactor. If the reactor design includes an Emergency Cooling System, such as an auxiliary heat exchanger, it should be described and discussed in Chapter 6. The following auxiliary systems that use fuel salt or primary cooling salts should be discussed in this section (if applicable):

- $\quad$ Experiment cooling

- $\quad$ Experimental facility cooling

- $\quad$ Biological shield cooling 
- Thermal shield cooling

- $\quad$ Fuel storage cooling and shielding

- $\quad$ Reflector cooling

The applicant should provide the following information about these systems in this section:

- Design bases and functional requirements of the auxiliary cooling systems based on discussions elsewhere in the SAR, such as Chapters 4, 9, and 10, "Experimental Facilities and Utilization."

- Schematic drawings and flow diagrams that show the source of the salt, locations of sensors and instruments, and locations of the components cooled.

- $\quad$ Tables of the range of important parameters of the systems and specifications of materials and components.

- Discussion of components to be cooled, the source of heat, source of salt, heat transfer to the salt, and salt heat dissipation.

- Discussion of the provisions in the auxiliary cooling system designs to prevent interference with safe reactor shutdown.

- Discussion of the provisions in the auxiliary cooling system design to prevent the uncontrolled release of fuel salt or radiation exposures that would exceed the requirements in 10 CFR Part 20 and the facility ALARA program guidelines.

- Discussion of any TS requirements for the auxiliary cooling systems, including the bases and surveillance requirements.

\subsection{Fuel Salt Drain System}

A fuel salt drain tank may be provided to allow for safe storage of the fuel salt in the event of a design-basis accident or for maintenance. The fuel salt drain tank maintains the fuel salt in a noncritical configuration and is cooled separately to remove decay heat. A detailed discussion of an engineered safety feature (ESF) function for the fuel salt drain tank system and its activation is provided in Chapter 6 of the SAR. The fuel salt drain tank cooling system is discussed in Chapter 9 of the SAR. Radiation protection for this system is discussed in Chapter 11 of the SAR. Accident analyses regarding ESF response for this system are discussed in Chapter 13 of the SAR. If included in the design, the applicant should summarize the fuel salt drain tank operation in this section of the SAR.

The applicant should provide the following information about the fuel salt drain tanks:

- Design bases and functional requirements of the fuel salt drain tanks.

- Schematic and flow diagrams of the fuel salt drain tanks, showing such essentials as how the drain tank connects to the respective fuel salt system, pumps, piping, valves, control and safety instrumentation, and interlocks. 
- Locations and functions of control instrumentation, including sensors, readout displays, and interlocks.

- $\quad$ Specifications and limitations on fuel salt chemistry, composition limits, quality and corrosion of the drain tank components, including off gassing.

- $\quad$ Discussion of any TS requirements, including the bases and surveillance requirements.

\subsection{References}

1. MSRE Design and Operations Report, Part 1: Description of Reactor Design, ORNL-TM-728, Robertson, 1965.

2. Format and Content for Safety Analysis Reports for Research Reactors, American National Standards Institute/American Nuclear Society, ANSI/ANS-15.21-2012, ANS, LaGrange Park, Illinois, 2012.

3. The Development of Technical Specifications for Research Reactors, American National Standards Institute/American Nuclear Society, ANSI/ANS-15.1-R2013, ANS, LaGrange Park, Illinois, 2013. 
B-18 


\section{APPENDIX B. CHAPTER 5, "MOLTEN SALT REACTOR COOLING SYSTEMS"-MSR ADAPTATION OF PART 2}

\section{MOLTEN SALT REACTOR COOLING SYSTEMS (Part 2)}

Replace NUREG-1537, Part 2, Chapter 5, in its entirety with the following guidance.

NUREG-1537, Part 2, Chapter 5, of the standard review plan and acceptance criteria, as augmented by this ISG, is applicable to reviewing a description of the cooling systems for the licensing of a nonpower molten salt reactor (MSR) facility. Whenever the term MSR or reactor appears, it is understood to mean a nonpower reactor facility.

This chapter contains guidance for evaluating the design bases, descriptions, and functional analyses of the MSR cooling systems. ${ }^{14}$ The principal purpose of the cooling systems is to safely remove the fission and decay heat from the fuel salt ${ }^{15}$ and dissipate it to the environment. The design of the reactor cooling systems is based on choosing among interdependent parameters, including thermal power level, research capability, available fuel type, Active Reactor Core physics requirements, and radiation shielding.

The following glossary contains terms often used when discussing an MSR.

Active Reactor Core: In an MSR, the Vessel region occupied by the fuel salt where the majority of prompt neutrons are generated and where most fissions occur. In an MSR, the core geometry might change with time as a result of changes in density and voiding of the solution. The core does not include the part of the fuel salt that can become entrained into the cover gas.

Coating: Intervening protective layer of material between the corrosive fuel salt and the structural container alloy. Multiple layer configurations are possible (ranging in thickness from $>1 \mathrm{~mm}$, similar to liners used in current LWRs, to $<500 \mathrm{~nm}$, which adhere to the underlying substrate). Also included are embedded coatings, which are chemically resistant material that is embedded into the surface of the structural alloy, allowing surface modification to be performed to the structure to enhance its corrosion resistance.

Control Element(s): Object(s) employed to interact with an MSR's neutron population to adjust reactivity. Control elements can act through fuel displacement, neutron absorption, neutron reflection, neutron spectral adjustment, or a combination of these methods. Control elements can be solids, liquids, or gases, and they can be passively or actively positioned.

Emergency Cooling System: System that provides decay heat removal from the Reactor Fuel following an accident (e.g., a direct reactor auxiliary cooling system or a reactor vessel auxiliary cooling system).

\footnotetext{
${ }^{14}$ MSRs are a class of reactors in which a molten salt performs a significant function in the core.

${ }^{15}$ There are also salt-cooled reactor designs that propose using fixed-position, coated-particle ceramic fuel. The discussion in this chapter is focused on MSRs operating with liquid fuel.
} 
Fission Product Barrier: Portion of the Fuel System Boundary in contact with fission products only (e.g., the gas management system boundary).

Fuel Barrier: Portion of the Fuel System Boundary in contact with the fuel salt (principally the Vessel, heat exchanger, control element thimbles, instrumentation thimbles, piping, tanks, and valves).

Fuel System Boundary: All structures that prevent the release of fuel, fission gas, or other fission products. For an MSR, this includes the Vessel, waste-handling tank, pumps, valves, and piping. (Essentially includes the Fission Product Barrier and the Fuel Barrier.)

Heat Dissipation System: Set of components or system(s) that interface with the Primary Cooling System to provide the principal means of transferring the heat from the core to the environment. The Heat Dissipation System might use a variety of coolants (e.g., salt, liquid metal, or water) but does not contain fuel.

Neutron Moderator: In an MSR, materials in or near the core that consist of light elements. Moderators are generally solid form.

Primary Cooling System: Directly interfaces with the Fuel System Boundary at the fuel salt/primary cooling system heat exchanger(s) to provide the principal means of removing heat from the fuel salt by transferring the heat to the Heat Dissipation System. The Primary Cooling System typically contains a salt but does not contain fuel.

Reactor Fuel: In an MSR, fuel salt which consists of fissionable and possibly fertile halide salts, fission products, and generally solvent halide salt(s).

Vessel: For an MSR, structure containing the Active Reactor Core. Other components might reside in the Vessel but outside the Active Reactor Core, such as heat exchangers in certain design configurations.

The class of MSRs discussed in this chapter use liquid fuel rather than solid heterogeneous fuel. The homogeneous Reactor Fuel (fuel salt) is contained within the Fuel System Boundary. Reactor Fuel can typically be added online, and fission products can be removed from the fuel salt online through a fuel salt cleanup system and gas management system. Under normal operation, the fuel salt moves through the Active Reactor Core where it is brought into a critical configuration and heat is added to the fuel salt as discussed in Chapter 4, "Molten Salt Reactor Description," of the SAR. Subsequently, the fuel salt continues through a fuel salt/primary cooling heat exchanger where heat is transferred from the fuel salt to the Primary Cooling System containing a compatible non-fuel salt (coolant salt). The fuel salt then returns to the Active Reactor Core. The coolant salt passes heat to the Heat Dissipation System through subsequent system interfaces. The subsystems may be forced convection or natural thermal convection.

The principal licensing basis of nonpower reactors is the thermal power developed in the core during operation. This basis also applies to MSRs licensed to operate at such low power levels 
that no significant core temperature increases would occur during normal operation. Such reactors might not require an engineered cooling system. For those reactors, the applicant should, in Chapter 4 of the SAR, discuss the dissipation of the heat produced, estimate potential temperature increases during reactor operation, and justify why an engineered cooling system is not required. In this chapter, the applicant should summarize those considerations and conclusions.

For all other nonpower reactors, the applicant should describe and discuss all systems to remove and dispose of the heat from the fuel salt. The design bases of the core cooling systems for the full range of normal operation should be derived in Chapter 4 of the SAR. All auxiliary systems and subsystems that use and contribute to the heat load of either the fuel salt or Primary Cooling System should also be described and discussed in this chapter. Any auxiliary systems using cooling from other sources should be discussed in Chapter 9, "Auxiliary Systems," of the SAR. The design bases of any features of the fuel salt cooling system designed to respond to potential accidents or to mitigate the consequences of potential accidents should be derived from the analyses in Chapter 13, "Accident Analyses," of the SAR. These features should be summarized in this chapter and discussed in detail in Chapter 6, "Engineered Safety Features," of the SAR. In this chapter, the applicant should discuss and reference the technical specifications (TS) that are needed to ensure operability consistent with SAR analyses assumptions.

The fuel salt system of most licensed MSRs is of two basic types, forced convection and natural thermal convection. Facilities using forced-convection cooling might also be licensed to operate in natural-convection mode and should be capable of dissipating decay heat in that mode.

In this chapter, MSR applicants should describe and discuss all systems that remove and dispose of heat from the Active Reactor Core, as well as major components. This chapter gives the review plan and acceptance criteria for information on the heat removal systems. The information suggested for this section of the SAR is outlined in Chapter 5 of the format and content guide.

\subsection{Summary Description}

In this section, the applicant should give a brief description of fuel salt cooling systems, including the supplementary core heat removal pathways, summarizing the principal features. Information should include the following:

- Description of the fuel salt system.

- Type of coolant flow in the fuel salt system: forced convection, natural convection, or both.

- $\quad$ Type of Primary Cooling System, if one is present, and the method of heat transfer.

- $\quad$ Type of Heat Dissipation System, if one is present, and the method of heat transfer to the environment.

- Description of the capability to provide sufficient heat removal to support continuous operation at full licensed power. 
- $\quad$ Description of any supplementary methods of removing core decay heat.

- Description of special or facility-unique features.

The applicant should summarize the principal features of the Primary Coolant Systems unique to the MSR. In addition to fuel salt heat removal through the fuel salt/ coolant salt heat exchanger, other means of heat transport from the fuel salt should be described, including the corresponding amount of heat transported from the fuel salt and the fraction of total core heat removed. These are the supplementary core heat removal pathways.

\subsection{Fuel System Boundary}

\section{Areas of Review}

For an MSR, the Fuel System Boundary provides the Fuel Barrier for the fuel salt. The Fuel System Boundary includes an interface with the Primary Cooling System to remove heat from the fuel salt. The Primary Cooling System is a key component in the overall design and should have the capability to do the following:

- $\quad$ Remove the fission and decay heat from the fuel salt during reactor operation and decay heat during reactor shutdown.

- $\quad$ For most nonpower reactors, transfer the heat to the Primary Cooling System for controlled dissipation to the environment by the Heat Dissipation System.

- Maintain high fuel salt quality to limit corrosion of the Fuel Barrier, internal control elements (if any), components in the Vessel, and other essential interfacing components.

- $\quad$ Prevent uncontrolled leakage or discharge of fuel salt to the unrestricted environment.

The MSR fuel salt could be corrosive and will contain radioactive fission products and actinides. No fuel cladding barrier exists for the fuel salt, as is characteristic of heterogeneous fuel elements in conventional nonpower reactors. Instead, the MSR Fuel Barrier provides an analogous function to fuel cladding. Because this affects the design of MSR heat removal systems, consideration should be given to the following:

- $\quad$ Construction materials of components and fabrication specifications of safety-related components as they relate to corrosion resistance of the fuel salt.

- $\quad$ Fuel salt quality requirements for operation and shutdown conditions to prevent corrosion on either side of heat removal components.

- Locations, designs, and functions of essential components because these components ensure that the Fuel System Boundary is operable and that uncontrolled loss or discharge of fuel salt into the Primary Cooling System does not occur.

The basic requirements for these functions are generally derived and analyzed in other chapters of the SAR. In this chapter, the applicant should describe how the Fuel System Boundary 
provides these functions. Section 5.2 of the format and content guide discusses specific areas of review for this section.

\section{Acceptance Criteria}

The acceptance criteria for information on the Fuel System Boundary include the following:

- $\quad$ Chapter 4 of the SAR should contain analyses of the Active Reactor Core including the fuel salt parameters necessary to ensure removal of heat from the core to provide Fuel System Boundary integrity. Safety limits (SLs), limiting safety system settings (LSSSs), and limiting conditions for operation (LCOs) should be derived from those analyses and included in the TS. Examples of fuel salt system variables on which LSSSs and LCOs might be established are maximum thermal power level for operation in naturalconvection flow, maximum fuel salt temperature, minimum fuel salt flow rate, fuel salt viscosity, and fuel salt pressure range. The analyses in this section should show that the components and the functional design of the Fuel System Boundary will ensure that no LSSS will be exceeded through the normal range of reactor operation. The analyses should address forced flow or natural-convection flow, or both for MSRs licensed for both modes. The design should show that the passive or fail-safe transition from forced flow to natural-convection flow is reasonably ensured in all forced-flow MSRs.

- The functional design should show that safe reactor shutdown and decay heat removal are sufficient to ensure Fuel System Boundary integrity for all possible reactor conditions, including potential accident scenarios. Scenarios that postulate loss of flow or loss of fuel salt should be analyzed in Chapter 13 and the results summarized in this section of the SAR. Emergency Cooling System (ECS) interfaces with the fuel salt system, such as any use of an auxiliary heat exchanger or a drain tank for accident mitigation and decay heat removal, should be discussed in Chapter 6 and summarized in this section of the SAR.

- $\quad$ The descriptions and discussions should show that sufficient instrumentation, fuel salt parameter sensors, and control systems are provided to monitor and ensure stable fuel salt flow, respond to changes in reactor power levels, and provide for a rapid reactor shutdown in the event of loss of cooling from the Primary Cooling System.

- $\quad$ The fuel salt should provide a chemical environment that limits corrosion of the Fuel Barrier, control element surfaces, the Vessel, and other essential interface components. Chapter 4 of the SAR should contain discussion and analyses of fuel salt quality and other purity factors. Chemical conditions should be maintained, as discussed in Section 5.4 of this standard review plan.

- $\quad$ The applicant should discuss potential neutron activation and radiation damage in Chapter 4 of the SAR. To ensure that the design of the Vessel is acceptable, exposure limits on materials discussed in Chapter 4 should not be exceeded and exposures to personnel, as discussed in Chapter 11, "Radiation Protection Program and Waste Management," should not exceed the requirements of 10 CFR Part 20 and should be consistent with the facility ALARA (as-low-as-is-reasonably-achievable) program.

- $\quad$ Radioactive species, including fission product gases, soluble, and nonsoluble fission products and actinides, will be produced in the fuel salt as a result of reactor operation. 
Additional radioactivity could occur as a result of neutron activation of fuel salt contaminants. Provisions for limiting personnel radiological hazards should maintain potential exposures from fuel salt radioactivity below the requirements of 10 CFR Part 20 and should be consistent with the facility ALARA program. To ensure that facilities or components for controlling, shielding, or isolating these radioactive species are acceptable, potential exposures should not exceed the requirements of 10 CFR Part 20 and should be consistent with the facility ALARA program.

- $\quad$ Because the Fuel System Boundary provides essential fuel cooling and includes fission products and actinides, the system design should avoid uncontrolled release or loss of fuel salt. Some design features to limit losses include using a guard boundary outside the Fuel System Boundary, providing syphon breaks in piping that enters the Fuel System Boundary, and providing check valves to preclude backflow. The designs and locations of such features should provide reasonable assurance that Fuel System Boundary failure is unlikely. A potential accident of rapid loss of fuel salt should be analyzed in Chapter 13 and summarized in this section of the SAR.

- If fuel salt were lost from the Fuel System Boundary, the design and analyses should ensure that potential personnel exposures and uncontrolled releases to the unrestricted environment do not exceed acceptable radiological dose consequence limits derived from the accident analyses. The radiological consequences from the fuel salt release should be discussed in Chapter 11 and summarized in this section of the SAR. Necessary surveillance provisions should be included in the TS.

- $\quad$ The applicant should propose TS as discussed in Chapter 14 of the format and content guide to ensure that the Fuel System Boundary meets the safety-related design requirements. The applicant should justify the proposed TS in this section of the SAR.

\section{Review Procedures}

The reviewer should compare the functional design and operating characteristics of the Fuel System Boundary with the bases for the design presented in this and other relevant chapters of the SAR. The system design should meet the appropriate acceptance criteria presented previously while considering the specific facility design under review.

\section{Evaluation Findings}

This section of the SAR should contain sufficient information to support the following types of conclusions, which will be included in the staff's safety evaluation report:

- $\quad$ The Fuel System Boundary is designed in accordance with the design bases derived from all relevant analyses in the SAR.

- $\quad$ Design features of the Fuel System Boundary and components give reasonable assurance of boundary integrity under all possible reactor conditions, including potential accident scenarios. The Fuel System Boundary should be designed to remove sufficient fission heat from the fuel salt to allow all licensed operations without exceeding the established LSSSs that are included in the TS. 
- $\quad$ The design and location of Fuel System Boundary components have been specifically selected to avoid fuel salt loss that could lead to Fuel System Boundary failure or to an uncontrolled release of excessive radioactivity.

- $\quad$ The Fuel System Boundary is designed to convert in a passive or fail-safe method to natural-convection flow sufficient to avoid loss of Fuel System Boundary integrity. (This feature is evaluated in conjunction with the reviews of the reactor description and accidents. It is applicable to licensing MSRs to operate with forced-convection flow.)

- The chemical quality of the fuel salt will limit corrosion of the Fuel Barrier, internal control elements (if any), the inside of the Vessel, and other essential components in the Fuel System Boundary for the duration of the license and for the projected utilization time of the fuel salt.

- $\quad$ The Fuel System Boundary will include sufficient radiation shielding to maintain personnel exposures below the limits in 10 CFR Part 20.

- $\quad$ Fuel System Boundary instrumentation and controls are designed to provide all necessary functions and to transmit information on the operating status to the control room.

- $\quad$ The TS, including testing and surveillance, provide reasonable assurance of necessary Fuel System Boundary operability for reactor operations as analyzed in the SAR.

- $\quad$ The design bases of the Fuel System Boundary provide reasonable assurance that the environment and the health and safety of the public will be protected.

\subsection{Cooling Systems}

Most MSRs include a Primary Cooling System that interfaces directly with the fuel salt through the fuel salt/primary cooling heat exchanger(s). The guidance for evaluating the design bases, descriptions, and functional analyses of the Primary Cooling System is detailed in Subsection 5.3.1. Heat is transferred from the Primary Cooling System to the environment through a Heat Dissipation System. The guidance for evaluating the design bases, descriptions, and functional analyses of the Heat Dissipation System is detailed in Subsection 5.3.2.

\subsubsection{Primary Cooling System}

\section{Areas of Review}

A systematic means to remove heat from the fuel salt is required unless the MSR is licensed to operate at such low power levels that no significant fuel salt temperature increases would occur during normal operation, as justified in Chapter 4. The Primary Cooling System of an MSR should be designed to transfer heat from the fuel salt to the Heat Dissipation System. Nonpower reactors can be designed in three ways: with a continuously operating Primary Cooling System, with an on-demand Primary Cooling System, and without a Primary Cooling System. For most MSRs, the Primary Cooling System is designed for continuous operation at licensed power level. Therefore, the Primary Cooling System should be designed to dissipate heat continuously. In this section of the SAR, the applicant should justify how any necessary heat transfer to the Heat 
Dissipation System is accomplished. Specific areas of review for this section are discussed in Section 5.3 of the format and content guide.

\section{Acceptance Criteria}

The acceptance criteria for information on the Primary Cooling System include the following:

- $\quad$ The analyses and discussions of Section 5.3 should demonstrate that the Primary Cooling System is designed to allow the Fuel System Boundary to transfer heat from the fuel salt as necessary to ensure Fuel System Boundary integrity. The analyses should address the Fuel System Boundary operating with forced flow, natural-convection flow, or both for reactors licensed for both modes. The design should show that the Primary Cooling System is capable of transferring all necessary fission and decay heat to the Heat Dissipation System for all potential reactor conditions as analyzed in the SAR.

- $\quad$ Some MSRs might be designed with Primary Cooling Systems that will not support continuous reactor operation at full licensed power. This is acceptable, provided the capability and such limiting conditions as maximum fuel salt temperature are analyzed in the SAR and included in the TS.

- $\quad$ The fuel salt will contain radioactive contamination. The design of the Primary Cooling System should ensure that release of such radioactivity through the Heat Dissipation System to the unrestricted environment would not lead to potential exposures of the public in excess of the requirements of 10 CFR Part 20 and the ALARA program guidelines. Designs should ensure that the fuel salt pressure is lower than the Primary Cooling System salt pressure across the fuel salt/primary cooling heat exchanger(s) under all anticipated conditions; the Primary Cooling System is closed; or radiation monitoring and an effective remedial capability are provided. The Primary Cooling System should prevent or acceptably mitigate uncontrolled release of radioactivity to the unrestricted environment. Periodic samples of Primary Cooling System salt should be analyzed for radiation. Action levels and required actions should be discussed.

- $\quad$ The Primary Cooling System should accommodate any heat load required of it in the event of a potential engineered safety feature operation or accident conditions as analyzed in Chapters 6 and 13 of the SAR.

- $\quad$ Primary Cooling System salt drain tanks, if provided, should accommodate any heat load required during normal operation or during accident conditions as analyzed in Chapter 9 of the SAR.

- $\quad$ The Primary Cooling System design should provide for any necessary chemical control to limit corrosion or other degradation of the heat transfer interfaces and prevent chemical contamination of the environment.

- $\quad$ The applicant should propose TS as discussed in Chapter 14 of the format and content guide to ensure that the Primary Cooling System meets the safety-related design requirements. The applicant should justify the proposed TS in this section of the SAR. 


\section{Review Procedures}

The reviewer should verify that all reactor conditions, including postulated accidents, requiring transfer of fuel salt heat from the Fuel System Boundary to the Primary Cooling System have been discussed. The reviewer should verify that the Primary Cooling System is capable of transferring the amount of heat and the thermal power necessary to the Heat Dissipation System to ensure Fuel System Boundary integrity. The reviewer should also confirm analyses of Primary Cooling System malfunctions, including the effects on Fuel System Boundary integrity and the health and safety of the public.

\section{Evaluation Findings}

This section of the SAR should contain sufficient information to support the following types of conclusions, which will be included in the staff's safety evaluation report:

- Design features of the Primary Cooling System and components allow transfer of the necessary fuel salt heat from the Fuel System Boundary under all possible reactor conditions.

- Locations and design specifications for Primary Cooling System components ensure that malfunctions in the system will not lead to reactor damage, Fuel System Boundary failure, or uncontrolled release of radioactivity to the environment.

- $\quad$ The Primary Cooling System instrumentation and controls are designed to provide all necessary functions and to transmit information on the operating status to the control room.

- $\quad$ The Primary Cooling System is designed to respond, as necessary, to such postulated events as a significant reduction of forced fuel salt flow or a total loss of forced fuel salt flow. Loss of fuel salt flow could lead to an overcooling situation in the fuel salt/primary cooling heat exchanger(s).

- $\quad$ The TS, including testing and surveillance, provide reasonable assurance of necessary Primary Cooling System operability for normal reactor operations.

\subsubsection{Heat Dissipation System}

\section{Areas of Review}

A systematic means to remove heat from the fuel salt is required unless the MSR is licensed to operate at such low power levels that no significant fuel salt temperature increases would occur during normal operation, as justified in Chapter 4. The Heat Dissipation System of an MSR should be designed to transfer heat from the Primary Cooling System to the environment. The Heat Dissipation System should be designed to dissipate heat continuously. In this section of the SAR, the applicant should justify how any necessary heat transfer to the environment is accomplished. Specific areas of review for this section are discussed in Section 5.3 of the format and content guide. 


\section{Acceptance Criteria}

The acceptance criteria for information on the Heat Dissipation System include the following:

- The analyses and discussions of Section 5.3 should demonstrate that the Heat Dissipation System is designed to allow the Primary Cooling System to transfer the heat from the fuel salt as necessary to the environment to ensure Fuel System Boundary integrity. The design should show that the Primary Cooling System is capable of transferring all necessary fission and decay heat to the Heat Dissipation System for all potential reactor conditions as analyzed in the SAR.

- $\quad$ Some MSRs might be designed with Heat Dissipation Systems that will not support continuous reactor operation at full licensed power. This is acceptable, provided the capability and such limiting conditions as maximum fuel salt temperature are analyzed in the SAR and included in the TS.

- The Heat Dissipation System should accommodate any heat load required in the event of a potential engineered safety feature operation or accident conditions as analyzed in Chapters 6 and 13 of the SAR.

- Heat Dissipation System coolant drain tanks or storage tanks, if provided, should accommodate any heat load required during normal operation or during accident conditions as analyzed in Chapter 9 of the SAR.

- $\quad$ The Heat Dissipation System design should provide for any necessary chemical control to limit corrosion or other degradation of the heat transfer interfaces and to prevent chemical contamination of the environment.

- $\quad$ The applicant should propose TS as discussed in Chapter 14 of the format and content guide to ensure that the Heat Dissipation System meets the safety-related design requirements. The applicant should justify the proposed TS in this section of the SAR.

\section{Review Procedures}

The reviewer should verify that all reactor conditions, including postulated accidents, requiring transfer of fuel salt heat through the Primary Cooling System to the environment have been discussed. The reviewer should verify that the Heat Dissipation System is capable of transferring the amount of heat and the thermal power necessary to the environment to ensure Fuel System Boundary integrity. The reviewer should also confirm the analyses of Heat Dissipation System malfunctions, including the effects on Fuel System Boundary integrity and the health and safety of the public.

\section{Evaluation Findings}

This section of the SAR should contain sufficient information to support the following types of conclusions, which will be included in the staff's safety evaluation report: 
- Design features of the Heat Dissipation System and components allow the transfer of the necessary fuel salt heat from the Fuel System Boundary to the environment under all possible reactor conditions.

- $\quad$ Locations and design specifications for Heat Dissipation System components ensure that malfunctions in the system will not lead to reactor damage, Fuel System Boundary failure, or uncontrolled release of radioactivity to the environment.

- $\quad$ The Heat Dissipation System instrumentation and controls are designed to provide all necessary functions and to transmit information on the operating status to the control room.

- $\quad$ The Heat Dissipation System is designed to respond, as necessary, to postulated events in the Fuel System Boundary or the Primary Cooling System.

- $\quad$ The TS, including testing and surveillance, provide reasonable assurance of necessary Heat Dissipation System operability for normal reactor operations.

\subsection{Fuel Salt Cleanup System}

\section{Areas of Review}

In MSRs evaluated under this chapter, fission products are released from the liquid fuel directly into the fuel salt because there is no fuel cladding. Gaseous fission products, such as xenon and krypton, bubble off continuously and are typically collected in a cover gas space and removed through a gas management system without any significant impact on reactor operation. The gas management system is discussed in Chapters 4 and 11 of the SAR. The gas management system cooling is discussed in Chapter 9 of the SAR. Soluble and nonsoluble fission products remain in the fuel salt and can be removed from the fuel salt by chemical processing, polishing, or filtration. The radiological controls for the fuel salt cleanup system are discussed in Chapter 11 of the SAR. Cooling for soluble and nonsoluble fission product cleanup systems are discussed in Chapter 9 of the SAR. In some MSR designs, the fuel salt cleanup system might also be used to add additional fuel to the fuel salt. Fuel handling is discussed in Chapter 9 of the SAR; if appropriate, fuel addition is summarized here. The purity of the fuel salt should be maintained as high as reasonably possible for the following reasons:

- $\quad$ To limit the chemical corrosion of the Fuel System Boundary

- To limit the concentrations of particulate and dissolved contaminants that might become radioactive by neutron irradiation

Specific areas of review for this section are discussed in Section 5.4 of the format and content guide.

\section{Acceptance Criteria}

The acceptance criteria for information on the fuel salt cleanup system include the following: 
- $\quad$ The fuel salt quality should be maintained in the ranges established as acceptable in Chapters 4 and 11 of the SAR.

- $\quad$ The geometry of all fuel salt cleanup system equipment and piping should be favorable (e.g., subcritical when filled with optimally moderated fuel salt).

- $\quad$ Radioactive contaminated filters and other materials associated with operation of the fuel salt cleanup system should be disposed of or regenerated in accordance with the radiological waste management plans discussed in Chapter 11, and potential exposures and releases to the unrestricted environment shall not exceed the requirements of 10 CFR Part 20 and should be consistent with the facility ALARA program.

- The location, shielding, and radiation monitoring of the fuel salt cleanup system for routine operations and potential accidental events should be such that the occupational staff and the public are protected from radiation exposures exceeding the requirements of 10 CFR Part 20 and acceptable radiological consequence dose limits for accidents.

- The location and functional design of the components of the fuel salt cleanup system should ensure the following:

- Malfunctions or leaks in the system do not cause uncontrolled loss or release of fuel salt.

- $\quad$ Personnel exposure and release of radioactivity do not exceed the requirements of 10 CFR Part 20 and are consistent with the facility ALARA program.

- $\quad$ Safe reactor shutdown is not prevented.

- $\quad$ The applicant should propose TS as discussed in Chapter 14 of the format and content guide to ensure that the fuel salt cleanup system meets the safety-related design requirements. The applicant should justify the proposed TS in this section of the SAR.

\section{Review Procedures}

The reviewer should compare the design bases for the fuel salt quality with the design bases by which the fuel salt cleanup system will achieve the requirements. The comparison should include performance specifications, schematic diagrams, and discussion of the functional characteristics of the cleanup system. The reviewer should evaluate (1) design features to ensure that leaks or other malfunctions would not cause inadvertent damage to the reactor or exposure of personnel and (2) the plan for control and disposal of radioactive filters and other materials associated with the fuel salt cleanup system.

\section{Evaluation Findings}

This section of the SAR should contain sufficient information to support the following types of conclusions, which will be included in the staff's safety evaluation report:

- $\quad$ The design bases and functional descriptions of the fuel salt cleanup system give reasonable assurance that the required fuel salt quality can be achieved (i.e., heat exchange surface corrosion, film buildup, fouling, and plugging). 
- $\quad$ The fuel salt cleanup system and its components have been designed and selected so that malfunctions are unlikely. Any malfunctions or leaks will not lead to radiation exposure to personnel or releases to the environment that exceed the requirements of 10 CFR Part 20 and the facility ALARA program guidelines.

- $\quad$ The plans for controlling and disposing of radioactivity accumulated in components of the fuel salt cleanup system, which results from normal operations and potential accident scenarios, conform with applicable regulations, including 10 CFR Part 20, and acceptable radiological consequence dose limits for accidents.

- $\quad$ The TS, including testing and surveillance, provide reasonable assurance of necessary fuel salt cleanup system operability for normal reactor operations.

\subsection{Salt Makeup Systems}

During MSR operation, there might be a need for salt to be replaced or replenished in the fuel salt system or the Primary Cooling System. The guidance for evaluating the design bases, descriptions, and functional analyses of the fuel salt makeup system is detailed in Subsection 5.5.1. The guidance for evaluating the design bases, descriptions, and functional analyses of the Primary Cooling System salt makeup is detailed in Subsection 5.5.2.

\subsubsection{Fuel Salt Makeup System}

\section{Areas of Review}

During MSR operations, it could be necessary to replace or replenish the generally solvent halide salt(s) in the Reactor Fuel. Salt can be lost because of operational activities or there could be a need to adjust the fuel salt composition. Although each reactor should have a makeup salt system or procedure to meet projected operational needs for the Reactor Fuel, the system need not be designed to provide a rapid, total replacement of the fuel salt inventory. In some MSR designs, the fuel salt makeup system might also be used to add additional fuel to the fuel salt. Fuel handling is discussed in Chapter 9 of the SAR; if appropriate, fuel addition is summarized here. Specific areas of review for this section are discussed in Section 5.5.1 of the format and content guide.

\section{Acceptance Criteria}

The acceptance criteria for information on the makeup salt system for the Reactor Fuel include the following:

- $\quad$ The projected loss of salt inventory in the Reactor Fuel for anticipated reactor operations should be discussed. The design or plan for supplying makeup salt should ensure that those operational requirements are satisfied.

- $\quad$ The geometry of all fuel salt makeup system equipment and piping should be favorable (e.g., subcritical when filled with optimally moderated fuel salt). 
- $\quad$ Storage of salt for the Reactor Fuel should be provided as required by the design bases of the MSR, or a plan should ensure that such salt is provided.

- $\quad$ The makeup salt system or plan should include features to prevent loss or release of fuel salt from the Fuel System Boundary.

- $\quad$ The makeup salt system need not have a functional relationship with any installed ECS. If it does, it should not interfere with the availability and operability of the ECS.

- $\quad$ The makeup salt system or plan should include provisions for recording the use of makeup salt to detect changes that indicate leakage or other malfunction of the Fuel System Boundary.

- $\quad$ The applicant should propose TS as discussed in Chapter 14 of the format and content guide to ensure that the fuel salt makeup system meets the safety-related design requirements. The applicant should justify the proposed TS in this section of the SAR.

\section{Review Procedures}

The reviewer should compare the design bases and functional requirements for replenishing salt in the Reactor Fuel, including the quantity and quality of the salt, the activities or functions that remove salt, and the systems or procedures to accomplish salt makeup with the acceptance criteria. The review should focus, as applicable, on safety precautions to preclude overfilling of the Fuel System Boundary and the release of fuel salt back through the salt makeup system into the environment.

\section{Evaluation Findings}

This section of the SAR should contain sufficient information to support the following types of conclusions, which will be included in the staff's safety evaluation report:

- $\quad$ The design bases, functional descriptions, and procedures for salt makeup in the Reactor Fuel give reasonable assurance that the quantity and quality of salt required will be provided.

- $\quad$ The fuel salt makeup system design or procedures prevent overfilling of the Fuel System Boundary or malfunction of the makeup salt system and prevent the loss or release of fuel salt that would exceed the requirements of 10 CFR Part 20 and the facility ALARA program guidelines.

- $\quad$ The TS, including testing and surveillance, provide reasonable assurance of necessary makeup salt system operability for normal reactor operations. 


\subsubsection{Primary Cooling Makeup System}

\section{Areas of Review}

During MSR operations, it could be necessary to replace or replenish the salt in the Primary Cooling System or other coolants in the Heat Dissipation System. Salt could be lost because of operational activities, or there might be a need to adjust the salt composition. Although each reactor should have a primary cooling makeup system or procedure to meet projected operational needs for heat removal, the system need not be designed to provide a rapid, total replacement of the Primary Cooling System salt inventory. Specific areas of review for this section are discussed in Section 5.5.2 of the format and content guide.

\section{Acceptance Criteria}

The acceptance criteria for information on the salt makeup systems include the following:

- The projected loss of salt inventory in the Primary Cooling System (or other coolants in the Heat Dissipation System) for anticipated reactor operations should be discussed. The design or plan for supplying makeup salt should ensure that those operational requirements are satisfied.

- $\quad$ Storage of salt for the Primary Cooling System should be provided as required by the design bases of the MSR, or a plan should ensure that such salt is provided.

- $\quad$ The primary cooling makeup system or plan should include features to prevent loss or release of salt from the Primary Cooling System.

- $\quad$ The primary cooling makeup system or plan should include provisions for recording the use of makeup salt to detect changes that indicate leakage or other malfunction of the Primary Cooling System.

- $\quad$ The applicant should propose TS as discussed in Chapter 14 of the format and content guide to ensure that the primary cooling makeup system meets the safety-related design requirements. The applicant should justify the proposed TS in this section of the SAR.

\section{Review Procedures}

The reviewer should compare the design bases and functional requirements for replenishing salt in the Primary Cooling System, including the quantity and quality of the salt, the activities or functions that remove salt, and the systems or procedures to accomplish salt makeup with the acceptance criteria. The review should focus, as applicable, on safety precautions to preclude overfilling of the Primary Cooling System.

\section{Evaluation Findings}

This section of the SAR should contain sufficient information to support the following types of conclusions, which will be included in the staff's safety evaluation report: 
- $\quad$ The design bases, functional descriptions, and procedures for the primary cooling makeup system give reasonable assurance that the quantity and quality of salt required will be provided.

- $\quad$ The primary cooling makeup system design or procedures prevent overfilling of the Primary Cooling System.

- $\quad$ The TS, including testing and surveillance, provide reasonable assurance of necessary primary cooling makeup system operability for normal reactor operations.

\subsection{Nitrogen-16 Control System}

\section{Areas of Review}

Nitrogen-16, a high-energy beta and gamma emitter with a 7-second half-life, is a significant concern in water-cooled, water-moderated reactors. MSRs with fluoride-based salts will also generate ${ }^{16} \mathrm{~N}$. However, with operation, the MSR fuel salt becomes highly radioactive because of the presence of fission products and actinides. Therefore, the ${ }^{16} \mathrm{~N}$ formed in fluoride-based fuel salts is not an isolated radiological concern and a separate ${ }^{16} \mathrm{~N}$ control system is not expected to be necessary for MSRs.

\subsection{Auxiliary Systems}

\section{Areas of Review}

The fuel salt, primary cooling salt, or other Heat Dissipation System coolants might serve functions other than cooling the fuel salt. Some of these auxiliary functions involve cooling other heated components, which could affect the heat load of the respective cooling system.

Auxiliary uses of the fuel salt, primary cooling salt, or other Heat Dissipation System coolant could affect system availability for fuel salt cooling, which is the principal use. Although the principal discussions of these auxiliary systems should be located in other sections of the SAR, their effects on the respective cooling systems should be summarized in this section. Auxiliary systems that could use coolant salt include the following:

- $\quad$ Experiment cooling

- $\quad$ Experimental facility cooling

Specific areas of review for this section are discussed in Section 5.7 of the format and content guide.

\section{Acceptance Criteria}

The acceptance criteria for information on the auxiliary systems using fuel salt, primary cooling salt, or other Heat Dissipation System coolants include the following: 
- $\quad$ The systems should remove sufficient projected heat to avoid damage to the cooled device.

- $\quad$ The system should not interfere with required heat removal from the fuel salt.

- $\quad$ Any postulated malfunction of an auxiliary system should not cause uncontrolled loss of fuel salt or prevent a safe reactor shutdown.

- $\quad$ The system should not cause radiation exposures or release of radioactivity to the environment that exceeds the requirements of 10 CFR Part 20 and the facility ALARA program guidelines.

- $\quad$ The applicant should propose TS as discussed in Chapter 14 of the format and content guide to ensure that auxiliary systems meet the safety-related design requirements. The applicant should justify the proposed TS in this section of the SAR.

\section{Review Procedures}

The reviewer should verify that auxiliary cooling using fuel salt, primary cooling salt, or other Heat Dissipation System coolants is described in this section of the SAR for any component in which potentially damaging temperature increases or excessive radiation exposures are predicted. If the potential exists for radiation heating of components near the Vessel, the reviewer should verify that the heat source, temperature increases, heat transfer mechanisms, and heat disposal have been discussed and analyzed.

\section{Evaluation Findings}

This section of the SAR should contain sufficient information to support the following types of conclusions, which will be included in the staff's safety evaluation report:

- $\quad$ The applicant has (1) described and analyzed auxiliary systems that use fuel salt, primary cooling salt, or other Heat Dissipation System coolants for functions other than fuel salt cooling; (2) derived the design bases from other chapters of the SAR; (3) analyzed any reactor components located in high-radiation areas near the core for potential heating that could cause damage to the Fuel System Boundary or failure of the component; and (4) planned acceptable methods to remove sufficient heat to ensure the integrity of the components. Cooling for these systems is obtained from the fuel salt, primary cooling salt, or other Heat Dissipation System coolants without decreasing the capability of any system below its acceptable performance criteria to maintain Fuel System Boundary integrity.

- $\quad$ The TS, including testing and surveillance, provide reasonable assurance of necessary auxiliary cooling system operability for normal reactor operations. 


\subsection{Fuel Salt Drain System}

\section{Areas of Review}

A fuel salt drain tank might be provided to allow for safe storage of the fuel salt in the event of a design-basis accident or for maintenance. The fuel salt drain tank maintains the fuel salt in a noncritical configuration and is cooled separately to remove decay heat. A detailed discussion of any ECS function for the fuel salt drain tank system and its activation is provided in Chapter 6 of the SAR. The fuel salt drain tank cooling system is discussed in Chapter 9 of the SAR. Any accident analyses regarding this system are discussed in Chapter 13 of the SAR. If included in the design, fuel salt drain tank operation is summarized in this section of the SAR. Specific areas of review for this section are discussed in Section 5.8 of the format and content guide.

\section{Acceptance Criteria}

The acceptance criteria for information on the fuel salt drain system include the following:

- $\quad$ The fuel salt drain tank should maintain the fuel salt in a noncritical configuration.

- $\quad$ The fuel salt drain tank should have an independent decay heat removal system as discussed in Chapter 9 of the SAR.

- $\quad$ Any postulated malfunction of the fuel salt drain tank system should not cause uncontrolled loss of fuel salt or prevent a safe reactor shutdown.

- $\quad$ The system should not cause radiation exposures or release of radioactivity to the environment that exceeds the requirements of 10 CFR Part 20 and the facility ALARA program guidelines as discussed in Chapter 11 of the SAR.

- $\quad$ The fuel salt drain tank design should provide for any necessary chemical control to limit corrosion or other degradation of the heat transfer interfaces and prevent chemical contamination of the environment.

- $\quad$ The applicant should identify operational limits, design parameters, and surveillances to be included in the TS.

\section{Review Procedures}

The reviewer should compare the functional design and operating characteristics of the fuel salt drain tank system with the bases for the design presented in this and other relevant chapters of the SAR. The system design should meet the appropriate acceptance criteria presented previously while considering the specific facility design under review.

\section{Evaluation Findings}

This section of the SAR should contain sufficient information to support the following types of conclusions, which will be included in the staff's safety evaluation report: 
- $\quad$ The fuel salt system drain tank should accommodate any heat load required during normal operation or during accident conditions as analyzed in Chapters 9 and 13 of the SAR.

- $\quad$ The fuel salt drain tank system is designed in accordance with the design bases derived from all relevant analyses in the SAR.

- $\quad$ Design features of the fuel salt drain tank system and components give reasonable assurance of fuel salt system boundary integrity under all possible reactor conditions. The fuel salt drain tank system should be designed to remove sufficient fission heat from the fuel to allow all licensed operations without exceeding the established LSSSs that are included in the TS.

- $\quad$ The fuel salt drain tank system design or procedures will prevent radiation exposures or release of radioactivity to the environment that would exceed the requirements of $10 \mathrm{CFR}$ Part 20 and the facility ALARA program guidelines.

- $\quad$ Fuel salt drain tank system instrumentation and controls are designed to provide all necessary functions and to transmit information on the operating status to the control room.

- $\quad$ The TS, including testing and surveillance, provide reasonable assurance of necessary fuel salt drain tank system operability for reactor operations as analyzed in the SAR.

\subsection{References}

1. MSRE Design and Operations Report, Part 1: Description of Reactor Design, ORNL-TM-728, Robertson, 1965.

2. The Development of Technical Specifications for Research Reactors, American National Standards Institute/American Nuclear Society, ANSI/ANS-15.1-R2013, ANS, LaGrange Park, Illinois, 2013. 
B-38 


\section{APPENDIX C. CHAPTER 6, "ENGINEERED SAFETY FEATURES" -MSR ADAPTATION}





\section{APPENDIX C. CHAPTER 6, "ENGINEERED SAFETY FEATURES"-MSR ADAPTATION OF PART 1}

\section{ENGINEERED SAFETY FEATURES (Part 1)}

Replace NUREG-1537, Part 1, Chapter 6, in its entirety with the following guidance.

NUREG-1537, Part 1, Chapter 6, of the format and content guide, as augmented by this ISG, is applicable to providing a description of the engineered safety features for the licensing of a nonpower molten salt reactor (MSR) facility. Whenever the term MSR or reactor appears, it is understood to mean a nonpower reactor facility.

In this chapter, the applicant should discuss and describe engineered safety features (ESFs) for a molten salt reactor (MSR). ${ }^{16}$ ESFs are active or passive features designed to mitigate the consequences of accidents and to keep radiological exposures to the public, the facility staff, and the environment within acceptable values. The concept of ESFs evolved from the defense-indepth philosophy of multiple layers of design features to prevent or mitigate the release of radioactive materials to the environment during accident conditions. The need for ESFs is determined by the SAR analyses of accidents that could occur, even though prudent design of the facility has made the incidence of an accident very unlikely. It is also possible that for a particular MSR design, the SAR analyses will show that ESFs are not needed.

The following glossary contains terms often used when discussing an MSR.

Active Reactor Core: In an MSR, the Vessel region occupied by the fuel salt where the majority of prompt neutrons are generated and where most fissions occur. In an MSR, the core geometry might change with time as a result of changes in density and voiding of the solution. The core does not include the part of the fuel salt that can become entrained into the cover gas.

Coating: Intervening protective layer of material between the corrosive fuel salt and the structural container alloy. Multiple layer configurations are possible (ranging in thickness from $>1 \mathrm{~mm}$, similar to liners used in current LWRs, to $<500 \mathrm{~nm}$, which adhere to the underlying substrate). Also included are embedded coatings, which are chemically resistant material that is embedded into the surface of the structural alloy, allowing surface modification to be performed to the structure to enhance its corrosion resistance.

Control Element(s): Object(s) employed to interact with an MSR's neutron population to adjust reactivity. Control elements can act through fuel displacement, neutron absorption, neutron reflection, neutron spectral adjustment, or a combination of these methods. Control elements can be solids, liquids, or gases, and they can be passively or actively positioned.

Emergency Cooling System: System that provides decay heat removal from the Reactor Fuel following an accident (e.g., a direct reactor auxiliary cooling system or a reactor vessel auxiliary cooling system).

\footnotetext{
${ }^{16}$ MSRs are a class of reactors in which a molten salt performs a significant function in the core.
} 
Fission Product Barrier: Portion of the Fuel System Boundary in contact with fission products only (e.g., the gas management system boundary).

Fuel Barrier: Portion of the Fuel System Boundary in contact with the fuel salt (principally the Vessel, heat exchanger, control element thimbles, instrumentation thimbles, piping, tanks, and valves).

Fuel System Boundary: All structures that prevent the release of fuel, fission gas, or other fission products. For an MSR, this includes the Vessel, waste-handling tank, pumps, valves, and piping. (Essentially includes the Fission Product Barrier and the Fuel Barrier.)

Heat Dissipation System: Set of components or system(s) that interface with the Primary Cooling System to provide the principal means of transferring the heat from the core to the environment. The Heat Dissipation System might use a variety of coolants (e.g., salt, liquid metal, or water) but does not contain fuel.

Neutron Moderator: In an MSR, materials in or near the core that consist of light elements. Moderators are generally solid form.

Primary Cooling System: Directly interfaces with the Fuel System Boundary at the fuel salt/primary cooling system heat exchanger(s) to provide the principal means of removing heat from the fuel salt by transferring the heat to the Heat Dissipation System. The Primary Cooling System typically contains a salt but does not contain fuel.

Reactor Fuel: In an MSR, fuel salt which consists of fissionable and possibly fertile halide salts, fission products, and generally solvent halide salt(s).

Vessel: For an MSR, structure containing the Active Reactor Core. Other components might reside in the Vessel but outside the Active Reactor Core, such as heat exchangers in certain design configurations.

Normal operation of an MSR is defined as operation with all process variables and other reactor parameters within allowed conditions of the license, technical specifications (TS), applicable regulatory limits, and design requirements for the system. Accidents at MSR facilities assume failure of a major component such as the Fuel System Boundary or a reactivity addition event. Licensees analyze a maximum hypothetical accident that assumes an incredible failure that leads to unacceptable Fuel System Boundary degradation. These postulated accidents are compared with acceptance criteria such as the safety limits from the TS or, where there are radiological consequences, to accepted regulatory limits (10 CFR Part 100). Consideration must also be given to the fission product decay heat generated in the interfacing gas management system and fuel salt cleanup system (if applicable). Cooling systems described in Chapter 9, "Auxiliary Systems," are designed to provide normal cooling for these systems. However, the maximum hypothetical accident that assumes an incredible failure should also consider these interfacing systems because of the radioactive material content and the potential radiological consequences to accepted regulatory limits (10 CFR Part 100) resulting from interfacing system boundary 
degradation. The results of the accident analyses are presented in the SAR, Chapter 13, "Accident Analyses." ESF systems must be designed to function for the range of conditions from normal operation through accident conditions.

Because most MSRs operate at atmospheric pressure, at relatively low power levels, and with adequate safety margins, few credible postulated accidents result in radiological risk to the public. The analyzed accident scenarios that the applicant should present in Chapter 13 of the SAR include the following:

- $\quad$ Loss of fuel salt

- $\quad$ Loss of fuel salt flow

- Insertion of excess reactivity (rapid or ramp)

- $\quad$ Loss of Fuel System Boundary integrity or mishandling of fuel salt

- $\quad$ Loss of gas management system integrity or fuel salt cleanup system integrity

- $\quad$ Precipitation of fuel

- $\quad$ Other uncontrolled release of radioactive material

- $\quad$ Loss of electrical power

- $\quad$ External events such as floods and earthquakes

The SAR accident analyses for many MSRs might show that ESFs are not required, even for the maximum hypothetical accident. In other cases, the accident analyses might show that ESFs need to be considered in mitigating the potential release of radioactive material to the environment. Note that there could be several systems containing highly radioactive materials within separate boundaries that should be analyzed apart from the Fuel System Boundary when considering the maximum hypothetical accident.

The accident analyses provide the design bases for any required ESF. The ESF design should be as basic and fail-safe as practical. Because MSRs are designed to ensure adequate public safety, few, if any, accidents should require redundant or diverse ESF systems. However, consideration should be given to adding redundancy and diversity to ESF systems if the reactor is of a higher power level (2 MW or greater thermal power level), if an ESF system would be susceptible to loss of capability to function because of a single failure, or if the radiological consequences to the public of the accident that the ESF is designed to protect against would be very serious if the ESF failed.

In addition to the design and functional characteristics of each ESF, the applicant should describe the methods and criteria for testing to demonstrate ESF system operability. The functional requirements, related set points, interlocks, and bypasses for each ESF should be described, analyzed, and included in the facility TS. The TS surveillance requirements for system components that ensure the integrity and operational capability of the ESFs should be identified and discussed in the SAR. 
The discussion should include how the ESFs interact with site utilities, such as electrical power, and, if applicable, how the transfer between normal and emergency sources of electricity is accomplished. The applicant should discuss and demonstrate the need for site utility redundancy or diversity and the specific design features that provide it for each ESF component.

The SAR should include schematic diagrams, showing all components, their interrelationships, and the relationship of each ESF to other reactor systems (e.g., the Fuel System Boundary, the Primary Cooling System, the gas management system, or the fuel salt cleanup system). It should include a brief description of the instrumentation and control (I\&C) system for each ESF, with detailed descriptions presented in SAR Chapter 7, "Instrumentation and Control Systems." The material presented should show how I\&C systems necessary for ESF operation are designed to function in the environment created by the accident.

Typical ESFs that might be required at MSRs are (1) the confinement, (2) the containment, and (3) the Emergency Cooling System (ECS). In addition, features required in the facility heating, ventilation, and air-conditioning (HVAC) system to mitigate the consequences of accidents should be treated as part of the ESFs of the confinement or containment system. HVAC systems are discussed in Chapter 9 of the SAR. The applicant should discuss any additional ESFs in a comparable way.

Brief definitions and illustrations of the confinement, containment, and ECS follow:

(1) The confinement is an enclosure of the overall facility (e.g., a reactor vault) that is designed to limit the exchange of effluents between the enclosure and its external environment to controlled or defined pathways. A confinement should include the capability to maintain sufficient internal negative pressure to ensure inleakage (i.e., prevent uncontrolled leakage outside the confined area) but need not be capable of supporting positive internal pressure or significantly shielding the external environment from internal sources of direct radiation. Air movement in a confinement could be integrated into the HVAC systems, including exhaust stacks or vents to the external environment, filters, blowers, and dampers.

(2) The containment is an enclosure of the facility designed to (a) be at a negative internal pressure to ensure inleakage, (b) control the release of effluents to the environment, and (c) mitigate the consequences of certain analyzed accidents. The containment is designed (a) to be sealed to support a defined pressure differential across it and (b) to have a defined upper limit on leakage from it. Both design conditions are testable. An accident scenario that might require containment for an MSR would involve positive internal pressures, either static or transient, or the need to shield the external environment from internal sources of direct radiation, or both. Exhaust stacks, vents, particulate filters, activated charcoal filters, or piping might be provided for controlled venting of containment, and the design should provide for both normal and emergency operational modes. A containment can be designed to be integral with the facility HVAC and liquid waste systems.

For an MSR that employs a confinement system, such a system: 
- Usually responds to accidents by reducing and changing the airflow paths to and from the building (a containment seals the building from the environment and significantly reduces releases of radioactive material to the environment).

- $\quad$ Has doors with gasket-type seals (airlocks for containments).

- $\quad$ Might not have sealing isolation dampers on air penetrations (sealing isolation dampers for containments).

- Cannot maintain as high a negative differential pressure as a containment.

- Is not as leak tight as a containment, and the leak rate normally cannot be confirmed through testing.

- $\quad$ Cannot control the release from an event that results in positive pressure in the reactor building.

- Usually has less direct radiation shielding capacity than a containment because the walls are thinner.

- Is less resistant than a containment to challenges placed on the building by the external environment.

If the analyses show that a confinement ESF will mitigate the consequences of the most limiting accident scenario to acceptable levels, a containment ESF would not be required, although some licensees have chosen to build containments as an additional design conservatism. MSR designs can employ multiple individual containments around interfacing systems containing highly radioactive materials such as the gas management system or the fuel salt cleanup system.

(3) An ECS is designed to provide a source of heat removal to limit Fuel System Boundary damage or interfacing system boundary degradation from decay heat should the normal path for heat removal be lost.

For the MSR test reactor facility, the exposures will be compared with the doses in 10 CFR Part 100. As discussed in the footnotes to 10 CFR 100.11, the doses in 10 CFR Part 100 are reference values. References to 10 CFR Part 100 in this chapter pertain to test reactors only.

\subsection{Summary Description}

In this section of the SAR, the applicant should briefly describe all of the ESFs in the facility design and summarize the postulated accidents they are designed to mitigate. These summaries should include the design bases and performance criteria and contain enough information for an overall understanding of the functions of the ESFs and the reactor conditions under which the equipment or systems must function. 
Simple block diagrams and drawings may be used to show the location, basic function, and relationship of each ESF to the facility. Detailed drawings, schematic diagrams, data, and analyses should be presented in subsequent sections of this chapter for specific ESFs.

\subsection{Detailed Descriptions}

In this section of the SAR, the applicant should discuss in detail the particular ESFs incorporated into the reactor design. Not all of these ESFs are found in any single design. Other systems in addition to the systems discussed in this section may be considered ESFs. The applicant should discuss these ESFs in a manner similar to the discussions in this section.

\subsubsection{Confinement}

The applicant should discuss in detail the confinement and associated HVAC systems that function as ESFs. For the confinement to function as an ESF, the design bases for the consequence-mitigation functions should be derived from the accident analyses in the SAR, Chapter 13. Confinements and HVAC systems can also have functions that are not considered functions of ESFs and that need not be addressed in this chapter.

Most MSRs release small quantities of airborne radioactive material, primarily fission product gaseous radionuclides, to the environment during normal operations. To protect the health and safety of the public and the staff, it could be necessary to control airflow through spaces containing radioactive materials and release the air in a controlled manner at a location that allows for dilution and diffusion of the radioactive material before it comes in contact with the public. In some cases, it could also be efficient to use the confinement and HVAC systems to prevent an uncontrolled release to the environment of radioactive effluents resulting from operation. This aspect of the use of ESFs during normal system operation is not considered an ESF function. However, the design bases and detailed discussions of these systems for normal operations to control releases should be given in Chapter 3, "Design of Structures, Systems, and Components," and Chapter 9. Diffusion and dispersion of airborne radioactivity in both restricted and unrestricted environments should be discussed in Chapter 11, "Radiation Protection Program and Waste Management."

A radioactive release need not be a rapid or burst-type release. It also includes leakage and diffusion of airborne radioactivity from a room through cracks or gaps in building structural components. Such releases could be controlled by a system of ducts, louvers, blowers, exhaust vents, or stacks. MSRs should have the capability to quantify releases and calculate potential exposures in both restricted and unrestricted areas. Calculating potential exposures provides the bases for actions to ensure that the public is protected during both normal operation and accident conditions.

If the confinement and HVAC or air (stack) exhaust systems are designed to change state or operating condition in response to a potential accident and, in so doing, mitigate the radiological consequences of the accident, those features should be designated as ESFs and should be described in detail. The discussion of the ESF functions should demonstrate how dispersion or distribution of contaminated air to the environment or occupied spaces other than the reactor 
room is controlled. The discussion should include the design bases for the location and operating characteristics of the air exhaust stack, if applicable, and the design bases for effluent monitoring systems.

The discussion of mitigative effects should contain a comparison of potential radiological exposures to the facility staff and the public with and without the ESF. Either operational data for an operating facility or results of analyses for a new facility should be presented showing airflow rates, reduction in quantities of airborne radioactive material by filter systems, system isolation, and other parameters that demonstrate the effectiveness of the system.

A schematic diagram of the system should be presented showing the blowers, dampers, filters, other components necessary for operation of the system, and flow paths. Automatic and manual trip circuits, bypasses, interlocks, and special I\&C systems for the ESF system should be described briefly in this section and in detail in Chapter 7.

In this section, the applicant should develop requirements to be specified in the TS for system operability, periodic surveillance, set points, and other specific requirements to ensure a functional ESF system during postulated events. Examples include the requirement for operability of the ESFs during reactor operation or other significant events. Periodic functional testing of damper closure, room isolation, minimum airflow rates, automatic system shutdown and startup, and activation set points should be required and specified. See Chapter 14, "Technical Specifications," of this format and content guide, for details on what TS requirements should be identified and justified in this section.

\subsubsection{Containment}

Most MSRs will likely include containment. When the containment and associated HVAC system are required for a reactor to mitigate the consequences of a postulated accident, they are considered ESFs.

Containment for an MSR should be designed to prevent the rapid, uncontrolled release of radioactive material to the environment. A possible scenario for such a release could be an accident that involves a loss of Fuel System Boundary integrity and the rapid release of fission products from the fuel salt into the reactor room. The containment is designed to control the release to the environment of airborne radioactive material released in the reactor room even if the accident is accompanied by a pressure surge within the room. The walls of the containment can also help mitigate direct radiation exposure during certain accidents. The analyses in Chapter 13 of the SAR should include details of the postulated scenario, including the assumptions and justification for the initiating event, the progression of the scenario, the consequence-mitigating effects of the containment, and the potential radiological exposures to the most exposed member of the public. The design bases for the containment should include the postulated peak pressures, duration of the event, pressure-versus-time envelope, time during which containment integrity must be maintained while recovery from the event is implemented, limits on leakage or controlled release from the containment to the environment, loss of Fuel System Boundary integrity, and the quantity and type of released radioactive material. 
A radioactive release need not be a rapid or burst-type release. It also includes leakage and diffusion of airborne radioactivity from a room through cracks or gaps in building structural components. Such releases could be controlled by a system of ducts, louvers, blowers, exhaust vents, or stacks. MSRs should have the capability to quantify releases and calculate potential exposures in both restricted and unrestricted areas. Calculating potential exposures provides the bases for actions to ensure that the public is protected during both normal operation and accident conditions.

The description must include the bases for the protection factors provided by the containment. The goal is that the containment should reduce the consequences to the public, facility personnel, and the environment to acceptable values as specified previously.

In this section the applicant should explain how the design and functional details of the containment meet the design bases and criteria described previously. System drawings, component and material specifications, and structural details should be included. The information should demonstrate that the radiation protection factors assumed in the accident analyses are provided. The design bases and discussions should describe how the containment functions over the range of normal operation and the events that initiate switching to emergency mode. The discussions should address which reactor operations and evolutions require the containment to be operable and whether an emergency electrical power source is required to be operable.

To qualify as a containment, the reactor building should be a robust structure with airlocks and all other penetrations sealed (e.g., cable penetrations sealed with epoxy) or sealable (e.g., hydraulic dampers on ventilation penetrations). The building should be capable of maintaining a negative pressure in relation to the atmosphere (e.g., at least -0.5 inches of water) during normal operation and have a measurable leakage rate (e.g., less than 5 percent over 24 hours). The actual performance requirements are determined from the accident analyses in Chapter 13 of the SAR. For example, the normal function of the containment ventilation exhaust system can be divided into two trains - one that ventilates the reactor room and one that ventilates areas with high airborne radiation generation such as the gas management system or cleanup system holdup facilities. The ventilation system is normally equipped with high-efficiency particulate filters, and the accident ventilation system has a separate train(s) equipped with high-efficiency particulate and activated charcoal filters to sorb iodine.

Automatic containment trip circuits, interlocks, special I\&Cs, and monitoring requirements for the ESF should be described. The description should detail their relationship and interaction with the I\&C systems for normal operation as described in SAR Chapter 7.

The discussion should give the TS and their bases to ensure that the containment ESF is operable when required. The TS should also provide for necessary surveillance, testing, and maintenance of the containment components to ensure operability. The TS should define an operable containment ESF and describe the reactor conditions and operations for which the containment shall be operable. See Chapter 14 of this format and content guide for details on what TS requirements should be identified and justified in this section. 


\subsubsection{Emergency Cooling System}

An ECS might be required at some MSRs to remove decay heat from the fuel salt to prevent failure or degradation of the Fuel System Boundary if cooling is lost. It could also be required to mitigate interfacing system boundary degradation in systems with significant decay heat such as the gas management system or the fuel salt cleanup system. Cooling systems described in Chapter 9 typically provide these functions. The applicant should give the analysis of the ECS if one was identified as needed in the Chapter 13 accident analyses.

A schematic diagram should show the relationships among the major system components such as tanks, valves, pumps, piping, and any I\&C systems. Special ECS I\&C systems should be described briefly in this section and described fully in Chapter 7. In this section, the applicant should discuss any effects of the ECS design on normal operations and reactor safety. Analyses for MSRs should demonstrate that Fuel System Boundary integrity and, if applicable, interfacing system integrity will be maintained for postulated-accident scenarios.

If the ECS is a passive system (e.g., a gravity-driven system or a natural-convection cooling system), a complete description with associated analyses and data should show how cooling flow is initiated and why the system is effective. The information should demonstrate that the ECS will provide the required decay heat removal function in terms of minimum flow and time of operation for all accidents considered.

If the ECS is an active system that requires sensors and an action or event to initiate operation, descriptions should include details of initiation response times and backup or redundant sensing and control systems. The discussion should include the source of electrical power, source of cooling, heat sink, or other systems required to operate the ECS and show how operability and availability are ensured.

The ECS design should show how radioactive material such as emergency coolant, is controlled.

In this section, the applicant should also give the bases for TS that ensure that the ECS is available and operable when required. TS should include minimum operability requirements and the possible operations and conditions under which the ECS would be required. Test and surveillance functions and intervals should be stated in the TS to ensure operability of the ECS. See Chapter 14 of this format and content guide for details on what TS requirements should be identified and analyzed in this section.

\subsection{References}

1. Format and Content for Safety Analysis Reports for Research Reactors, ANSI/ANS-15.21-2012, American National Standards Institute/American Nuclear Society, ANS, LaGrange Park, Illinois, 2012.

2. The Development of Technical Specifications for Research Reactors, ANSI/ANS-15.1-R2013, American National Standards Institute/American Nuclear Society, ANS, LaGrange Park, Illinois, 2013. 
C-12 


\section{APPENDIX C. CHAPTER 6, "ENGINEERED SAFETY FEATURES"-MSR ADAPTATION OF PART 2}

\section{ENGINEERED SAFETY FEATURES (Part 2)}

Replace NUREG-1537, Part 2, Chapter 6, in its entirety with the following guidance.

NUREG-1537, Part 2, Chapter 6, of the standard review plan and acceptance criteria, as augmented by this ISG, is applicable to reviewing a description of the engineered safety features for the licensing of a nonpower molten salt reactor (MSR) facility. Whenever the term MSR or reactor appears, it is understood to mean a nonpower reactor facility.

This chapter gives the review plan and acceptance criteria for active or passive engineered safety features (ESFs) of the $\mathrm{MSR}^{17}$ facility that are designed to mitigate the consequences of accidents. The concept of ESFs evolved from the defense-in-depth philosophy of multiple design features to prevent or mitigate the release of radioactive materials to the environment during accident conditions. The applicant determines the need for ESFs from the SAR analyses of accidents that could occur, even though prudent designs of the facility have made these accidents very unlikely. The NRC reviewer may find that the SAR analyses show that ESFs are not needed for a proposed design.

The following glossary contains terms often used when discussing an MSR.

Active Reactor Core: In an MSR, the Vessel region occupied by the fuel salt where the majority of prompt neutrons are generated and where most fissions occur. In an MSR, the core geometry might change with time as a result of changes in density and voiding of the solution. The core does not include the part of the fuel salt that can become entrained into the cover gas.

Coating: Intervening protective layer of material between the corrosive fuel salt and the structural container alloy. Multiple layer configurations are possible (ranging in thickness from $>1 \mathrm{~mm}$, similar to liners used in current LWRs, to $<500 \mathrm{~nm}$, which adhere to the underlying substrate). Also included are embedded coatings, which are chemically resistant material that is embedded into the surface of the structural alloy, allowing surface modification to be performed to the structure to enhance its corrosion resistance.

Control Element(s): Object(s) employed to interact with an MSR's neutron population to adjust reactivity. Control elements can act through fuel displacement, neutron absorption, neutron reflection, neutron spectral adjustment, or a combination of these methods. Control elements can be solids, liquids, or gases, and they can be passively or actively positioned.

Emergency Cooling System: System that provides decay heat removal from the Reactor Fuel following an accident (e.g., a direct reactor auxiliary cooling system or a reactor vessel auxiliary cooling system).

\footnotetext{
${ }^{17}$ MSRs are a class of reactors in which a molten salt performs a significant function in the core.
} 
Fission Product Barrier: Portion of the Fuel System Boundary in contact with fission products only (e.g., the gas management system boundary).

Fuel Barrier: Portion of the Fuel System Boundary in contact with the fuel salt (principally the Vessel, heat exchanger, control element thimbles, instrumentation thimbles, piping, tanks, and valves).

Fuel System Boundary: All structures that prevent the release of fuel, fission gas, or other fission products. For an MSR, this includes the Vessel, waste-handling tank, pumps, valves, and piping. (Essentially includes the Fission Product Barrier and the Fuel Barrier.)

Heat Dissipation System: Set of components or system(s) that interface with the Primary Cooling System to provide the principal means of transferring the heat from the core to the environment. The Heat Dissipation System might use a variety of coolants (e.g., salt, liquid metal, or water) but does not contain fuel.

Neutron Moderator: In an MSR, materials in or near the core that consist of light elements. Moderators are generally solid form.

Primary Cooling System: Directly interfaces with the Fuel System Boundary at the fuel salt/primary cooling system heat exchanger(s) to provide the principal means of removing heat from the fuel salt by transferring the heat to the Heat Dissipation System. The Primary Cooling System typically contains a salt but does not contain fuel.

Reactor Fuel: In an MSR, fuel salt which consists of fissionable and possibly fertile halide salts, fission products, and generally solvent halide salt(s).

Vessel: For an MSR, structure containing the Active Reactor Core. Other components might reside in the Vessel but outside the Active Reactor Core, such as heat exchangers in certain design configurations.

Normal operation of a nonpower MSR is defined as operation with all process variables and other reactor parameters within allowed conditions of the license, technical specifications (TS), applicable regulatory limits, and design requirements for the system. Accidents at nonpower MSR facilities assume failure of a major component such as the fuel salt system boundary or a reactivity addition event. Licensees analyze a maximum hypothetical accident that assumes an incredible failure that leads to unacceptable fuel salt system boundary degradation. These postulated accidents are compared with acceptance criteria such as the safety limits from the TS or, where there are radiological consequences, to accepted regulatory limits (10 CFR Part 100). Consideration must also be given to the fission product decay heat generated in the interfacing gas management system and fuel salt cleanup system (if applicable). Cooling systems described in Chapter 9, "Auxiliary Systems," are designed to provide normal cooling for these systems. However, the maximum hypothetical accident that assumes an incredible failure should also consider these interfacing systems because of the radioactive material content and the potential radiological consequences to accepted regulatory limits (10 CFR Part 100) resulting from interfacing system boundary degradation. The results of the accident analyses are presented in 
SAR, Chapter 13, "Accident Analyses." ESF systems must be designed to function for the range of conditions from normal operation through accident conditions.

Because most MSRs operate at atmospheric pressure, at relatively low power levels, and with adequate safety margins, few credible postulated accidents result in significant radiological risk to the public. Accident scenarios that should be discussed by the applicant in Chapter 13 of the SAR include the following:

- $\quad$ Loss of fuel salt

- $\quad$ Loss of fuel salt flow

- Insertion of excess reactivity (rapid or ramp)

- $\quad$ Loss of Fuel System Boundary integrity or mishandling of fuel salt

- $\quad$ Loss of gas management system integrity or fuel salt cleanup system integrity

- $\quad$ Precipitation of fuel

- Other uncontrolled release of radioactive material

- Loss of electrical power

- $\quad$ External events such as floods and earthquakes

The SAR accident analyses for a nonpower MSR design may support the conclusion that ESFs are not required, even for the maximum hypothetical accident. In other cases, the accident analyses may conclude that ESFs need to be considered in mitigating the potential release of hazardous quantities of radioactive material to the environment. Note that there could be several systems containing highly radioactive materials within separate boundaries that should be analyzed apart from the Fuel System Boundary when considering the maximum hypothetical accident.

The accident analyses by the applicant should contain the design bases for any required ESF. The ESF design should be as basic and fail-safe as practicable. Because MSRs are designed to ensure adequate public safety, few accidents should require redundant or diverse ESF systems. Some factors the reviewer should evaluate to verify whether redundant or diverse ESFs should be required for a particular reactor design are discussed in this chapter.

In addition to reviewing the design and functional characteristics of each ESF, the reviewer should examine the methods and criteria proposed by the applicant for testing to demonstrate ESF operability. The reviewer should evaluate the necessary components, functional requirements, related set points, interlocks, bypasses, and surveillance tests for each ESF and should check that they are included in the facility TS. The TS surveillance requirements for system components that ensure the integrity and operational capability of the ESFs should also be reviewed.

For the MSR test reactor facility, the reviewer should compare the results against the doses in 10 CFR Part 100. As discussed in the footnotes to 10 CFR Part 100.11, the doses in 
10 CFR Part 100 are reference values. Any further references to 10 CFR Part 100 in this chapter pertain to test reactors only.

The reviewer should evaluate how the ESFs interact with site utilities, such as electrical power, and how the transfer between normal and emergency sources of electricity, if applicable, is to be accomplished. The applicant should present any need for site utility redundancy and the specific design features that provide redundancy for the components of each ESF.

The applicant should provide schematic diagrams showing all components, their interrelationships, and the relationship of each ESF to systems used for normal operations (e.g., the direct reactor auxiliary cooling system to the Primary Cooling System or the confinement to the reactor room ventilation system).

Typical ESFs that might be required for a proposed design are the confinement, containment, and Emergency Cooling System (ECS), which are discussed in this chapter of the format and content guide. The postulated accident analyses by the applicant determine whether an MSR facility needs confinement, containment, an ECS, or no ESFs. The reviewer will find that heating, ventilation, and air-conditioning (HVAC) and air exhaust systems at MSRs generally serve to limit the release of airborne radioactive material. The reviewer should verify that those features in HVAC systems required to mitigate the consequences of accidents were treated as ESFs. This review plan gives guidance for the evaluation of information on confinement, containment, and ECS ESFs. Information on any additional ESFs required at nonpower MSRs can be evaluated by the reviewer in a similar manner.

Most MSRs designs will include containment. If the reviewer confirms that the safety analyses show that a confinement ESF is sufficient to mitigate the consequences of the most limiting accident to acceptable levels, containment ESF would not be required. Some licensees have chosen to build containments as additional design conservatism.

\subsection{Summary Description}

In this section of the SAR, the applicant should briefly describe all of the ESFs in the facility design and summarize the postulated accidents for which consequences could be unacceptable without mitigation. A specific postulated accident scenario should indicate the need for each ESF. The details of the accident analyses should be given in Chapter 13 of the SAR and the detailed discussions of the ESFs in Section 6.2 of the SAR. These summaries should include the design bases, performance criteria, and full range of reactor conditions, including accident conditions, under which the equipment or systems must maintain function. The evaluation procedures and criteria for the confinement, containment, and ECS are given in the following section.

The applicant may submit simple block diagrams and drawings that show the location, basic function, and relationship of each ESF to the facility. The summary description should contain enough information for an overall understanding of the functions and relationships of the ESFs to the operation of the facility. Detailed drawings, schematic diagrams, data, and analyses should be presented in Section 6.2 of the SAR for each specific ESF. 


\subsection{Detailed Descriptions}

In this section of the SAR, the applicant should discuss in detail particular ESF systems that might be incorporated into the reactor design. Not all of these ESFs are found in any single design. Other systems in addition to the systems discussed in this section may be considered ESFs. The reviewer should evaluate these ESFs in a manner similar to that for the ESFs in this section.

\subsubsection{Confinement}

If the HVAC and any air exhaust or liquid release systems associated with the confinement are designed to change configuration or operating mode in response to a potential accident analyzed in Chapter 13 and thereby mitigate its consequences, they should be considered part of the confinement ESF and should be discussed in this section of the SAR.

During normal operations, the MSR could release small amounts of radioactive material. Specifically, relatively small amounts of fission product gaseous radionuclides could escape from the reactor primary Fission Product Barrier. The applicant should describe how these releases to the environment will be controlled so that neither the public nor the facility's operating staff will receive radiation doses greater than regulatory limits. This function of the confinement and the HVAC system is not considered a function of an ESF. If the effluent control systems provide no unique accident consequence-mitigation function, the design bases and detailed discussions of the systems for normal operations should be given in Chapter 3, "Design of Structures, Systems, and Components," and Chapter 9 of the SAR. Discussions and calculations of diffusion and dispersion of airborne radioactivity in both restricted and unrestricted environments should be given in Chapter 11, "Radiation Protection Program and Waste Management."

\section{Areas of Review}

The reviewer should evaluate the following:

- Design bases and functional description of the required mitigative features of the confinement ESFs, derived from the accident scenarios.

- Drawings, schematic diagrams, and tables of important design and operating parameters and specifications for the confinement ESFs, including

- $\quad$ seals, gaskets, filters, and penetrations (e.g., electrical, pneumatic, and cooling medium);

- $\quad$ necessary ESF equipment included as part of the confinement; and

- fabrication specifications for essential and safety-related components.

- Discussion and analyses, keyed to drawings, of how the structure provides the necessary confinement analyzed in Chapter 13, with cross-references to other chapters for 
discussion of normal operations (such as Chapter 4, "Reactor Description," and Chapter 11 ), as necessary.

- Description of control and safety instrumentation, including the locations and functions of sensors, readout devices, monitors, and isolation components, as applicable. (Design features should ensure operability in the environment created by the accident.)

- Discussion of the required limitations on release of confined effluents to the environment.

- $\quad$ Surveillance methods and intervals included in the TS that ensure operability and availability of the confinement ESFs, when required.

\section{Acceptance Criteria}

The acceptance criteria for information on the confinement and HVAC system ESFs include the following:

- $\quad$ The need for a confinement ESF has been properly identified. To be considered an ESF, design features must exist to mitigate the consequences of specific accident scenarios.

- $\quad$ Any ESF in addition to the confinement (e.g., HVAC systems) does not interfere with normal operations or safe reactor shutdown.

- $\quad$ The ESF design features should ensure that the system is available and operable when it is required for mitigating accident consequences.

- $\quad$ The minimum design goal of the confinement ESFs should be to reduce below regulatory limits the potential radiological exposures to the facility staff and members of the public for the accidents discussed at the beginning of this chapter for test and research reactors. Any additional reduction in potential radiological exposures below the regulatory limits is desirable and should be a design goal if it can be reasonably achieved.

- $\quad$ The design of the confinement should not transfer undue radiological risk to the health and safety of the public in order to reduce potential exposures to the facility staff.

- $\quad$ The instrumentation and control (I\&C) system of the confinement ESF systems should be as basic and fail-safe as possible. It should be designed to remain functional for the full range of potential operational conditions, including the environment created by accident scenarios.

- The applicant should propose TS as discussed in Chapter 14, "Technical Specifications," of the format and content guide to ensure that the confinement meets the safety-related design requirements. The applicant should justify the proposed TS in this section of the SAR.

\section{Review Procedures}

The applicant should show that the confinement ESFs reduce predicted radiological exposures and releases from applicable potential accidents to acceptable levels as discussed at the beginning of this chapter. The reviewer should examine all accident scenarios analyzed in 
Chapter 13 of the SAR that could lead to significant radiological exposures or releases and verify that consequences can be sufficiently mitigated by the confinement ESF. The reviewer should confirm that the design and functional bases of confinement ESFs are derived from the accidents analyzed. The reviewer should compare the dispersion and diffusion of released airborne radionuclides discussed in SAR chapters 6 and 13 with methods described in SAR Chapter 11 as applicable.

\section{Evaluation Findings}

This section of the SAR should contain sufficient information to support the following types of conclusions, which will be included in the safety evaluation report:

- The scenarios for all potential accidents at the reactor facility have been analyzed by the applicant and reviewed by the staff. Mitigation of consequences by a confinement system has been proposed in the SAR analyses for any accident that could lead to potential unacceptable radiological exposures to the public, facility staff, or the environment.

- $\quad$ The staff has reviewed the designs and functional descriptions of the confinement ESF and has reasonably ensured that the consequences will be limited to the levels found acceptable in the accident analyses of Chapter 13 of the SAR.

- The designs and functional descriptions of the confinement ESF reasonably ensure that control of radiological exposures or releases during normal operation will not be degraded by the ESF.

- The radiological consequences from accidents to the public, environment, and facility staff will be reduced by the confinement ESF to values that do not exceed the applicable limits of 10 CFR Part 100 for test reactors and that are as far below the regulatory limits as can be reasonably achieved.

- $\quad$ The TS, including testing and surveillance, provide reasonable assurance of necessary confinement operability for reactor operations as analyzed in the SAR.

\subsubsection{Containment}

If the HVAC and any air exhaust or liquid release systems associated with the containment are designed to change configuration or operating mode in response to a potential accident analyzed in Chapter 13 and thereby mitigate its consequences, they should be considered part of the containment ESF and should be discussed in this section of the SAR.

Most MSRs will likely include containment. In fact, it is possible that multiple individual containments will be included around interfacing systems containing highly radioactive materials such as the gas management system or the fuel salt cleanup system.

Containment is considered necessary for MSR facilities if potential credible accidents, or a maximum hypothetical accident, could lead to unacceptable radiological consequences to the public in the absence of its mitigating functions. There is also the possibility that the applicant's 
analyses might show that a confinement is an acceptable ESF but the applicant chooses to construct a containment for additional conservatism.

Most MSRs release a small amount of radioactive material during normal operation. Even though the quantity of radioactive material produced might not be large, the applicant should describe how releases to the environment will be controlled. The airborne radionuclide normally released from the envelope of the reactor is fission product gaseous radionuclides, which can be continuously swept from the reactor building to diffuse and disperse in the atmosphere. The applicant should ensure that during the controlled release, neither the public nor the facility staff would receive a dose greater than regulatory limits. This function of the containment and the HVAC system is not considered the function of an ESF. If the effluent control systems provide no unique accident consequence-mitigation function, the design bases and detailed discussions of the systems for normal operations should be given in Chapter 3 and Chapter 9 of the SAR. Discussions and calculations of diffusion and dispersion of airborne radioactivity in both restricted and unrestricted environments should be given in Chapter 11 .

\section{Areas of Review}

The reviewer should evaluate the assumptions and progressions of potential accident scenarios as presented in Chapter 13 of the SAR. The analyses should show whether any postulated accident could cause an unacceptable radiological exposure, as discussed previously, to the public, environment, or facility staff. For any accidents that could cause such an exposure, the analyses should address how the containment ESF prevents rapid release of radiation or radioactive material to the environment and how the ESF design features reduce potential exposures to acceptable levels.

MSRs that are required to have a containment that functions as an ESF during an accident could operate it as a vented structure for normal operations. For such a use, the applicant should describe the conditions for both uses and the signals and equipment required to initiate switching to the emergency mode. Information on the design of the containment as a vented structure for normal operation should be given in the SAR, Chapters 3 and 9 and in Chapter 11 with regard to the diffusion and dispersion of airborne radioactivity in restricted and unrestricted environments.

The reviewer should evaluate the following:

- Design bases and functional description of the required mitigative features of the containment, derived from the accident scenarios.

- $\quad$ Drawings, schematic diagrams, and tables of important design and operating parameters and specifications for the containment, including:

- $\quad$ volume and overpressure capability;

- $\quad$ seals, gaskets, filters, and penetrations (e.g., electrical, pneumatic, and cooling medium);

necessary ESF equipment included as part of the containment; and 
- $\quad$ fabrication specifications for essential and safety-related components.

- $\quad$ Discussion and analyses, keyed to drawings, of how the structure provides the necessary containment presented in Chapter 13, with cross-references to other chapters for discussion of normal operation (such as Chapters 4 and 11), as necessary.

- Description of control and safety instrumentation, including the locations and functions of sensors, readout devices, monitors, and isolation components, as applicable. (Design features should ensure operability in the environment created by the accident.)

- $\quad$ Discussion of shielding protection factors provided for direct radiation and the required limitations on leakage or release of contained effluents to the environment.

- $\quad$ Conditions under which operability is required, and the surveillance methods and intervals in the TS that ensure operability and availability of the containment, when required.

\section{Acceptance Criteria}

The acceptance criteria for information on the containment ESF include the following:

- $\quad$ The need for a containment ESF should be properly identified. To be considered an ESF, design features should exist to mitigate the consequences of specific accident scenarios.

- $\quad$ The design that should reduce below regulatory limits the potential radiological exposures to the facility staff and members of the public for the accidents discussed at the beginning of this chapter. Any additional reduction in potential radiological exposures below the regulatory limits is desirable and should be a design goal if it can be reasonably achieved.

- The containment should not interfere with either normal operation or reactor shutdown.

- $\quad$ The design features and surveillance program should ensure that the containment will be available and operable if the ESF system is needed.

- $\quad$ The design of the containment should not transfer undue radiological risk to the health and safety of the public in order to reduce potential exposures to the facility staff.

- $\quad$ The I\&C system of the containment ESF system should be as basic and fail-safe as possible. It should be designed to operate in the environment created by the accident scenario.

- $\quad$ The applicant should propose TS as discussed in Chapter 14 of the format and content guide to ensure that the containment meets the safety-related design requirements. The applicant should justify the proposed TS in this section of the SAR.

\section{Review Procedures}

The reviewer should review the accident scenarios and applicable design bases for a containment ESF and the design and functional features of the ESF and the mitigating effects on the 
radiological consequences evaluated. The net projected radiological exposures should be compared with the limits of 10 CFR Part 100 to determine whether the design is acceptable.

\section{Evaluation Findings}

This section of the SAR should contain sufficient information to support the following types of conclusions, which will be included in the safety evaluation report:

- The applicant has identified a potential or maximum hypothetical accident as a result of which projected exposures to the public without containment would be greater than acceptable limits.

- $\quad$ The design and functional features proposed for a containment reasonably ensure that exposures will be reduced below the limits of 10 CFR Part 100 for test reactors, with an additional factor to achieve residual doses as far below the regulatory limits as can be reasonably achieved. The maximum projected dose to a member of the public is determined from the analyses in Chapter 13 of the SAR for all analyzed accidents.

- $\quad$ The TS, including testing and surveillance, provide reasonable assurance of necessary containment operability for reactor operations as analyzed in the SAR.

- $\quad$ The design of the containment ESF gives reasonable assurance that it will not interfere with reactor operation or shutdown.

\subsubsection{Emergency Cooling System}

\section{Areas of Review}

For most MSRs, heat must be removed from the fuel salt during normal operations, and decay heat from radioactive fission products in the fuel salt must be removed after the reactor is shut down. Cooling systems described in Chapter 5, "Molten Salt Reactor Cooling Systems," are designed to provide these functions. If cooling is accidentally lost, the decay heat in some nonpower MSRs could be high enough to require an emergency fuel salt cooling system to avoid unacceptable Fuel System Boundary degradation as a result of high system temperatures. In addition, decay heat must be removed from interfacing systems with radioactive fission products such as the gas management system and fuel salt cleanup system. Cooling systems described in Chapter 9 typically provide these functions.

In Chapter 13 of the SAR, each applicant should present analysis of the maximum hypothetical accident that defines the envelope of potential radiological consequences to the facility staff, the public, and the environment. The reviewer should evaluate the design bases and functional requirements of the proposed ECS for the maximum hypothetical accident through the progression of the accident scenario.

\section{Acceptance Criteria}

The acceptance criteria for information on the ECS include the following: 
- $\quad$ The design bases and functional description should be derived from the maximum hypothetical accident scenario and be presented in Chapter 13 of the SAR. This includes interfacing systems with radioactive fission products such as the gas management system and fuel salt cleanup system.

- $\quad$ The design features ensure that the ECS will provide decay heat removal for the time interval required by the scenario. The design features ensure that any necessary utility sources, such as normal electricity, emergency power, and cooling, will be available to the ECS.

- $\quad$ The ECS should not interfere with either normal operations or reactor shutdown.

- $\quad$ The consequences of the maximum hypothetical accident event, as mitigated by the ECS, will not exceed the limits of 10 CFR Part 100 for test reactors and will be as far below the regulatory limits as can be reasonably achieved.

- $\quad$ The applicant should propose TS as discussed in Chapter 14 of the format and content guide to ensure that the ECS meets the safety-related design requirements. The applicant should justify the proposed TS in this section of the SAR.

\section{Review Procedures}

The reviewer should evaluate the accidents in Chapter 13 of the SAR to determine the scenario and consequences for each accident and to ascertain if the integrity of the Fuel System Boundary or any interfacing systems can be compromised. The reviewer should verify that the proposed ECS can prevent or mitigate degradation of the fuel salt and the fuel salt boundary. The reviewer should compare the design details of the proposed ECS with the design and functional requirements of the SAR accidents in Chapter 13 and the mitigated radiological consequences with 10 CFR Part 100 for test reactors to determine whether the design is acceptable.

\section{Evaluation Findings}

This section of the SAR should contain sufficient information to support the following types of conclusions, which will be included in the staff's safety evaluation report:

- $\quad$ The applicant has identified a potential or maximum hypothetical accident that could lead to unacceptable Fuel System Boundary degradation or loss of Fuel System Boundary integrity and unacceptable radiological consequences.

- $\quad$ The applicant has identified a potential or maximum hypothetical accident that could lead to unacceptable interfacing system degradation or loss of integrity and unacceptable radiological consequences.

- $\quad$ The applicant's analysis of this accident in Chapter 13 includes a proposed ECS whose design and function is to cool the fuel to prevent failure of the Fuel System Boundary and associated containment. 
- $\quad$ The ECS would not interfere with normal operations and would not prevent safe reactor shutdown.

- $\quad$ The design and operation of the ECS would not lead to uncontrolled release of radioactive material.

- $\quad$ The TS, including testing and surveillance, provide reasonable assurance of necessary ECS operability for reactor operations as analyzed in the SAR.

- $\quad$ The design of the ECS is adequate for operation at the required flow rate and time interval as determined by the accident analysis. The design also considered the availability of normal electrical power and cooling sources and provides for alternative sources, if necessary.

- $\quad$ The functioning of the ECS as designed reasonably ensures that the maximum hypothetical accident at the reactor facility would not subject the public, environment, or facility staff to unacceptable radiological exposure.

\subsection{References}

1. Radiation Protection at Research Reactor Facilities, American National Standards Institute/American Nuclear Society, ANSI/ANS-15.11-2016, ANS, LaGrange Park, Illinois, 2016.

2. The Development of Technical Specifications for Research Reactors, American National Standards Institute/American Nuclear Society, ANSI/ANS-15.1-R2013, ANS, LaGrange Park, Illinois, 2013. 
APPENDIX D. CHAPTER 9, “AUXILIARY SYSTEMS" -MSR ADAPTATION 



\section{APPENDIX D. CHAPTER 9, “AUXILIARY SYSTEMS"-MSR ADAPTATION OF PART 1}

\section{AUXILIARY SYSTEMS (Part 1)}

Replace NUREG-1537, Part 1, Chapter 9, in its entirety with the following guidance.

NUREG-1537, Part 1, Chapter 9, of the format and content guide, as augmented by this ISG, is applicable to providing a description of the auxiliary systems for the licensing of a nonpower molten salt reactor (MSR) facility. Whenever the term MSR or reactor appears, it is understood to mean a nonpower reactor facility.

In this chapter of the SAR, the applicant should discuss the auxiliary systems at the MSR ${ }^{18}$ facility. Auxiliary systems are those systems not fully described in other chapters of the SAR that are important to the safe operation and shutdown of the reactor and to the protection of the health and safety of the public, facility staff, and the environment. The applicant should provide sufficient information for all auxiliary systems to support an understanding of the design and functions of the systems, with emphasis on those aspects that could affect the reactor and its safety features, radiation exposures, and the control or release of radioactive material.

The following glossary contains terms often used when discussing an MSR.

Active Reactor Core: In an MSR, the Vessel region occupied by the fuel salt where the majority of prompt neutrons are generated and where most fissions occur. In an MSR, the core geometry might change with time as a result of changes in density and voiding of the solution. The core does not include the part of the fuel salt that can become entrained into the cover gas.

Coating: Intervening protective layer of material between the corrosive fuel salt and the structural container alloy. Multiple layer configurations are possible (ranging in thickness from $>1 \mathrm{~mm}$, similar to liners used in current LWRs, to $<500 \mathrm{~nm}$, which adhere to the underlying substrate). Also included are embedded coatings, which are chemically resistant material that is embedded into the surface of the structural alloy, allowing surface modification to be performed to the structure to enhance its corrosion resistance.

Control Element(s): Object(s) employed to interact with an MSR's neutron population to adjust reactivity. Control elements can act through fuel displacement, neutron absorption, neutron reflection, neutron spectral adjustment, or a combination of these methods. Control elements can be solids, liquids, or gases, and they can be passively or actively positioned.

Emergency Cooling System: System that provides decay heat removal from the Reactor Fuel following an accident (e.g., a direct reactor auxiliary cooling system or a reactor vessel auxiliary cooling system).

Fission Product Barrier: Portion of the Fuel System Boundary in contact with fission products only (e.g., the gas management system boundary).

\footnotetext{
${ }^{18}$ MSRs are a class of reactors in which a molten salt performs a significant function in the core.
} 
Fuel Barrier: Portion of the Fuel System Boundary in contact with the fuel salt (principally the Vessel, heat exchanger, control element thimbles, instrumentation thimbles, piping, tanks, and valves).

Fuel System Boundary: All structures that prevent the release of fuel, fission gas, or other fission products. For an MSR, this includes the Vessel, waste-handling tank, pumps, valves, and piping. (Essentially includes the Fission Product Barrier and the Fuel Barrier.)

Heat Dissipation System: Set of components or system(s) that interface with the Primary Cooling System to provide the principal means of transferring the heat from the core to the environment. The Heat Dissipation System might use a variety of coolants (e.g., salt, liquid metal, or water) but does not contain fuel.

Neutron Moderator: In an MSR, materials in or near the core that consist of light elements. Moderators are generally solid form.

Primary Cooling System: Directly interfaces with the Fuel System Boundary at the fuel salt/primary cooling system heat exchanger(s) to provide the principal means of removing heat from the fuel salt by transferring the heat to the Heat Dissipation System. The Primary Cooling System typically contains a salt but does not contain fuel.

Reactor Fuel: In an MSR, fuel salt which consists of fissionable and possibly fertile halide salts, fission products, and generally solvent halide salt(s).

Vessel: For an MSR, structure containing the Active Reactor Core. Other components might reside in the Vessel but outside the Active Reactor Core, such as heat exchangers in certain design configurations.

For each auxiliary system, the applicant should discuss the capability to function as designed without compromising reactor operation or the capability to shut down the reactor. This capability should be shown for normal operation and reactor accident conditions. The applicant should include the following information for each auxiliary system:

(1) Design basis.

(2) System description, including drawings and specifications of principal components and any special materials.

(3) Operational analysis and safety function.

(4) Instrumentation and control requirements not described in Chapter 7, "Instrumentation and Controls Systems," of the SAR.

(5) Required technical specifications (TS) and their bases, including testing and surveillance.

The design, operation, and use of nonpower reactors vary widely. Typical auxiliary systems that might be discussed in this chapter of the SAR include the following: 
- Heating, ventilation, and air-conditioning (HVAC) systems for normal reactor operation. (The applicant should discuss any engineered safety feature functions of the HVAC systems for accident conditions in Chapter 6, "Engineered Safety Features," of the SAR.)

- $\quad$ For reactors designed for homogeneous fuel, handling and storage of special nuclear material (SNM) used for Reactor Fuel, both new and irradiated, including systems (tanks, valves, pumps, instrumentation, controls), related cooling systems, processes (chemical blending, SNM transfers, waste storage, preparation for shipment), criticality control and monitoring, vaults, shielding, and contamination control.

- $\quad$ Fire protection systems that could affect reactor safety or protection of licensed materials.

- $\quad$ Communication systems, both internal and external to the facility.

- $\quad$ Control, storage, or use of byproduct, source, and special nuclear material produced, used, or possessed under the reactor operating license. (The applicant should also discuss applicable laboratory facilities designed to handle or use byproduct materials other than radioactive waste.)

- $\quad$ Gas management system control and processing. (The applicant should include features of MSRs designed to control fission gases.)

- $\quad$ Fission gas collection and storage systems in homogeneous-fueled reactors where fission gas generated in liquid fue ${ }^{19}$ is collected and directed to a radioactive waste treatment system. Details of this system are discussed in Chapter 11, "Radiation Protection Program and Waste Management," of the SAR. The applicant should demonstrate that the auxiliary system and any malfunction could not create conditions or events that could cause an unanalyzed accident or the uncontrolled release of radioactive material beyond those analyzed in Chapter 13, "Accident Analysis," of the SAR.

- $\quad$ Auxiliary cooling systems for irradiated fuel storage tanks that are not part of cooling systems described in Chapter 5, "Molten Salt Reactor Cooling Systems," for example experimental facilities, gas management system cooling, flush and drain tank cooling, and other equipment and uses that are not part of the Primary Cooling System described in Chapter 5, of the SAR.

- Demineralizer resin regeneration system and other filtration systems.

- $\quad$ Control and storage of radioactive waste and reusable radioactive components (e.g., experiments). (If applicable, the applicant should describe the systems and show how they are designed to perform the design-basis functions derived in Chapter 10, "Experimental Facilities and Utilization," or Chapter 11 of the SAR.)

- $\quad$ Control of contaminated air, gas, or liquid from experimental facilities. (If applicable, the applicant should describe the systems and show how they are designed to perform the design-basis functions derived in Chapters 10 or 11.)

\footnotetext{
${ }^{19}$ There are also salt-cooled reactor designs that propose using fixed-position, coated-particle ceramic fuel. The discussion in this chapter is focused on MSRs operating with liquid fuel.
} 
- $\quad$ Compressed air or gas systems for reactor operating systems, fuel transfer, and experiment equipment.

- $\quad$ Auxiliary physical protection and access control that are not part of the facility physical security plan.

These examples are not intended as a complete list of auxiliary systems that might be discussed in this chapter of the SAR. The descriptions of some auxiliary systems might be better suited to other chapters, which should be referenced in this section.

\subsection{Heating, Ventilation, and Air-Conditioning Systems}

All used spaces in a facility could require HVAC systems to provide acceptable environments for personnel and equipment. In this section, the applicant should describe how temperature and humidity are controlled and discuss the bases, including how the control function is integrated into the HVAC systems. The applicant should address the prevention of uncontrolled releases of airborne radioactive effluents to the environment for normal operation. Special consideration should be given to a reactor with a homogeneous-fueled Active Reactor Core because of the concentrations of fission gas in the fuel. Chapter 5 of the SAR addresses numerous systems unique to liquid salt-fueled reactors that should be considered if applicable. The discussions should contain explanations of how airborne radioactive material from operations and experiments is limited in occupied areas to maintain radiation exposures below the requirements of 10 CFR Part 20 and the facility ALARA (as-low-as-is-reasonably-achievable) program guidelines. Controls limiting diffusion or leakage of radioactive material to adjacent spaces should be presented. The applicant also should discuss how air exhaust systems or stacks are designed to reduce the radiological impact on the unrestricted environment during normal reactor operations.

Analyses of radiation exposures in Chapter 11 should include the applicable normal operating characteristics of the HVAC systems described in this section of the SAR. The interactions among airflow patterns in the reactor room, the air exhaust stacks, and the effluent and continuous air monitors should be discussed. If the HVAC systems also are designed to mitigate the consequences of accidents, the engineered safety features should be noted in this section of the SAR but described in detail in Chapter 6.

The applicant should describe instrumentation and control systems that control the release of radioactive material (automatic and manual) in Chapters 7 and 11 of the SAR. The information in this section of the SAR should be sufficient to support an understanding of the safety functions of radiation sensors that initiate alarms and automatic closures, fail-safe dampers, interlocks, and function displays during normal reactor operations. The applicant should discuss the bases and purpose of TS that apply to the HVAC systems, including calibrations, testing, and surveillance.

The applicant should discuss the possible effects of malfunctions of the HVAC systems on safe reactor operation or on the release of airborne radioactive material during normal reactor operation. The radiological effects of malfunctions should be discussed in Chapter 11. 
In this section of the SAR, the applicant should propose and justify TS that constitute important design features, safety limits (SLs), limiting safety system settings (LSSSs), limiting conditions for operation (LCOs), and surveillance requirements (SRs) discussed in Chapter 14 of this format and content guide.

\subsection{Handling and Storage of Reactor Fuel}

In this section, the applicant should discuss the life cycle of Reactor Fuel from the time it enters its jurisdiction until it is released from such jurisdiction. For most reactors this means from arrival on-site until shipment off-site. However, the safety and performance of the fuel while in the Active Reactor Core is discussed in Chapter 4, "Reactor Description," of the SAR.

For facilities designed to fabricate fuel on-site, the discussion should include a description of the form in which the fissile material is received, how and where it is stored before use, and how it is blended into a useable liquid fuel, including criticality control measures and monitoring.

The applicant should provide analyses and discuss how subcriticality is ensured ( $k_{e f f}$ not to exceed 0.90) under all conditions, except during transportation off-site. During transportation, the shipping container license is applicable. (Existing usage with $k_{\text {eff }}$ greater than 0.90 will be acceptable if the usage was previously reviewed and approved by the NRC.) The applicant should address the applicability and implementation of 10 CFR 70.24, which addresses criticality monitors.

The applicant should address the nuclear and chemical stability of materials subject to long-term exposure to irradiated liquid fuel stored on-site (e.g., $k_{\text {eff }}$ changes resulting from a heat-induced recombination of gas in a highly irradiated liquid fuel storage tank). Container or tank corrosion and off-gassing considerations for irradiated liquid fuel stored on-site should also be addressed.

The applicant should discuss briefly the methods that ensure the prudent control of fuel. The discussion should include a description that does not contain proprietary or safeguards information of the physical protection of fuel against theft or diversion in the facility physical security plan. Implementation of 10 CFR 73.6(b) concerning self-protection for irradiated highly enriched uranium fuel should be addressed. Reference can be made to the physical security plan, which should be treated as proprietary or safeguards information.

For liquid-fueled reactors, the applicant should describe the various systems and operations involving the liquid fuel such as receipt from off-site (if applicable), storage, dissolution, blending, fuel makeup and removal, fission heat extraction, fuel cleanup, and draining of the system. However, if an extensive fuel cleanup process is part of the design, that material might fit better in Chapter 11.

Irradiated fuel cooling systems and methods may be described in detail in Chapter 5 of the SAR if they are integral to the Primary Cooling System or the Heat Dissipation System. Otherwise, the discussion should be in this section. 
During liquid-fuel storage or handling, if a loss of fuel, fuel-handling accident, or system failure could result in the release of fission products, the applicant should discuss the mechanisms and analyze the consequences in Chapter 13, "Accident Analyses," of the SAR.

In this section of the SAR, the applicant should propose and justify TS that constitute important design features, SLs, LSSSs, LCOs, and SRs discussed in Chapter 14 of this format and content guide.

\subsection{Fire Protection Systems and Programs}

In this section, the applicant should describe the systems and programs designed to protect the reactor facility from damage by fire and discuss how the facility meets all local building and fire codes. For a new facility, this could be a general discussion of how the facility meets local fire and building codes. Documentation from the local authority that authorizes the construction or verifies compliance with local codes could be submitted as part of the discussion. NRC construction inspectors would review design features for fire protection during facility construction. For existing facilities requesting license renewal for which the original construction documentation might be difficult to reproduce, the applicant could submit the results of a recent fire inspection to show compliance with local codes. The applicant should discuss additional active and passive design features required by the reactor design characteristics. Further, the discussion should address the potential for release of radioactive material as a result of a fire. Active systems might include sprinkler, suppression, hand extinguisher, and detection systems. Passive systems might include fire walls and doors, isolation, and control of combustible materials. Three important considerations for MSRs are:

1. Fire suppression with water in areas with high temperature components creates a potential for rapid pressurization (i.e., steam hazard).

2. Water always creates the potential for a criticality excursion around fissile material.

3. A properly written FHA contains a discussion on the control of run off from fire suppression. In the case of MSRs, water is probably the most efficient transport mechanism for fuel salts.

The applicant should discuss how the potential release of radioactive materials as a result of fires in the reactor room and other applicable spaces was considered in the design of the facility. The discussion should include the reactor and all facilities where special nuclear material and other radioactive materials are stored or used under the reactor license. It should include any possible effects of a fire on safe shutdown of the reactor. The objectives of the fire protection program should include the following:

- $\quad$ Preventing fires, including limiting combustible materials.

- Detecting, controlling, and extinguishing fires to limit consequences.

- $\quad$ Protecting reactor systems so that a fire would not prevent safe reactor shutdown, result in an inadvertent criticality, or cause an uncontrolled release of radioactive material. 
In this section of the SAR, the applicant should propose and justify TS that constitute important design features, SLs, LSSSs, LCOs, and SRs discussed in Chapter 14 of this format and content guide.

The National Fire Protection Association (NFPA) standard 802, 1993 edition, contains general information on research reactor fire protection. The applicant may also consult the NFPA performance-based standard for LWRs, NFPA 805, 2015 edition, or the performance-based standard for advanced reactors, NFPA 806, 2015 edition.

\subsection{Communication Systems}

The applicant should describe the communication systems that will be used at the facility for which public disclosure is not limited by the physical security plan. Communication systems used between the control room, the reactor room, reactor access point or top, reactor utilities rooms, experiment areas, and all other required areas should be described. Systems such as telephone, paging, radio, or video that will be used to announce changes of reactor status to experimenters, summon supervisory operators, request radiation protection assistance, and announce emergencies should be discussed. For a complete description of communications, the applicant should also briefly summarize in this section the communication systems used for emergency or physical security purposes (this discussion should not contain proprietary or safeguards information).

In this section of the SAR, the applicant should propose and justify TS that constitute important design features, SLs, LSSSs, LCOs, and SRs discussed in Chapter 14 of this format and content guide.

\subsection{Possession and Use of Byproduct, Source, and Special Nuclear Material}

The 10 CFR Part 50 operating license applies to possession and operation of the reactor; possession and use of byproduct material produced by the operation of the reactor; and, to the extent authorized, the receipt, possession, and use of other byproduct, source, or special nuclear material needed for operation of the reactor and its experimental programs.

The NRC regulatory approach is to include in the reactor license only material that is produced by the reactor or that is required to directly operate the reactor and associated experimental facilities. Other material at a reactor facility is authorized by an NRC byproduct, source, or special nuclear materials license. If the facility is located in an Agreement State, an Agreement State license could also exist. This other material is normally not required to operate the reactor or associated experimental facilities. A special case exists for material that is received for irradiation from another licensee. If this material is to be placed into the reactor for irradiation within 31 days of receipt, it may be possessed under the reactor license. However, this authorization for receipt and possession must be specifically stated in the reactor license. If more than 31 days passes before the material is placed into the reactor, it should be included in an NRC or Agreement State materials license until irradiation occurs. Further information on this subject can be found in memoranda dated March 8 and August 18, 1988, from Dennis M. 
Crutchfield, director, Division of Reactor Projects - III, IV, V, and Special Projects, to NRC regional administrators (provided as Appendixes 9.1 and 9.2).

The receipt, possession, or use of materials authorized by the reactor license may occur in the reactor room and contiguous operational spaces and in laboratory spaces for research and development purposes. Some licensees take a narrow view, transferring material produced in the reactor to another NRC or Agreement State license when the material is removed from the Vessel. Others take a broad view and allow all materials produced by the reactor or authorized by the license to be in various locations and laboratories in the facility. Spaces could be used to process and package byproduct materials for shipment or could be used for performing experiments involving the byproduct materials. A broad view of materials and areas authorized by the 10 CFR Part 50 reactor license avoids maintaining multiple licenses and allows, in some cases, indemnity protection for materials in laboratories and other auxiliary spaces. The applicant should clearly state the materials and areas of the facility requested to be authorized by the reactor license. The reactor license and TS will also include regulatory conditions that apply to the possession, management, and use of such materials, including requirements stated in $10 \mathrm{CFR}$ Parts 20,30,40, or 70 .

The applicant should discuss in this section laboratories under the reactor license in which reactor-licensed material will be used. This discussion should address all five factors noted at the beginning of this chapter for any such auxiliary laboratories. The applicant should specify the types and quantities of radionuclides authorized, as well as the general types of experiments or uses. Radiological design bases for handling radioactive materials and radioactive waste should be derived from Chapter 11 of the SAR. These design bases may apply to chemical, fume, and air exhaust hoods; drains for radioactive liquids; and radiation shields. The discussions should show how the physical security and emergency plans apply to the licensed spaces and possession of byproduct materials. The applicant should discuss the bases for special operating procedures. The administrative aspects of the use of materials in these areas should be addressed in Chapter 12 , "Conduct of Operations," of the SAR.

The use of liquid fuel adds numerous new issues pertaining to quantification of byproduct, source, and special nuclear material unique to operation of a homogeneous reactor. The applicant will have described in Chapter 4 of the SAR, the liquid fuel cycle, its salient features being the following:

- $\quad$ Liquid fuel has no start and end date in the homogeneous reactor analogous to each fuel element in a heterogeneous reactor where a fuel element is placed in the reactor for a defined period of time and then removed for ultimate shipment off-site during which the history of its location in the core, the energy extracted from it, and the transformative reactions (fission, neutron activation, radioactive decay) resulting in new materials (fission fragments, activation products, conversion to fissile material) can be tracked.

- $\quad$ The intent of the fuel salt concept is to replenish fissioned material with more fissile material than what is consumed in the fission process, replacing fissioned ${ }^{235} \mathrm{U}$ with ${ }^{239} \mathrm{Pu}$ resulting from the neutron capture of ${ }^{238} \mathrm{U}$. 
- The initial liquid fuel-loading fissile material for a reactor could consist of ${ }^{235} \mathrm{U}$ only, ${ }^{235} \mathrm{U}$ and ${ }^{239} \mathrm{Pu}$, or a ${ }^{233} \mathrm{U} / \mathrm{Th}$ fuel cycle.

- $\quad$ Knowing the concentration and quantity of byproduct, source, and special nuclear material in the liquid fuel at any time requires a complex calculational or measurement program or a combination of the two.

In this section of the SAR, the applicant should propose and justify TS that constitute important design features, SLs, LSSSs, LCOs, and SRs discussed in Chapter 14 of this format and content guide.

\subsection{Gas Management System}

Gaseous fission products from liquid-fueled reactors must be collected in some form of gaseous fission products gas management system to protect workers from high radiation doses. The gas must be further treated to isolate it until decayed. This might be done through delay lines/tanks, cryogenic storage, or another delay-before-release system.

For reactors with gas management systems, the applicant should discuss control of the cover gas and all decay heat removal components, addressing the five factors listed at the beginning of this chapter. The discussions should describe cover gas systems that cool, circulate, decontaminate, recover, store, monitor, and dispose of the gas. Processing, storing, and recombining of reactive gases, if applicable, should also be discussed. The design bases should define which inert gases are acceptable to use, their impact on safe reactor operations and shutdown, and the methods for controlling the concentrations.

In this section of the SAR, the applicant should propose and justify TS that constitute important design features, SLs, LSSSs, LCOs, and SRs discussed in Chapter 14 of this format and content guide.

\subsection{Cooling Systems}

Among the auxiliary systems that should be addressed are any cooling systems that are part of the licensed facility. Chapter 5, "Molten Salt Reactor Cooling Systems," identifies the following cooling systems that could be associated with an MSR:

- $\quad$ Fuel salt drain tank

- $\quad$ Primary Cooling System drain tank, if applicable

- Gas management system cooling

- Cooling for chemical processing/polishing loop

- $\quad$ Other cooling systems 
The applicant should describe and analyze each cooling system, addressing the five factors listed at the beginning of this chapter, and include the following:

- $\quad$ Demonstrate that the cooling system will function under normal operation and analyzed reactor accident conditions, if required.

- Demonstrate that the cooling system and any malfunction could not create conditions or events that could cause an unanalyzed reactor accident or the uncontrolled release of radioactive material beyond those analyzed in Chapter 13 of the SAR.

- $\quad$ Demonstrate that the cooling system could not prevent safe reactor shutdown.

In this section of the SAR, the applicant should propose and justify TS that constitute important design features, SLs, LSSSs, LCOs, and SRs discussed in Chapter 14 of this format and content guide.

\subsection{Other Auxiliary Systems}

As noted previously, a unique set of auxiliary systems could exist at a nonpower reactor. The previous examples are found at many reactor facilities; other facilities could have additional auxiliary systems. The applicant should describe and analyze all auxiliary systems, address the five factors listed at the beginning of this chapter, and include the following:

- $\quad$ Demonstrate that the auxiliary system will function under analyzed reactor accident conditions, if required.

- $\quad$ Demonstrate that the auxiliary system and any malfunction could not create conditions or events that could cause an unanalyzed reactor accident or the uncontrolled release of radioactive material beyond those analyzed in Chapter 13 of the SAR.

- $\quad$ Demonstrate that the auxiliary system could not prevent safe reactor shutdown.

In this section of the SAR, the applicant should propose and justify TS that constitute important design features, SLs, LSSSs, LCOs, and SRs discussed in Chapter 14 of this format and content guide.

\subsection{References}

1. Recommended Practice for Nuclear Research and Production Reactors, NFPA 802, National Fire Protection Association, 1993.

2. Performance-Based Standard for Fire Protection for Light-Water Reactor Electric Generating Plants, NFPA 805, National Fire Protection Association, 2015.

3. Performance-Based Standard for Fire Protection for Advanced Reactor Electric Generating Plants Change process, NFPA 806, National Fire Protection Association, 2015. 
4. Format and Content for Safety Analysis Reports for Research Reactors, ANSI/ANS-15.21-2012, American National Standards Institute/American Nuclear Society, ANS, LaGrange Park, Illinois, 2012.

5. The Development of Technical Specifications for Research Reactors, ANSI/ANS-15.1-R2013, American National Standards Institute/American Nuclear Society, ANS, LaGrange Park, Illinois, 2013. 
D-14 


\section{APPENDIX D. CHAPTER 9, “AUXILIARY SYSTEMS”-MSR ADAPTATION OF PART 2}

\section{AUXILIARY SYSTEMS (Part 2)}

Replace NUREG-1537, Part 2, Chapter 9, in its entirety with the following guidance.

NUREG-1537, Part 2, Chapter 9, of the standard review plan and acceptance criteria, as augmented by this ISG, is applicable to reviewing a description of the auxiliary systems for the licensing of a nonpower molten salt reactor (MSR) facility. Whenever the term MSR or reactor appears, it is understood to mean a nonpower reactor facility.

This chapter contains guidance for evaluating the information on auxiliary systems in the MSR ${ }^{20}$ facility. Auxiliary systems are those systems not fully described in other chapters of the SAR that are important to the safe operation and shutdown of the reactor and to the protection of the health and safety of the public, facility staff, and environment. There are also auxiliary systems or subsystems that do not have a direct impact on protecting the reactor or the public from exposure to radiation. However, for all auxiliary systems at an MSR, sufficient information should be provided so that the reviewer can understand their design and functions. Emphasis should be placed on those aspects of auxiliary systems that might affect the reactor, its safety features, and its safe shutdown, or contribute to the control of radioactivity and radiation exposures.

The following glossary contains terms often used when discussing an MSR.

Active Reactor Core: In an MSR, the Vessel region occupied by the fuel salt where the majority of prompt neutrons are generated and where most fissions occur. In an MSR, the core geometry might change with time as a result of changes in density and voiding of the solution. The core does not include the part of the fuel salt that can become entrained into the cover gas.

Coating: Intervening protective layer of material between the corrosive fuel salt and the structural container alloy. Multiple layer configurations are possible (ranging in thickness from $>1 \mathrm{~mm}$, similar to liners used in current LWRs, to $<500 \mathrm{~nm}$, which adhere to the underlying substrate). Also included are embedded coatings, which are chemically resistant material that is embedded into the surface of the structural alloy, allowing surface modification to be performed to the structure to enhance its corrosion resistance.

Control Element(s): Object(s) employed to interact with an MSR's neutron population to adjust reactivity. Control elements can act through fuel displacement, neutron absorption, neutron reflection, neutron spectral adjustment, or a combination of these methods. Control elements can be solids, liquids, or gases, and they can be passively or actively positioned.

Emergency Cooling System: System that provides decay heat removal from the Reactor Fuel following an accident (e.g., a direct reactor auxiliary cooling system or a reactor vessel auxiliary cooling system).

\footnotetext{
${ }^{20}$ MSRs are a class of reactors in which a molten salt performs a significant function in the core.
} 
Fission Product Barrier: Portion of the Fuel System Boundary in contact with fission products only (e.g., the gas management system boundary).

Fuel Barrier: Portion of the Fuel System Boundary in contact with the fuel salt (principally the Vessel, heat exchanger, control element thimbles, instrumentation thimbles, piping, tanks, and valves).

Fuel System Boundary: All structures that prevent the release of fuel, fission gas, or other fission products. For an MSR, this includes the Vessel, waste-handling tank, pumps, valves, and piping. (Essentially includes the Fission Product Barrier and the Fuel Barrier.)

Heat Dissipation System: Set of components or system(s) that interface with the Primary Cooling System to provide the principal means of transferring the heat from the core to the environment. The Heat Dissipation System might use a variety of coolants (e.g., salt, liquid metal, or water) but does not contain fuel.

Neutron Moderator: In an MSR, materials in or near the core that consist of light elements. Moderators are generally solid form.

Primary Cooling System: Directly interfaces with the Fuel System Boundary at the fuel salt/primary cooling system heat exchanger(s) to provide the principal means of removing heat from the fuel salt by transferring the heat to the Heat Dissipation System. The Primary Cooling System typically contains a salt but does not contain fuel.

Reactor Fuel: In an MSR, fuel salt which consists of fissionable and possibly fertile halide salts, fission products, and generally solvent halide salt(s).

Vessel: For an MSR, structure containing the Active Reactor Core. Other components might reside in the Vessel but outside the Active Reactor Core, such as heat exchangers in certain design configurations.

The design, operation, and use of MSRs vary widely, resulting in a wide variety of auxiliary systems. The applicant should discuss the capability of each auxiliary system to function as designed without compromising the safe operation or shutdown of the reactor facility under the range of operational conditions. Any functions of auxiliary systems required during analyzed reactor accidents should also be discussed. The information the applicant should provide in this chapter of the SAR for each auxiliary system is given at the beginning of Chapter 9 of the format and content guide. The typical auxiliary systems listed there are not intended to be a complete list of auxiliary systems to be discussed in this chapter of the SAR. The reviewer should be aware that some auxiliary systems could be discussed in more than one chapter. The following sections contain guidance pertaining to the five items listed at the beginning of Chapter 9 of the format and content guide for the systems discussed in Sections 9.1 to 9.8 of the guide. 


\subsection{Heating, Ventilation, and Air-Conditioning Systems}

\section{Areas of Review}

At MSRs, the heating, ventilation, and air-conditioning (HVAC) systems are designed to provide conditioned air for an acceptable working environment for personnel and equipment. The areas of review for this section include HVAC system operating characteristics for the full range of reactor operation. In many MSRs, the HVAC systems are also designed to limit concentrations and prevent the uncontrolled release of airborne radioactive material to the unrestricted environment. Any operating modes or functions designed to mitigate the consequences of accidents should be discussed in Chapter 6, "Engineered Safety Features," of the SAR. Radiological exposures to airborne radioactive material that result from the full range of reactor operations should be analyzed in detail in Chapter 11, "Radiation Protection Program and Waste Management," where design bases for the full range of reactor operations of the HVAC system should be developed.

In a liquid-fueled reactor, ${ }^{21}$ gaseous fission products are released directly to the Reactor Fuel. This gas must be trapped and directed to a radioactive waste treatment system. Review of the HVAC system must consider any intrusion of this highly radioactive waste stream into occupied areas. The review of systems with this potential should be covered in their review as is discussed in depth in Chapter 5, "Molten Salt Reactor Cooling Systems." Areas of review should include the following:

- $\quad$ Discussion of the characteristics and functions of the HVAC system if no airborne radioactivity is present.

- Discussion of all sources of radioactive materials that could become airborne during the full range of reactor operation and of the way the HVAC system is designed to affect the distribution and concentration of those materials.

- $\quad$ Features of the HVAC system designed to limit exposures of personnel to radiation in the restricted area as a result of the full range of reactor operation.

- $\quad$ Features of the HVAC system and associated reactor building designed to prevent inadvertent or uncontrolled release of airborne radioactive material to areas outside the reactor room and to the unrestricted environment.

- $\quad$ Modes of operation and features of the HVAC system designed to control (contain or confine) reactor facility atmospheres, including damper closure or flow-diversion functions, during the full range of reactor operation.

- $\quad$ Features of the HVAC system that affect habitability and the working environment in the reactor facility for personnel and equipment.

- $\quad$ Applicable technical specifications (TS) and their bases, including testing and surveillance.

\footnotetext{
${ }^{21}$ There are also salt-cooled reactor designs that propose using fixed-position, coated-particle ceramic fuel. The discussion in this chapter is focused on MSRs operating with liquid fuel.
} 


\section{Acceptance Criteria}

The acceptance criteria for information on the HVAC systems include the following:

- $\quad$ The system design should ensure that temperature, relative humidity, and air exchange rate (ventilation) are within the design-basis limits for personnel and equipment.

- $\quad$ The system design should address all normal sources of airborne radioactive material and ensure that these sources are diluted, diverted, or filtered so that occupational doses do not exceed the requirements of 10 CFR Part 20 and are consistent with the facility ALARA (as-low-as-is-reasonably-achievable) program.

- $\quad$ The design features should ensure airflow and relative pressure that prevent inadvertent diffusion or other uncontrolled release of airborne radioactive material from the reactor room.

- The design and operating features of the system should ensure that no uncontrolled release of airborne radioactive material to the unrestricted environment could occur.

- The analyses of operations of the system should show that planned releases of airborne radioactive material to the unrestricted environment will not expose the public to doses that exceed the limits of 10 CFR Part 20 and the facility ALARA program guidelines. The exposure analyses should be given in detail in Chapter 11 of the SAR.

- If design bases of the system include containment or confinement during the full range of reactor operation, the system design and analyses should show how this condition is ensured. If the function is used to mitigate accident scenarios as discussed in Chapter 13, "Accident Analyses," of the SAR, the function should be described in Chapter 6.

- $\quad$ Required TS and their bases should ensure system operability

\section{Review Procedures}

Using the five items listed at the beginning of Chapter 9 of the format and content guide, the reviewer should evaluate the submittal for all operations and functions of the HVAC systems during the full range of reactor operations. The design bases should be compared with requirements from other chapters of the SAR, especially Chapters 4 ("Reactor Description"), 6, 7 ("Instrumentation and Control Systems"), 11, and 13. The reviewer should determine whether the HVAC system designs agree with all acceptance criteria for the full range of reactor operations.

\section{Evaluation Findings}

This section of the SAR should contain sufficient information to support the following types of conclusions, which will be included in the safety evaluation report:

- A review of the design bases and functional and safety characteristics of the HVAC systems shows that the proposed systems are adequate to control the release of airborne 
radioactive effluents during the full range of reactor operations in compliance with the regulations.

- The applicant has discussed all sources of radioactive material that could become airborne in the reactor room from the full range of reactor operations. The analyses demonstrate that the radioactive material is controlled by the HVAC system and could not inadvertently escape from the reactor room. They show that the distributions and concentrations of the airborne radionuclides in the reactor facility are limited by operation of the HVAC system so that during the full range of reactor operations, no potential occupational exposures would exceed the design bases derived in Chapter 11.

- $\quad$ The applicant has considered the height and flow rate of the stack that exhausts facility air to the unrestricted environment for the design-basis dose rates derived in Chapter 11 for the maximum exposed personnel in the unrestricted environment.

- $\quad$ The HVAC system is an integral part of a containment (confinement) system at the reactor facility. The design of the containment (confinement) system and analysis of its operation ensure that it will function to limit normal airborne radioactive material to the extent analyzed in this chapter and in Chapter 11 . The potential radiation doses will not exceed the limits of 10 CFR Part 20 and are consistent with the facility ALARA program.

- $\quad$ The applicant has proposed TS, including testing and surveillance that will provide reasonable assurance of necessary HVAC system operability for the full range of reactor operations.

\subsection{Handling and Storage of Reactor Fuel}

The fuel for a reactor is the most important component bearing on the health and safety of the public and the common security. Protecting the fuel from malfunction or failure should be discussed in many chapters in the SAR.

For some MSRs, the handling and storage of Reactor Fuel is a continuous operation that is more significant during operation than during a shutdown.

\section{Areas of Review}

The reviewer should evaluate the handling, protection, and storage of the Reactor Fuel when it is not in the Vessel, both before it is inserted and after it is removed.

Areas of review should include the following:

- $\quad$ Equipment, systems, methods, and administrative procedures for receipt of new Reactor Fuel.

- $\quad$ Methods for inspection and verification of new fuel to ensure that procurement specifications have been met.

- $\quad$ Systems and methods for movement, physical control, and storage of new fuel within the facility. 
- Methods, analyses, and systems for secure storage of new and irradiated Reactor Fuel that will prevent criticality (keff not to exceed 0.90 ) under all conditions of moderation during storage and movement. (The use of criticality monitors, if applicable, should be reviewed, in accordance with 10 CFR 70.24.)

- $\quad$ Systems and methods for inserting fuel into the Vessel and for removing fuel from the Vessel. (This discussion should include physical and administrative methods to ensure that Reactor Fuel is handled only by authorized persons.)

- $\quad$ Systems, components, and methods for radiation shielding and for protecting irradiated Reactor Fuel during removal from the core, movement within the reactor facility, and storage.

- $\quad$ Systems, components, and methods used to prepare and ship Reactor Fuel off-site in accordance with applicable regulations. (This function should also be discussed for facilities that expect to retain the fuel until reactor decommissioning.)

- Nuclear and chemical stability of materials subject to long-term exposure to irradiated liquid fuel stored on-site (e.g., keff changes resulting from a heat-induced recombination of gas in a highly irradiated liquid fuel storage tank).

- $\quad$ TS that define controls on fuel during handling and storage, including testing and surveillance.

\section{Acceptance Criteria}

The acceptance criteria for information on the handling and storage of Reactor Fuel include the following:

- $\quad$ The design of all systems, components, and methods for handling, moving, or storing fuel outside the Active Reactor Core should ensure with a high confidence level that the neutron multiplication, keff, will not exceed 0.90 under any possible conditions. (Existing usage with keff greater than 0.90 will be acceptable if the usage was previously reviewed and approved by the NRC.) Neutron multiplication requirements for shipping containers should be determined by their specific licenses.

- $\quad$ All systems, components, and methods for handling, moving, or storing fuel, including insertion and removal from the reactor, should be designed to prevent release of fission products.

- $\quad$ The design of all systems, components, and methods for handling, moving, or storing fuel should demonstrate that the facility staff and the public are protected from radiation and that radiation exposures do not exceed the requirements of 10 CFR Part 20 and are consistent with the facility ALARA program.

- $\quad$ All systems, components, and methods for handling, moving, or storing fuel should be designed to control special nuclear material to the extent required by applicable regulations, such as 10 CFR Part 73. The discussions related to diversion and theft of the fuel should be withheld from public disclosure and should be contained in the facility physical security plan. 
- If 10 CFR 73.6(b), "Self-Protection for HEU Reactor Fuel," applies to the storage of irradiated fuel, the applicant should discuss measurement methods or other techniques to ensure compliance.

- $\quad$ The TS should contain limitations on the storage conditions necessary to ensure subcriticality, prevent thermal failure, and administratively and physically control the fuel (special nuclear material) because of its potential for fission and potential hazards as a radiation source.

\section{Review Procedures}

The reviewer should evaluate the systems and methods used to handle and store new and irradiated Reactor Fuel, compare the design bases with any requirements in this and other chapters of the SAR (such as Chapters 4, 11, and 13) and the requirements of the regulations, and focus on the design features that maintain Fuel System boundary integrity, control radiation, and prevent criticality.

\section{Evaluation Findings}

This section of the SAR should contain sufficient information to support the following types of conclusions, which will be included in the safety evaluation report:

- $\quad$ The discussions of plans for receiving, inspecting, and documenting the arrival of new fuel give reasonable assurance that all special nuclear material will be accounted for and that the fuel will meet procurement specifications.

- $\quad$ The analyses show that fuel storage features will ensure that criticality cannot occur. Even under optimum neutron moderation and reflection conditions, the maximum neutron multiplication could not exceed 0.90 (or for license renewals, the maximum neutron multiplication previously approved by the $N R C$ ). Plans to implement the applicable requirements of 10 CFR 70.24 for criticality monitoring are acceptable (if applicant has to adhere to 10 CFR 70.24).

- $\quad$ Methods for assessing irradiated Reactor Fuel radioactivity and potential exposure rates are adequate to avoid overexposure of the staff.

- Methods for shielding, cooling, and storing irradiated Reactor Fuel give reasonable assurance of the following:

- $\quad$ Potential personnel doses will not exceed the regulatory limits of 10 CFR Part 20 and are consistent with the facility ALARA program.

- Irradiated Reactor Fuel can be cooled as necessary to avoid loss of integrity and corrosive deterioration during both moving and storage within the facility.

- $\quad$ Provisions to ensure compliance with 10 CFR 73.6(b), "Self-Protection for HEU Reactor Fuel," are acceptable (if self-protection for HEU fuel is applicable). 


\subsection{Fire Protection Systems and Programs}

\section{Areas of Review}

Areas of review should include the following:

- $\quad$ Brief discussion of potential causes and consequences of fires at the facility.

- Discussion of fire protection plans and protective equipment used to limit the consequences of a fire, including defense in depth in the event of escalation of a fire.

- List of the objectives of the fire protection program, as well as discussion of the organizations, methods, and equipment for attaining the objectives.

- $\quad$ All passive designs or protective barriers planned to limit fire consequences, including features of the facility that could affect a safe reactor shutdown or release radioactive material in the event of a continuing fire.

- $\quad$ The source of facility fire protection brigades and their training and a summary of the more detailed discussions of these personnel and off-site fire protection forces in the facility emergency plan.

- $\quad$ Compliance with local and national fire and building codes applicable to fire protection.

\section{Acceptance Criteria}

The acceptance criteria for information on the fire protection systems and programs include the following:

- $\quad$ The fire protection plan should discuss the prevention of fires, including limiting the types and quantities of combustible materials.

- Methods to detect, control, and extinguish fires should be stated in the plan.

- $\quad$ The facility should be designed and protective systems should exist to ensure safe reactor shutdown and prevent uncontrolled release of radioactive material if a fire were to occur.

\section{Review Procedures}

The reviewer should evaluate the discussions of potential fires; provisions for early detection, including during those times when the buildings are not occupied; methods for isolating, suppressing, and extinguishing fires; passive features designed into the facility to limit fire consequences; response organization training and availability to fight fires as detailed in the emergency plan; designs of reactor systems that can ensure safe reactor shutdown in the event of fire; and potential radiological consequences to the public, staff, and environment if firefighting efforts are unsuccessful. 


\section{Evaluation Findings}

This section of the SAR should contain sufficient information to support the following types of conclusions, which will be included in the safety evaluation report:

- $\quad$ The plans for preventing fires ensure that the facility meets local and national fire and building codes.

- The systems designed to detect and combat fires at the facility can function as described and limit damage and consequences at any time. This includes consideration of the following for MSRs:

- $\quad$ Fire suppression with water in areas with high temperature components creates a potential for rapid pressurization (i.e., steam hazard).

- Water always creates the potential for a criticality excursion around fissile material.

- A properly written FHA contains a discussion on the control of run off from fire suppression. In the case of MSRs, water is probably the most efficient transport mechanism for fuel salts.

- $\quad$ Personnel training programs as described in the facility emergency plan and in Chapter 12, "Conduct of Operations," provide reasonable assurance that training for fire protection is adequately planned.

- The potential radiological consequences of a fire will not prevent safe reactor shutdown, and any fire-related release of radioactive material from the facility to the unrestricted environment has been adequately addressed in the appropriate sections of the facility emergency plan.

- $\quad$ Any release of radioactive material as a result of fire would not cause radiation exposures that exceeded the requirements of 10 CFR Part 20.

- $\quad$ Acceptable TS related to fire protection have been proposed and justified (if applicable). These TS include acceptable requirements for testing and surveillance to ensure operability of fire detection and protection equipment.

\subsection{Communication Systems}

\section{Areas of Review}

The reviewer should include the following:

- Methods of communication between all necessary locations during the full range of reactor operations.

- $\quad$ Summary of emergency communications that are discussed in detail in the physical security and emergency plans and evaluated by the staff. 
- $\quad$ Method for providing two-way communication between the reactor control room and other locations in the reactor facility.

\section{Acceptance Criteria}

The acceptance criteria for information on communication systems include the following:

- The communication system should allow the reactor operator on duty to contact the supervisor on duty, health physics staff, and other personnel required by the TS any time the reactor is operating.

- The communication system should allow the operator, or other designated staff member, to announce the existence of an emergency to all areas of the reactor site.

- $\quad$ The communication system should allow two-way communication between all operational areas, such as between the control room and the reactor fuel-loading location and between the control room and reactor experiment halls.

\section{Review Procedures}

The reviewer should determine where discussions address the five items listed at the beginning of Chapter 9 of the format and content guide to formulate conclusions about the adequacy of the communication systems.

\section{Evaluation Findings}

This section of the SAR should contain sufficient information to support the following types of conclusions, which will be included in the safety evaluation report:

- $\quad$ The facility communication systems are designed to provide two-way communication between the reactor control room and all other locations necessary for safe reactor operation.

- The communication systems allow the reactor operator on duty to communicate with the supervisor on duty and with health physics personnel.

- The communication systems allow a facility-wide announcement of an emergency.

- $\quad$ The communication systems have provisions for summoning emergency assistance from designated personnel, as discussed in detail in the physical security and emergency plans.

- $\quad$ All TS related to the facility communication systems are acceptable and provide for minimum necessary communication.

\subsection{Possession and Use of Byproduct, Source, and Special Nuclear Material}

\section{Areas of Review}


The operating license for an MSR authorizes the possession and operation of the reactor and the possession of all radioactive material that is a byproduct of that operation. The license also specifies the spaces and areas within the site associated with reactor operations. Licenses granted under 10 CFR Part 50 may also authorize the possession of other specified byproduct and special nuclear material used at the reactor for research and development purposes. Byproduct materials may be used at the licensee facilities or shipped off-site to be used by others under a different license.

For a liquid-fueled reactor, the quantities and concentrations of byproduct, source, and special nuclear material is an integral part of fuel management.

Areas of review should include the following:

- $\quad$ The types and quantities of radionuclides authorized.

- $\quad$ The rooms, spaces, equipment, and procedures to be used.

- $\quad$ The general types of uses, such as research and development, processing, or packaging for shipment.

- $\quad$ The provisions for controlling and disposing of radioactive wastes, including special drains for liquids and chemicals and air exhaust hoods for airborne materials, with design bases derived in Chapter 11 of the SAR.

- $\quad$ The provisions for radiation protection, including shielding materials and radiation survey methods, with design bases derived in Chapter 11.

- $\quad$ The relationship between these auxiliary facility designs and the physical security and emergency plans.

- $\quad$ Required TS and their bases, including testing and surveillance.

\section{Acceptance Criteria}

The acceptance criteria for information on the possession and use of byproduct, source, and special nuclear material under the 10 CFR Part 50 license include the following:

- $\quad$ The design of spaces and equipment and the procedures should ensure that no uncontrolled release of radioactive materials (solid, liquid, or airborne) from the facilities can occur.

- $\quad$ The design and procedures should ensure that personnel exposures to radiation, including ingestion or inhalation, do not exceed limiting values in 10 CFR Part 20, as verified in Chapter 11, and are consistent with the facility ALARA program as described in Chapter 11.

- $\quad$ The design and procedures should ensure compliance with all regulations subsumed within the 10 CFR Part 50 license, such as 10 CFR Parts 30 and 70. 
- $\quad$ The operating procedures for auxiliary facilities should ensure that only radioactive byproducts produced by the reactor are permitted, unless specifically authorized by the 10 CFR Part 50 license or an additional license.

- $\quad$ The facilities should be addressed specifically in the emergency plan, physical security plan, and fire protection provisions, as applicable.

- $\quad$ The proposed TS covering these auxiliary facilities should ensure protection of the health and safety of the public, reactor users, and the environment and the control of licensed byproduct and special nuclear materials.

\section{Review Procedures}

The reviewer should evaluate the five items listed at the beginning of Chapter 9 of the format and content guide for auxiliary systems and facilities that possess or use byproduct material produced in the reactor, source material, or special nuclear material, as allowed by the 10 CFR Part 50 license.

The reviewer should compare the design bases for systems and procedures with the requirements developed in other chapters of the SAR, especially Chapters 11 and 12, "Conduct of Operations;" evaluate the design features against experience with possession and use of radioactive materials at other facilities and laboratories; and evaluate agreement with the acceptance criteria.

An important aspect of the control and use of this material is found in operations and health physics procedures. Although review of the actual procedures is not necessary, the reviewer should examine the basis for the procedures and the method for review and approval of facility procedures described in Chapter 12 of the SAR. In some cases, the reviewer may audit selected procedures as part of the review. Normally, inspectors selectively review procedures as part of the construction and startup inspection process or as part of the ongoing inspection program for existing facilities.

\section{Evaluation Findings}

This section of the SAR should contain sufficient information to support the following types of conclusions, which will be included in the safety evaluation report:

- $\quad$ Auxiliary facilities and systems are designed for the possession and use of byproduct materials produced by the reactor and (if applicable) source and special nuclear material. The design bases include limits on potential personnel exposures that are in compliance with 10 CFR Part 20 and are consistent with the facility ALARA program, as described in Chapter 11.

- $\quad$ To ensure that radiation exposures are acceptably limited, the design features and license conditions specify upper limits on source strengths of radionuclides authorized for possession or use in the auxiliary facilities under the 10 CFR Part 50 license. The applicant has described the authorized spaces for use of the material. 
- $\quad$ Design features and procedures provide reasonable assurance that uncontrolled release of radioactive material to the unrestricted environment will not occur.

- $\quad$ Design features and procedures ensure that the use of byproduct material produced by the reactor and (if applicable) source and special nuclear material and the auxiliary facilities where this material is stored or used is covered by the emergency plan, physical security plan, and fire protection provisions (as applicable).

- $\quad$ TS are proposed that will ensure that the use and possession of byproduct material produced by the reactor and (if applicable) source and special nuclear material and the use of the auxiliary facilities where this material is stored or used will not endanger the health and safety of the public, users, or the environment.

\subsection{Gas Management System}

\section{Areas of Review}

The core of an MSR is a solution of fuel salt within a gas-tight vessel. Therefore, a cover gas system is very important for MSR designs since the fission gas produced during operation is released directly into the Reactor Fuel. Section 4.7, "Gas Management System," covers flow of evolved gases and fission products from their generation in the Vessel to their ultimate release. This section of the SAR should contain the design information on control of the cover gas and all decay heat removal components in the gas management system. The design information should be presented in drawings, diagrams, text, and analysis in sufficient detail for the staff to understand system cooling. Using this information, the staff should determine whether there is reasonable assurance that the gas management system has adequate cooling resources to maintain Fuel System Boundary integrity.

In evaluating the analysis demonstrating these capabilities, the staff should ensure that these criteria can be met for the maximum power density that is considered credible during power oscillations. The applicant should justify the maximum fission product generation rates during power oscillations.

Areas of review should include the following:

- $\quad$ Design bases for the closed systems, addressing the types of gases to be contained, cooled, and controlled in them.

- $\quad$ Systems for assessing and maintaining any required pressure differential between the external atmosphere and the Fuel System Boundary.

- $\quad$ Systems for assessing the required purity or concentrations of the contained gases.

- Systems for removing heat from the gas management system.

- $\quad$ Methods and systems for circulating, processing, decontaminating, recovering, and storing the contained gases. 
- Analyses of the potential effect on reactor safety or operation if the characteristics of the gas mixture are changed, including type of majority gas and concentrations of minority gases.

- $\quad$ Any TS and their bases, including testing and surveillance, required to ensure operability of the gas management systems, if applicable.

\section{Acceptance Criteria}

The acceptance criteria for information on the auxiliary cover gas systems in MSRs include the following:

- $\quad$ The systems should be designed to perform the design-bases functions.

- $\quad$ The systems should be designed to remove decay heat from the gas management system. The analysis should show that the reactor would not be damaged and Fuel System Boundary integrity would not be lost.

- $\quad$ The systems should be designed to ensure the control and detection of leaks so that no uncontrolled release of radioactive material could occur and safe reactor shutdown could not be compromised by the system.

- $\quad$ Cover gases should be processed, recombined, or stored in such a way that the safety of the reactor and personnel is ensured.

- $\quad$ TS and their bases, including surveillances, should be provided as required to ensure system operability.

\section{Review Procedures}

The reviewer should evaluate the five items listed at the beginning of Chapter 9 of the format and content guide for auxiliary systems that provide, cool, and control cover gas for MSRs. The design should be compared with the design bases and with the acceptance criteria.

\section{Evaluation Findings}

This section of the SAR should contain sufficient information to support the following types of conclusions, which will be included in the safety evaluation report:

- $\quad$ The reactor is designed to operate with a gas-tight vessel, and the design of the cover gas control system helps provide that function. The gas management system is designed to prevent the uncontrolled release of radioactive material and interference with safe reactor operation or shutdown.

- $\quad$ The discussion of decay heat removal from the gas management system shows that a credible failure would not lead to loss of Fuel System Boundary integrity. Therefore, the information demonstrates that adequate heat removal mechanisms are available to the gas management system. 
- $\quad$ The gas management system is designed to ensure that the required type of gas, the acceptable concentrations of constituents (including processing, storing, and recombining of reactive gases, as applicable), and the design-basis pressure are maintained.

- $\quad$ TS and their bases that are necessary to protect the health and safety of the public and safe reactor operation have been provided.

\subsection{Cooling Systems}

Among the auxiliary systems that should be addressed are any cooling systems that are part of the licensed facility. Chapter 5, "Molten Salt Reactor Cooling Systems," identifies the following cooling systems that might be associated with a liquid fueled MSR:

- $\quad$ Fuel salt drain tank

- $\quad$ Primary Cooling System drain tank, if applicable

- Gas management system cooling

- $\quad$ Cooling for chemical processing/polishing loop

- $\quad$ Other cooling systems

For each type of cooling system that is part of the facility being licensed, the following review procedures should be followed:

\section{Areas of Review}

The reviewer should determine whether the applicant has addressed the five items listed at the beginning of Chapter 9 of the format and content guide.

\section{Acceptance Criteria}

The acceptance criteria for information on auxiliary cooling systems include the following:

- $\quad$ The design and functional description of the auxiliary cooling system should ensure that it conforms to the design bases.

- The design, functions, and potential malfunctions of the auxiliary cooling system should not cause accidents to the reactor or uncontrolled release of radioactivity.

- In the event radioactive material is released by the operation of an auxiliary cooling system, potential radiation exposures should not exceed the limits of 10 CFR Part 20 and should be consistent with the facility ALARA program.

- $\quad$ No function or malfunction of the auxiliary cooling system should interfere with or prevent safe shutdown of the reactor.

- $\quad$ The TS and bases applicable to an auxiliary cooling system should be provided. 


\section{Review Procedures}

The reviewer should compare the design and functional descriptions of the auxiliary cooling system with the design bases. The reviewer should review the discussion and analyses of the functions and potential malfunctions with respect to safe reactor operation and shutdown, the effect on reactor safety systems, and the potential for the auxiliary cooling system to initiate or affect the uncontrolled release of radioactive material.

\section{Evaluation Findings}

This section of the SAR should contain sufficient information to support the following types of conclusions, which will be included in the safety evaluation report:

- $\quad$ The auxiliary cooling system has been designed to perform the functions required by the design bases.

- $\quad$ Functions and potential malfunctions that could affect reactor operations have been considered in the design of the system. No analyzed functions or malfunctions could initiate a reactor accident, prevent safe reactor shutdown, or initiate uncontrolled release of radioactive material.

- $\quad$ The TS and their bases proposed in the SAR give reasonable assurance that the auxiliary cooling system will be operable, as required by the design bases.

\subsection{Other Auxiliary Systems}

The auxiliary systems addressed in the previous sections are typical examples of systems found at nonpower reactor facilities. As noted at the beginning of this chapter, many MSRs will have additional auxiliary systems and some will have facility-unique systems. Not all possible systems can be adequately addressed here. For other systems, the reviewer should apply the following review and evaluation approach.

\section{Areas of Review}

The reviewer should determine whether the applicant has addressed the five items listed at the beginning of Chapter 9 of the format and content guide.

\section{Acceptance Criteria}

The acceptance criteria for information on additional auxiliary systems include the following:

- $\quad$ The design and functional description of the auxiliary system should ensure that it conforms to the design bases.

- $\quad$ The design, functions, and potential malfunctions of the auxiliary system should not cause accidents to the reactor or uncontrolled release of radioactivity. 
- In the event radioactive material is released by the operation of an auxiliary system, potential radiation exposures should not exceed the limits of 10 CFR Part 20 and should be consistent with the facility ALARA program.

- No function or malfunction of the auxiliary system should interfere with or prevent safe shutdown of the reactor.

- $\quad$ The TS and bases applicable to an auxiliary system should be provided.

\section{Review Procedures}

The reviewer should compare the design and functional descriptions of the additional auxiliary systems with the design bases. The reviewer should review the discussion and analyses of the functions and potential malfunctions with respect to safe reactor operation and shutdown, the effect on reactor safety systems, and the potential for the auxiliary system to initiate or affect the uncontrolled release of radioactive material.

\section{Evaluation Findings}

This section of the SAR should contain sufficient information to support the following types of conclusions, which will be included in the safety evaluation report:

- $\quad$ The system has been designed to perform the functions required by the design bases.

- Functions and potential malfunctions that could affect reactor operations have been considered in the design of the system. No analyzed functions or malfunctions could initiate a reactor accident, prevent safe reactor shutdown, or initiate uncontrolled release of radioactive material.

- $\quad$ The TS and their bases proposed in the SAR give reasonable assurance that the system will be operable, as required by the design bases.

\subsection{References}

1. The Development of Technical Specifications for Research Reactors, ANSI/ANS-15.1R2013, American National Standards Institute/American Nuclear Society, ANS, LaGrange Park, Illinois, 2013. 

APPENDIX E. CHAPTER 11, "RADIATION PROTECTION PROGRAM AND WASTE MANAGEMENT"

-MSR ADAPTATION 



\section{APPENDIX E. CHAPTER 11, “RADIATION PROTECTION PROGRAM AND WASTE MANAGEMENT"-MSR ADAPTATION OF PART 1}

\section{RADIATION PROTECTION PROGRAM AND WASTE MANAGEMENT (Part 1)}

Replace NUREG-1537, Part 1, Chapter 11, in its entirety with the following guidance.

NUREG-1537, Part 1, Chapter 11, of the format and content guide, as augmented by this ISG, is applicable to providing a description of waste management and programs for the licensing of a nonpower molten salt reactor (MSR) facility. Whenever the term MSR or reactor appears, it is understood to mean a nonpower reactor facility.

In this chapter of the SAR, the applicant should discuss and analyze all radiological consequences related to normal operation of the $\mathrm{MSR}^{22}$ facility. In general, the design and function of structures, systems, and components and all facility operations and materials authorized by the operating license should be described in detail in other chapters of the SAR. Chapter 11 should contain the principal discussions of the facility program to control radiation and expected exposures due to operation, maintenance, and use of the reactor. In this chapter, the applicant should develop the methods for quantitative assessment of radiation doses in the restricted, controlled (if present), and unrestricted areas; should apply those methods to all applicable radiation sources related to the full range of operation; should describe the program and provisions for protecting the health and safety of the public (including workers) and the environment; and should provide the bases for analyzing radiological consequences from potential accidents addressed in detail in Chapter 13, "Accident Analyses."

The following glossary contains terms often used when discussing an MSR.

Active Reactor Core: In an MSR, the Vessel region occupied by the fuel salt where the majority of prompt neutrons are generated and where most fissions occur. In an MSR, the core geometry might change with time as a result of changes in density and voiding of the solution. The core does not include the part of the fuel salt that can become entrained into the cover gas.

Coating: Intervening protective layer of material between the corrosive fuel salt and the structural container alloy. Multiple layer configurations are possible (ranging in thickness from $>1 \mathrm{~mm}$, similar to liners used in current LWRs, to $<500 \mathrm{~nm}$, which adhere to the underlying substrate). Also included are embedded coatings, which are chemically resistant material that is embedded into the surface of the structural alloy, allowing surface modification to be performed to the structure to enhance its corrosion resistance.

Control Element(s): Object(s) employed to interact with an MSR's neutron population to adjust reactivity. Control elements can act through fuel displacement, neutron absorption, neutron

\footnotetext{
${ }^{22}$ MSRs are a class of reactors in which a molten salt performs a significant function in the core.
} 
reflection, neutron spectral adjustment, or a combination of these methods. Control elements can be solids, liquids, or gases, and they can be passively or actively positioned.

Emergency Cooling System: System that provides decay heat removal from the Reactor Fuel following an accident (e.g., a direct reactor auxiliary cooling system or a reactor vessel auxiliary cooling system).

Fission Product Barrier: Portion of the Fuel System Boundary in contact with fission products only (e.g., the gas management system boundary).

Fuel Barrier: Portion of the Fuel System Boundary in contact with the fuel salt (principally the Vessel, heat exchanger, control element thimbles, instrumentation thimbles, piping, tanks, and valves).

Fuel System Boundary: All structures that prevent the release of fuel, fission gas, or other fission products. For an MSR, this includes the Vessel, waste-handling tank, pumps, valves, and piping. (Essentially includes the Fission Product Barrier and the Fuel Barrier.)

Heat Dissipation System: Set of components or system(s) that interface with the Primary Cooling System to provide the principal means of transferring the heat from the core to the environment. The Heat Dissipation System might use a variety of coolants (e.g., salt, liquid metal, or water) but does not contain fuel.

Neutron Moderator: In an MSR, materials in or near the core that consist of light elements. Moderators are generally solid form.

Primary Cooling System: Directly interfaces with the Fuel System Boundary at the fuel salt/primary cooling system heat exchanger(s) to provide the principal means of removing heat from the fuel salt by transferring the heat to the Heat Dissipation System. The Primary Cooling System typically contains a salt but does not contain fuel.

Reactor Fuel: In an MSR, fuel salt which consists of fissionable and possibly fertile halide salts, fission products, and generally solvent halide salt(s).

Vessel: For an MSR, structure containing the Active Reactor Core. Other components might reside in the Vessel but outside the Active Reactor Core, such as heat exchangers in certain design configurations.

In accordance with 10 CFR 20.1101, it is the responsibility of the applicant to develop, document, and implement a radiation protection program commensurate with the scope and extent of licensed activities and sufficient to ensure compliance with the regulations in 10 CFR Part 20. To the extent practicable, the applicant should also use procedures and engineering controls based on sound principles of radiation protection to keep doses to occupational workers and members of the public as low as is reasonably achievable (ALARA). 
Waste materials resulting from maintenance, normal operations, or accident conditions at nonpower MSRs $^{23}$ may contain radioactive isotopes. Such wastes are governed by the operating license, and, like other licensed materials, they must be controlled. At a non-power reactor, management and control responsibility for radioactive waste may be assigned to the organization responsible for reactor operations, and the radiation protection organization may provide independent oversight for monitoring, assessing, and limiting risks related to radiation sources. Alternatively, facility management could assign primary responsibility for handling and disposing of radioactive wastes to the organization responsible for radiation protection. In either case, the applicant should require procedures to ensure that radiation exposures and releases of radioactive material are adequately assessed and controlled. The applicant should discuss these issues and submit the information necessary for NRC review. This format and content guide for Chapter 11, of the SAR integrates radioactive waste management and radiological protection in some sections and provides separate sections for some information. The applicant should organize the functions and present the information as best suits the facility consistent with this guide.

Waste management for the MSR has significant differences from conventional light water reactors. In an MSR, fission products are released to the liquid salt fuel solution and contained by the Fuel Barrier. Inherent in the design and operation of the MSR is the need to remove the fission gases for pressure control, high cross section fissions for reactivity control, and other bad actors (corrosion products, noble metals, oxidizers, etc.). An application for a license or an amendment should explain why such fuel cleanup does not constitute separation of special nuclear material.

Gaseous fission products will be gathered and processed within the Fission Product Barrier. The fission gas may require holdup for decay or further treatment before being released to the environment or disposed as waste.

Residue from the cleanup and polishing of the liquid fuel will be laden with fission products and will likely require treatment as radioactive waste. The applicant should address these unique aspects of waste management for the MSR in the manner discussed throughout this chapter, differentiating these cleanup activities from processes that have the potential for separating special nuclear material from the fission product laden liquid fuel.

\subsection{Radiation Protection}

The sections that follow provide guidance on the information the applicant should include in the description of the radiation protection program. The program is applied to the design of the reactor and its equipment, the experimental facilities, reactor operations, design and use of associated laboratories, planning and procedures, and the instrumentation, techniques, and practices employed to verify compliance with the radiation dose limits and other applicable requirements specified in the regulations. Plans and the bases used to develop procedures for assessing and controlling radioactive wastes and the ALARA program should be included. The responsibilities of the health physics organization at the reactor facility, as well as any other

\footnotetext{
${ }^{23}$ There are also salt-cooled reactor designs that propose using fixed-position, coated-particle ceramic fuel. The discussion in this chapter is focused on MSRs operating with liquid fuel.
} 
applicant radiation protection organizations (e.g., under a separate materials license), should be described. Facility organization charts should be included that show independence of the radiation protection function from the facility operations function.

In this chapter, the applicant should address all radiation sources and radioactive materials produced in the reactor and possessed or used within the reactor facility under the authorization of the reactor license. Other byproduct, special nuclear material (SNM), and source material possessed or used under the authorization of the reactor license but not produced by reactor operation should be described. Program details should be given in the sections that follow.

In this section of the SAR, the applicant should propose and justify technical specifications(TS) that constitute important design features, safety limits (SLs), limiting safety system settings (LSSSs), limiting conditions for operation (LCOs), and surveillance requirements (SRs) discussed in Chapter 14 of this format and content guide.

\subsubsection{Radiation Sources}

In this section, the applicant should describe the sources of radiation that are monitored and controlled by the radiation protection and radioactive waste programs. In general, the sources should be categorized as airborne, liquid, or solid as discussed in the sections that follow.

The applicant should include in this description a tabulation of all standard, check, and startup sources categorized by isotopic composition, principal radiations (e g., beta and gamma ray energies, abundance $>10 \%$ ), activity (curie content), neutron characteristics, geometry, physical and chemical form, and whether the source is sealed or unsealed.

The applicant should describe the fuel management program and record keeping of all fissile and fissionable materials, showing the status (fresh, in-use, in interim storage, or spent), original enrichment (including ${ }^{235} \mathrm{U}$ and $\mathrm{U}$ content), and current enrichment (including current ${ }^{235} \mathrm{U}$, total $\mathrm{U}$, and total $\mathrm{Pu}$, if appropriate).

Because of the varied nature of experimental programs, the source strengths of irradiated experimental materials are not necessarily tabulated in an SAR. However, the full range of source strengths expected to be encountered in the experimental program should be listed and discussed. Experimental protocols should provide detailed source data and should be subject to the review of facility operations staff, the health physicist, and, in the case of new experiments and specified deviations from previous experiments, the reactor review or audit committee. In evaluating all experiments, the applicant shall also consider the requirements of 10 CFR 50.59.

Conservative estimates should be made of the quantities and types of radioactive wastes expected to result from reactor operations and use based on previous or other similar reactor facility experience, or previous experimental results. Identification of such wastes should distinguish, if possible, which are associated with the operation of the reactor and which are associated with the utilization of the reactor, if utilization occurs under the reactor license. Nonpower reactor applicants tend to provide overly conservative estimates; although estimates should be conservative, they should also be realistic. 
Where feasible, the applicant should include the physical and chemical form, amounts, use, storage conditions, and locations of all sources. In occupied or accessible areas, conservative estimates of external radiation fields should be given. An estimate of the maximum annual dose and collective doses to workers and the public should be given for major and repetitive activities involving radiation. The applicant should discuss how the requirements of Subpart C of 10 CFR Part 20 (20.1201-20.1208), which contains regulations for occupational dose limits, and Subpart D of 10 CFR Part 20 (20.1301-20.1302), which contains regulations for radiation dose limits for individual members of the public, will be met. Regulations concerning compliance with dose limits for individual members of the public are given in 10 CFR 20.1302. Applicants that have licensed non-power reactors usually have historical information on radiation doses. They should discuss this information.

License conditions and, if applicable, TS, concerning material possession limits, enrichment, material forms, and source strengths should be developed and analyzed in this and other chapters, such as Chapter 4, "Reactor Description," of the SAR. These will control the use of the sources discussed above.

\subsubsection{Airborne Radiation Sources}

Airborne radioactive sources should be described in a manner suitable for designing worker protective measures and assessing and controlling workers' doses. In an MSR there are multiple sources of gaseous radiation to be considered. Gaseous fission products build up in the fission system boundary at a rate proportional to the reactor power level. Since the Reactor Fuel is a liquid the fission gas migrates directly to the gas space above the Vessel and enters the gas management system described in Section 9.6. Volatile actinides and volatile fission products could also migrate into the gas space above the Vessel, yielding entrained radioactive particles or aerosols. Radioactive gases created from neutron activation, such as tritium from the neutron

activation of certain salts or ${ }^{41} \mathrm{Ar}$ from the neutron activation of ${ }^{40} \mathrm{Ar}$ in air, are yet another source of gaseous radiation. Airborne radionuclides are important because they typically are the principal source of radiation exposure to the public from a non-power reactor.

The applicant should summarize in a table the predicted concentrations and quantities of airborne radionuclides during the full range of normal operation (which includes maintenance activities) according to the areas that could be occupied by personnel. The applicant should estimate the release of airborne radionuclides to the environment and should use these releases to determine consequences in the offsite environment. The applicant should discuss compliance with the applicable regulations (10 CFR Part 20 or Part 100 for accident doses at a test reactor). Note that while airborne radioactive sources from accidents are discussed in Chapter 13, the calculational methodologies developed here should be applicable to accident release analysis. Therefore, the models and assumptions used for the prediction and calculation of the dose rates and accumulative doses in both the restricted, controlled (if present), and unrestricted areas should be provided in detail. The guidance that follows gives an example of a description of appropriate methodology as illustrated for argon-41 that is also applicable to any airborne radionuclide, provided both internal and external dose delivery are accounted for. 
The potential for argon-41 production exists at most non-power reactor facilities over the full range of normal operations. Argon-41 is produced when the Ar-40 in air and air in solution in water is activated by neutrons. Argon-41 may be considered a radioactive waste produced by reactor operations. The specific source locations, predicted production rates, release mechanisms and rates, concentrations in occupied areas, possible personnel doses and dose rates, release points from the restricted area, dilution air (quantities and sources), quantities and concentrations predicted to be released, annual average atmospheric conditions, diffusion and dispersion, predicted concentrations in unrestricted areas, and potential dose rates and annual doses, including gamma-ray shine from elevated plumes, should be addressed in detail.

For argon-41, as well as other noble gases at non-power reactors, it is acceptable to assume that all significant radiation risk is from external exposure to beta and gamma radiation. Other radionuclides (e.g., halogens or particulates) could cause internal radiation risk by being ingested or inhaled. All these doses should be addressed, as applicable. The assumptions and methods should be conservative but physically realistic, and the validity of dose calculations should be assessed. Some non-power reactor applicants have used conservative assumptions and methods that have resulted in answers that, although acceptable, are conservative by large factors. The applicant should consider discussing the amount of conservatism built into the calculations. All assumptions should be justified, and sources of information should be adequately referenced. The calculations should address possible doses in the restricted areas, in the controlled areas (if applicable), and in the unrestricted areas. In the unrestricted area, potential doses should be analyzed for the maximally exposed individual, at the location of the nearest permanent residence, and at any locations of special interest, such as a classroom or a campus dormitory. Due care should be taken if finite or non-uniform airborne distributions are intermingled with infinite cloud approximations within buildings or in idealized gaussian plumes. Any such intermingling of models or assumptions should be justified. Similar discussions in this paragraph of the SAR should address the production of airborne particulates, aerosols, vapors, and nitrogen-16 or other radionuclides. While tritium, argon-41, and nitrogen-16 are used as examples to discuss the calculation of radiation dose from gaseous releases, some sources may be found to be negligible when compared to the fission gas in an MSR of moderate power level.

The discussion and calculations should show how the facility design ensures that doses to the facility staff and the public will not exceed 10 CFR Part 20 limits and that its ALARA requirements for effluents are satisfied.

\subsubsection{Liquid Radioactive Sources}

The applicant should identify all expected liquid radioactive sources, such as fuel salt, coolant salt, experimental solutions, reference sources, and fissile material. The applicant should identify their origin and should specify whether they result from reactor operations or the utilization program or whether they exist for special purposes. Information should include radionuclides, concentrations, total curie strength, solubility, container characteristics, and planned release or disposition. Liquid radioactive wastes should be included. However, since the types of such wastes, their origins, and the source strengths will vary with time and with the nature of the utilization program, only limited descriptions of liquid wastes should be provided. The applicant should estimate the quantity of liquid effluent released to the unrestricted environment. The 
applicant should discuss if credit is taken for dilution preceding release. The applicant should discuss compliance with the applicable sections of 10 CFR Part 20, such as.10 CFR 20.2003 and any disposal of licensed material approved under 10 CFR 20.2002. Any storage or disposal facilities should be noted, with reference to their management and use and the design basis of their radiation protection capabilities.

\subsubsection{Solid Radioactive Sources}

The applicant should identify all expected solid radioactive sources, such as Reactor Fuel (spent, in-core, and fresh), calibration and test sources, experiment samples, and facility components. The information should include, among other things, radionuclides, curie strengths, and physical characteristics and whether the source is sealed or unsealed. Solid radioactive waste should be noted, but because the types and quantities will vary with time and the utilization program, only limited descriptions of solid wastes need be provided. Provisions for classifying, monitoring, storing, packaging, volume reduction prior to shipment, and disposing of solid radioactive wastes should be discussed. The applicant should estimate the annual volume of solid waste expected to be removed from the site and its radioactive content (in curies). The applicant should discuss compliance with applicable sections of 10 CFR Parts 20, 61, and 71, and Department of Transportation regulations (49 CFR) for transporting radioactive material.

The applicant should discuss any capabilities or approvals received under NRC or State material licenses for onsite or offsite storage of solid radioactive wastes, including how the necessary characteristics of a restricted area are maintained. The applicant should discuss any disposal of licensed material approved under 10 CFR 20.2002.

This section should contain the design bases for temporary, permanent, and installed shielding components at the facility, including utilization, laboratory facilities, and radiation beams.

The following areas of the facility should be examined when developing the program for inventory and control of radiation sources:

- $\quad$ the exterior of the reactor biological shielding and reactor auxiliary locations (e.g., primary coolant system components and demineralizers) accessible to personnel

- the reactor experimental facilities, including beam ports, thermal columns, pneumatic or hydraulic transfer facilities, and all other irradiation facilities

- the radioactive material handling, preparation, packaging, and utilization facilities, including laboratories, hot cells, caves, and storage and processing areas

- $\quad$ other extraneous sources, including, for example, neutron and gamma irradiation facilities, check and standard sources, neutron sources, fuel handling and storage facilities, experimental equipment storage facilities, and radioactive waste handling and storage facilities 


\subsubsection{Radiation Protection Program}

In this section, the applicant should describe the structure of the organization that administers the radiation protection program required by 10 CFR 20.1101, including information about staffing levels, positions of authority and responsibility, and position qualifications. Working relationships with other safety organizations, including the reactor facility operations staff, should be described. The applicant should discuss the charters, standards, procedures, and other documents that specify the authority and responsibilities of the organization, including authority to interdict perceived unsafe practices. The administrative plans and procedures that implement the facility policy, the overall program, and the way the organization, policy, and program are designed for effective operation should be discussed. In this discussion, the applicant should describe the management policy governing the program and the allocation of policymaking responsibilities. Reference can be made to Chapter 12, "Conduct of Operations," if such information appears there.

The information should include the document control measures employed to ensure that the plans and procedures relative to the radiation protection program, including changes, are reviewed for adequacy, approved by authorized personnel, and distributed to and used by the applicable staff at the locations where radiation exposures could be encountered.

The radiation safety training program should be described in detail. This discussion should give the scope, and a summary of the content, of the training provided or required for all personnel, including facility-employed personnel health physics personnel, non-facility-employed research and service personnel, visitors, and security, fire, and other emergency personnel.

The applicant should describe the purpose, organization, and functions of any review and audit committees with responsibilities relating to radiation safety, including the charter, frequency of meetings, audits, scope of any reviews, and qualifications and requirements for committee members. The applicant should, describe how each committee's work relates to the radiation safety organization and how a comprehensive program is ensured. If this information is discussed in Chapter 12, it can be referenced here.

The program for conducting facility radiation safety audits of all functional elements of the radiation protection program to meet the requirements of 10 CFR 20.1 101(c) should be described, identifying the scope of the audits, the bases for scheduling the audits, the qualifications of the auditors, the management level to which reports are sent, and the process for following up on audit findings. The relationship of this program to any other selfassessment/internal appraisal program should be discussed. The bases for TS related to facility radiation safety audits should be provided.

The system that examines the experiences of the radiation protection program and uses these experiences to improve the program and the facility design for irradiation protection should be described. This system should also examine problem and incidents and develop "lessons learned," root causes, and effective corrective actions. 
For activities not described in the SAR or not governed by procedures, a work control process such as the use of radiation work permits should be used. The applicant should discuss the control program used at the facility.

The applicant should describe the recordkeeping process for the radiation safety program, including record-retention periods, accessibility, review, and archiving. Review of radiation safety records for accuracy and validity should be discussed. The use of records for developing trend analyses, informing management, planning radiation-related actions, and reporting to regulatory and other duly authorized entities should be discussed.

\subsubsection{ALARA Program}

In this section, the applicant should describe the ALARA program for the facility required by 10 CFR 20.1101. The description should include the basis for the program and the management level and authority by which the facility ALARA policy is established. The applicant should discuss how this program is implemented to maintain radiological doses of all personnel at the facility and releases of effluents to the unrestricted area ALARA. The applicant should discuss the criteria used to determine how low the projected doses should be to permit task implementation (i.e., ALARA goals). The discussion should include methods to ensure that the radiation protection staff, with their considerations of the facility ALARA program, is specifically involved during review and approval of design, in construction of facilities, in the planning and implementing of reactor utilization (experiment design and planning) and operation, in maintenance activities, and in the management and disposition of radioactive wastes.

\subsubsection{Radiation Monitoring and Surveying}

The program employed to routinely monitor workplaces and other locations accessible to people for identification and control of sources of radiation exposure should be described in this section, including the measures designed to ensure that air, liquids, and solids are monitored in all applicable areas. The applicant should also discuss the bases of the methods and procedures used for detecting and assessing contaminated areas, materials, and components, and should describe the records that document the applicability, quality, and accuracy of monitoring methods, techniques, and procedures.

The applicant should provide summary descriptions of all radiation monitoring equipment employed throughout the facility, including locations and functions of each device and system. This summary should also describe sampling equipment for liquid and gaseous process and effluent streams. This discussion may be combined with (and appropriately cross-referenced to) the discussions in Chapter 7, "Instrumentation and Control Systems." The applicant should discuss the interface between the radiation monitoring system and engineered safety features discussed in Chapter 6, "Engineered Safety Features," if any exist. Types of equipment should include systems of the following types (as appropriate to the facility):

- $\quad$ continuous air monitors (CAMs), including fixed and moving filter, and gaseous monitors 
- $\quad$ portable survey instruments (radiation fields and contamination)

- $\quad$ remote area monitors (RAMs)

- $\quad$ samplers

- $\quad$ effluent monitors

- $\quad$ environmental monitors (details should appear in Section 111.7)

- $\quad$ personal dosimeters

- portal monitors,

- $\quad$ radwaste storage monitors

- $\quad$ criticality monitors

The calibration of radiation protection instrumentation, including the procedures and standards governing calibration, control of the calibration process, use of national standards, and verification should be described. In this section, the applicant should also describe the calibration equipment and discuss sensitivities to environmental and other conditions with respect to the calibration requirements. The program to ensure that routine periodic calibration is performed in a timely manner and the bases of calibration schedules should be described.

The applicant should describe how routine monitoring provided at the facility is planned to ensure that radiation exposures to the public and workers or material releases can be detected and should discuss how the approach used for routine monitoring provides reasonable assurance that all radiation at, and released from, the site will be appropriately monitored.

Technical specifications and their bases related to the radiation monitoring equipment and procedures, as discussed in Chapter 14, "Technical Specifications," should be justified in this section.

\subsubsection{Radiation Exposure Control and Dosimetry}

Radiation exposure is controlled by controlling radioactive materials and effluent radioactive material releases. In this section of the SAR, the applicant should describe the design bases for the equipment and procedures utilized for controlling exposures to personnel and releases of radioactive materials from the facility, and should discuss how the facility structures, systems, and components are designed to provide assurance that there will be no uncontrolled effluent radioactive releases to the environment or to work areas. Some systems, such as containment, confinement, and ventilation, may have been discussed in other chapters of the SAR; reference to those discussions in this chapter of the SAR is appropriate. The applicant should also discuss how the bases of radiation shielding, ventilation, and remote handling and decontamination 
equipment are designed to ensure that doses to the workers are maintained ALARA and within the applicable regulatory limits.

How the design of required entry control devices (i.e., alarms, signals, or locked entry ways) alerts workers to, or prevents entry into, high radiation and very high radiation areas should be described. The regulations in 10 CFR Part 20, Subpart G, "Control of Exposure from External Sources in Restricted Areas," contain requirements for control of access to high and very high radiation areas. It should be noted that 10 CFR 20.1601(c) allows a licensee to apply to the Commission for approval of alternative methods for controlling access to high radiation areas if the licensee finds that the stated methods of control in the regulations would interfere with utilization programs. The application should contain a description of the proposed method along with a discussion of how the entrance or access point to high radiation areas will be controlled.

Equipment and materials (e.g., anti-contamination clothing and respiratory protection equipment) to protect personnel employed in the facility should be discussed. The applicant should describe the facility conditions for which this protective equipment should be employed and should also discuss whether respirators should be used at the facility. The use of respiratory protection equipment requires implementing and maintaining a respiratory protection program in accordance with the requirements of 10 CFR 20, Subpart $\mathrm{H}$. If a respiratory protection program will be maintained, that program should be described as it relates to the minimum program requirements of $10 \mathrm{CFR} 20.1703$.

The bases and values for the expected annual radiation exposure for all locations of the facility should be discussed, including the exposure estimates for applicant-employed personnel, nonapplicant-employed research and service personnel, and visitors. This discussion should include the exposure limits and controls for such groups as embryos, fetuses, declared pregnant women, minors, and students. The plans and procedures for exposure control and dosimetry during the fill range of normal facility operations, potential accident conditions, rescue and recovery, and planned special personnel exposures (non-emergency) should also be discussed. The applicant should describe the dosimetry used for assessing external radiation exposures (e.g., whole body, extremities), including the frequency of dosimeter readings, administrative dose action levels, and the suitability of the dosimetry chosen with respect to the radiation sources anticipated and observed. The same factors for how internal exposures and doses are assessed, evaluated, and controlled should be described.

The applicant should describe the type of records retained to document the conditions under which individuals were exposed to radiation. The applicant should discuss the historical and current exposures to personnel and the associated trends.

\subsubsection{Contamination Control}

The applicant should discuss the plans and bases of procedures for identifying and controlling radioactive contamination, including methods established to assess the effectiveness of the contamination control program. The discussion should include information on the following topics, showing their relationship to regulatory requirements and ALARA concepts: 
- $\quad$ program for routine monitoring to detect and identify fixed and loose contamination

- programs to control access to contaminated areas, avoid further spread of contamination, and remedy contaminated areas

- $\quad$ personal monitoring and assessment of internal and external doses to personnel occupying or entering contaminated areas, and methods for appropriate surveying and "frisking" upon exit

- use of anti-contamination techniques to protect workers, and control and disposition of possibly contaminated clothing and materials

- $\quad$ procedures for monitoring and handling contaminated equipment and components outside of contaminated areas that have not been decontaminated

- $\quad$ criteria for classifying contaminated material, equipment, and working areas, and managing, controlling, storing, and disposing of identified contamination

- $\quad$ training programs for staff and visitors on the risks of contamination and on techniques for avoiding, limiting, and controlling contamination

- $\quad$ recordkeeping for contamination events, both for personnel and for locations, including records to be available for facility maintenance and for eventual decommissioning

- $\quad$ the bases of TS if needed, applicable to contamination control: for example, limits on storage and handling of radioactive sources, especially unsealed ones; limitations on encapsulation of irradiated materials; and use of fume hoods and hot-waste drains

\subsubsection{Environmental Monitoring}

The applicant should describe the environmental monitoring program, including information relating to the following:

- $\quad$ verification of compliance with commitments made in environmental reports, or other documents, if applicable; discussion of any standards used in the environmental monitoring program

- for established programs, evaluation of the effectiveness of the program

- identification of potential facility impacts on the environment and the evaluation of the need for remedial action or mitigation measures

- $\quad$ establishment of baselines for environmental quality, including data comparing preconstruction or preoperational with operational environmental monitoring results 
The applicant should describe the written plans and the bases of procedures for implementing the environmental monitoring program and should discuss the document control measures employed to ensure that the plans and procedures, including changes, are reviewed for adequacy and approved by authorized personnel, and are distributed to and used at the appropriate locations throughout the facility.

The environmental surveillance program and its bases should be described. Air, water, and land environments should be specifically discussed. These discussions should include information on at least the following topics:

- $\quad$ probable facility-related contaminants and pathways to people

- $\quad$ selection of sampling materials and locations

- $\quad$ sample analyses (analytical techniques) and sensitivities (detection limits)

- $\quad$ records of results and trends

\subsection{Radioactive Waste Management}

The applicant should address the five factors for analyzing the safety of auxiliary systems stated in the beginning of Chapter 9, applying those factors to stored waste and fuel, assuring chemical and nuclear stability for long term storage. Phenomena such as heat-induced recombination resulting in positive reactivity addition or the release and required management of tritium should be addressed.

In this section of the SAR, the applicant should propose and justify TS that constitute important design features, SLs, LSSSs, LCOs, and SRs discussed in Chapter 14 of this format and content guide.

Each facility that is licensed to operate or utilize a non-power reactor should establish a program and procedures that are designed to ensure that radioactive waste materials are identified, assessed, controlled, and disposed of in conformance with all applicable regulations and in a manner to protect the health and safety of the public and the environment. The magnitude and nature of the effort required should depend upon the size and complexity of both the reactor facility and its utilization programs. Therefore, the nature and details of the radioactive waste management program should also be commensurate with those factors. As noted previously, management of radioactive wastes could be an auxiliary function assigned to existing personnel, such as people engaged in radiation protection or operations. Earlier sections of this chapter have addressed the program and procedures for controlling and assessing radiation exposures and doses at the facility due to all radiation and radioactive sources. In this section, the applicant should address the program and procedures for further managing sources classified as radioactive waste. 


\subsubsection{Radioactive Waste Management Program}

The applicant should address the five factors for analyzing the safety of auxiliary systems stated in the beginning of Chapter 9, applying those factors to stored waste and fuel, assuring chemical and nuclear stability for long term storage. Phenomena such as heat-induced recombination resulting in positive reactivity addition or the release and management of tritium should be addressed.

In this section, the applicant should discuss the philosophy and objectives of the program for managing radioactive waste. The applicant should describe the organizational structure within which it will administer the reactor-related radioactive waste management program, including the organization and staffing levels, authorities and responsibilities and position qualifications. The working relationships between such facility organizations as radiation protection and operations staff, and the standards, charters, procedures, or other documents that specify the authority, duties, and responsibilities of the personnel in the radioactive waste management organization should be discussed. The policy governing the program, the allocation of policymaking responsibilities, and the administrative plans and procedures that implement the facility policy should be described. The overall program and how the organization, policy, and program lead to effective management of radioactive waste should be evaluated and described.

The applicant should describe the purpose, organization, and functions of any committee's assigned responsibility for overseeing radioactive waste management. The description should include each committee's charter, responsibilities, frequency of meetings, audit and review responsibilities, scope of any audits or reviews, and qualifications and requirements for committee members. How each committee's work relates to the waste management organization and how they work together should be discussed. If this information has already been described, reference that discussion.

The applicant should describe the waste management training program. This description should include the scope of facility waste management training, as well as specific training requirements for personnel associated with the operation and use of the facility.

The applicant should describe the document control measures that ensure that the plans and procedures involving radioactive waste, including changes, are reviewed for applicability, approved by authorized personnel, and distributed to and used at the locations where waste management activities are conducted.

The applicant should describe the scope of waste management reviews and audits. This description should include the authority of waste management review and audit teams, the objectives and purposes of reviews and audits, and the bases for scheduling these reviews and audits.

The applicant should describe the radioactive waste management recordkeeping process, including retention periods, accessibility, review, and archiving, and should discuss any special review of waste management records for accuracy and validity. Records of radioactive wastes stored for the life of the facility or buried on site should be discussed, as well as records for trend 
analysis. The bases for any TS related to the radioactive waste management program should be described.

\subsubsection{Radioactive Waste Controls}

The applicant should discuss the definition of radioactive waste, the point in any process that a radioactive component or material becomes classified as waste, and the criteria for defining such waste. The applicant should describe the waste management program procedures which ensure that radioactive wastes are identified and characterized appropriately, as noted above, and the bases of the procedures which ensure that radioactive wastes are adequately segregated from nonradioactive wastes. The plans and procedures for managing all forms of radioactive wastes generated during operations, research, and utilization of the reactor should be described. Since radioactive wastes are radiation sources, they should be described, along with other such sources, in Section 11.1 of the SAR.

The applicant should be particularly vigilant of terminology that could confuse the process of waste removal with the production of special nuclear material. Some non-power reactor licenses do not allow the "separation of isotopes" or the "separation of byproduct materials" to enforce regulations dealing with the separation of plutonium or the enrichment of uranium-233 or uranium-235 to produce special nuclear material. In the strictest sense of the word that could be interpreted as not allowing the removal of wastes from MSR liquid fueled cores. Fission gases do this inherently by simply rising from the liquid. Other undesired fission products are removed from the liquid fuel by waste treatment processes with no intention of producing special nuclear material. The applicant should first clearly describe waste treatment processes as such and second, request that non-ambiguous terms be used in the license.

The applicant should include in the safety analysis consideration that when using conventional waste treatment systems for an MSR there may be criticality concerns in the accident analysis, during normal operation, or both. If so, the applicable provisions of 10 CFR Part 70.24 should be met.

The applicant should describe the plans and bases for procedures for managing gaseous and other airborne radioactive wastes generated during operations, research, and utilization of the reactor, and radioactive waste off-gas collection systems designed to be utilized at the facility. The function and the location of each off-gas collection system should be described. At many nonpower reactors, the system for removing gaseous radioactive waste is integral to the ventilation system for the facility and may have engineered safety functions. If these systems have been described in other chapters of the SAR, reference may be made here to those discussions. For all off-gas and ventilation systems, the applicant should describe the wastes produced by operation of the systems. Such items as filters and scrubbers, which collect and concentrate wastes, should be discussed to indicate the disposition of the radioactive material upon regeneration or replacement. If the radioactive materials enter other waste treatment systems, the applicant should indicate how such transfers are made and note any possible chemical or radiological effects of the transfer. The operation of any gas-cleaning equipment and its designed performance should be discussed in this section. The bases of any applicable TS that control these functions should be given. Also, the applicant should describe all secondary radioactive 
residues that are generated during process treatment, their chemical and physical composition, and the modes for handling, controlling, and storing them.

The applicant should describe how liquid radioactive wastes are generated and where they enter the waste control and treatment systems. Such items as laboratory wastes, liquid spills, and cleanup solutions, including detergent wastes, should be discussed. Information about the projected inventory levels, interim and long-term storage, and processing of those streams to achieve volume reduction or solidification should be included. This discussion should include information about fuel salt cleanup systems and resin regeneration solutions and wastes, if applicable.

The objectives of the processes designed to treat radioactive or mixed liquid wastes should be described. Any backup and special safety features designed to ensure that the radioactive waste is contained during treatment should be described. The designed equipment and systems should be described, and appropriate engineering drawings to show the location of the equipment, flow paths, piping, valves, instrumentation, and other physical features, should be included, along with information on all features, systems, or special handling techniques that prevent uncontrolled releases or personnel exposures.

The applicant should describe the plans and procedures for managing solid radioactive wastes generated during operations, research, and utilization of the reactor. This description should include how solid radioactive materials are generated and where they enter the waste control and treatment systems. For solid radioactive wastes retained or stored on site for the life of the facility, the applicant should discuss the control methods used. Integrity and corrosion characteristics and the monitoring of the containment should be discussed, as well as the plan for disposing of these radioactive wastes when the facility is permanently decommissioned.

The applicant should describe the systems and equipment selected for identifying, segregating, and safely managing the solid, liquid, and gaseous radioactive waste that is generated, and should include appropriate engineering drawings showing the location of the equipment and associated features used for volume reduction, containment, and/or packaging, storage, and disposal The applicant should also discuss the bases of procedures associated with operating treatment equipment, including performance tests, process limits, and the means for monitoring and controlling to meet these limits. The bases of applicable TS that control these procedures and functions should be discussed. The methods and agents planned for all activities involving routine disposal or release to the environment of radioactive wastes generated in the facility should be described, as should methods used for packaging and shipping solid and liquid radioactive wastes to other facilities or other means for processing, storage, or other disposition.

The applicant should describe the program for minimizing radioactive waste for the facility with respect to the following topics: (1) the specific numerical goals for reducing the volume or radioactivity of each waste stream; (2) the periodic assessments of reactor operations and experimental or utilization activities to identify opportunities to reduce or eliminate the generation of wastes; (3) the continuing efforts to identify and, where cost effective, implement waste reduction technologies; and (4) any periodic independent reviews performed to evaluate the effectiveness of programs to minimize radioactive waste. 


\subsubsection{Release of Radioactive Waste}

The applicant should identify all radioactive waste materials for which controlled release to the environment or transfer to other parties for disposal is planned. This discussion should include the projected concentrations, forms, chemical compositions, and annual quantities of radioactive waste released under normal operating conditions.

All points from which radioactive waste effluents are designed to be released from the facility to the environment should be identified, using a site map to locate the effluent release points and effluent monitoring equipment. Discussions and detailed analyses of potential radiological impact of radioactive waste effluents and the bases for continuous or intermittent monitoring should be provided in the earlier sections of Chapter 11. For liquid releases to the sanitary sewerage, the applicant shall ensure that the requirements of 10 CFR 20.2003 are met. The applicant should describe the systems and procedures designed to ensure that doses resulting from releases of radioactive effluents do not exceed applicable regulatory limits and ALARA goals.

\subsection{Respiratory Protection Program}

The applicant should describe how it plans to meet the requirements of 10 CFR Part 20 Subpart $\mathrm{H}$, Respiratory Protection and Controls to Restrict Internal Exposure in Restricted Areas by one of three methods.

- $\quad$ Pursuant to 10 CFR 20.1701 and in conjunction with ventilation equipment described in Chapter 9, "Auxiliary Equipment."

- $\quad$ Pursuant to 10 CFR 20.1702 and in conjunction with the use of other controls as discussed in this section or as referenced in this section and discussed elsewhere in the application.

- $\quad$ Pursuant to 10 CFR 20.1703 and in conjunction with individual respiratory protection equipment used and maintained under a program described in this section of the application and in compliance with 10 CFR 20.1703.

\subsection{References}

American National Standards Institute/American Nuclear Society, ANSI/ANS 15.7, "Research Reactor Site Evaluation," ANS, LaGrange Park, Illinois, 1977.

American National Standards Institute/American Nuclear Society, ANSI/ANS 15.11, "Radiation Protection at Research Reactor Facilities," ANS, LaGrange Park, Illinois, 1993.

American National Standards Institute/American Nuclear Society, ANSI/ANS 15.19, "Shipment and Receipt of Special Nuclear Material by Research Reactor Facilities," ANS, LaGrange Park, Illinois, 1991. 
Code of Federal Regulations, Title 10, "Energy," and Title 49, "Transportation," US Government Printing Office, Washington, D.C., revised periodically.

US Nuclear Regulatory Commission, NUREG-0851, "Nomograms for Evaluation of Doses from Finite Noble Gas Clouds,” January 1983.

US Nuclear Regulatory Commission, NUREG/CR-2260, “Technical Basis for RG 1.145,” 1981.

US Nuclear Regulatory Commission, Regulatory Guide 1.109, "Calculation of Annual Doses to Man from Routine Releases of Reactor Effluents.”

US Nuclear Regulatory Commission, Regulatory Guide 1.145, "Atmospheric Dispersion Models for Potential Accident Consequence Assessments at Nuclear Power Plants."

US Nuclear Regulatory Commission, Regulatory Guide 8.9, "Acceptable Concepts, Models, Equations, and Assumptions for a Bioassay Program."

US Nuclear Regulatory Commission, Regulatory Guide 8.9, proposed Revision 1, "Interpretation of Bioassay Measurements," Task DG-8009.

US Nuclear Regulatory Commission, Regulatory Guide 8.10, "Operating Philosophy for Maintaining Operational Exposures As Low As Is Reasonably Achievable."

US Nuclear Regulatory Commission, Regulatory Guide 8.13, Revision 3, "Instructions Concerning Prenatal Radiation Exposure."

US Nuclear Regulatory Commission, Regulatory Guide 8.29, "Instruction Concerning Risks from Occupational Radiation Exposure.”

US Nuclear Regulatory Commission, Regulatory Guide 8.29, proposed Revision 1, "Instruction Concerning Risks from Occupational Radiation Exposure," Task DG-8012.

US Nuclear Regulatory Commission, Regulatory Guide 8.37, "ALARA Levels for Effluents from Materials Facilities." 


\section{APPENDIX E. CHAPTER 11, "RADIATION PROTECTION PROGRAM AND WASTE MANAGEMENT"-MSR ADAPTATION OF PART 2}

\section{RADIATION PROTECTION PROGRAM AND WASTE MANAGEMENT (Part 2)}

Replace NUREG-1537, Part 2, Chapter 11, in its entirety with the following guidance.

NUREG-1537, Part 2, Chapter 11, of the standard review plan and acceptance criteria, as augmented by this ISG, is applicable to reviewing a description of waste management and programs for the licensing of a nonpower molten salt reactor (MSR) facility. Whenever the term $M S R$ or reactor appears, it is understood to mean a nonpower reactor facility.

This chapter provides guidance for the review and evaluation of Chapter 11 of the applicant's SAR, which should contain information about radiation protection and radioactive waste management provisions at the $\mathrm{MSR}^{24}$ facility. Information should include radiological design bases of the reactor structures, systems, components, experimental facilities, and laboratories under the reactor license; procedures, policies, and practices employed to ensure compliance with applicable standards and regulations on radiation doses and protection; procedures, policies, and practices to ensure that radioactive wastes are managed in compliance with applicable regulations and standards; and the program to keep radiation exposure at the facility as low as is reasonably achievable (ALARA). The responsibilities of the health physics organization at the reactor facility and of any other onsite radiation protection and radioactive waste management organizations should also be described. Throughout this chapter, the applicant should show that licensed activities will be conducted in compliance with applicable regulations, with emphasis on 10 CFR Part 20.

The following glossary contains terms often used when discussing an MSR.

Active Reactor Core: In an MSR, the Vessel region occupied by the fuel salt where the majority of prompt neutrons are generated and where most fissions occur. In an MSR, the core geometry might change with time as a result of changes in density and voiding of the solution. The core does not include the part of the fuel salt that can become entrained into the cover gas.

Coating: Intervening protective layer of material between the corrosive fuel salt and the structural container alloy. Multiple layer configurations are possible (ranging in thickness from $>1 \mathrm{~mm}$, similar to liners used in current LWRs, to $<500 \mathrm{~nm}$, which adhere to the underlying substrate). Also included are embedded coatings, which are chemically resistant material that is embedded into the surface of the structural alloy, allowing surface modification to be performed to the structure to enhance its corrosion resistance.

Control Element(s): Object(s) employed to interact with an MSR's neutron population to adjust reactivity. Control elements can act through fuel displacement, neutron absorption, neutron

\footnotetext{
${ }^{24}$ MSRs are a class of reactors in which a molten salt performs a significant function in the core.
} 
reflection, neutron spectral adjustment, or a combination of these methods. Control elements can be solids, liquids, or gases, and they can be passively or actively positioned.

Emergency Cooling System: System that provides decay heat removal from the Reactor Fuel following an accident (e.g., a direct reactor auxiliary cooling system or a reactor vessel auxiliary cooling system).

Fission Product Barrier: Portion of the Fuel System Boundary in contact with fission products only (e.g., the gas management system boundary).

Fuel Barrier: Portion of the Fuel System Boundary in contact with the fuel salt (principally the Vessel, heat exchanger, control element thimbles, instrumentation thimbles, piping, tanks, and valves).

Fuel System Boundary: All structures that prevent the release of fuel, fission gas, or other fission products. For an MSR, this includes the Vessel, waste-handling tank, pumps, valves, and piping. (Essentially includes the Fission Product Barrier and the Fuel Barrier.)

Heat Dissipation System: Set of components or system(s) that interface with the Primary Cooling System to provide the principal means of transferring the heat from the core to the environment. The Heat Dissipation System might use a variety of coolants (e.g., salt, liquid metal, or water) but does not contain fuel.

Neutron Moderator: In an MSR, materials in or near the core that consist of light elements. Moderators are generally solid form.

Primary Cooling System: Directly interfaces with the Fuel System Boundary at the fuel salt/primary cooling system heat exchanger(s) to provide the principal means of removing heat from the fuel salt by transferring the heat to the Heat Dissipation System. The Primary Cooling System typically contains a salt but does not contain fuel.

Reactor Fuel: In an MSR, fuel salt which consists of fissionable and possibly fertile halide salts, fission products, and generally solvent halide salt(s).

Vessel: For an MSR, structure containing the Active Reactor Core. Other components might reside in the Vessel but outside the Active Reactor Core, such as heat exchangers in certain design configurations.

This chapter should address all radioactive materials and radiation sources that are produced in the reactor or used within the reactor facility and that are possessed under the authority of the reactor operating license. Radioactive standards, check sources, and other byproduct material used in the reactor program, reactor startup sources, fuel and other special nuclear material, and source material that may be under the authority of the reactor license should be included.

The complexity of reactor facilities will vary widely from one non-power reactor to another, as will the risks due to radiation. Furthermore, a non-power reactor facility may be only a small 
component of a large organization, such as a university or corporation, and could obtain its radiation protection and radioactive waste management services from other parts of the organization. Therefore, the scope and magnitude of the radiation protection and radioactive waste management programs should be expected to vary and may be found acceptable as long as the program is consistent with a uniform requirement to adequately protect the health and safety of the public.

In some places in this chapter, reference is made to conservative best estimates or conservative but realistic calculations. This means that estimates or calculations performed by the applicant should always give results that are conservative. However, the applicant should try to avoid such large levels of conservatism that results are orders of magnitude from the expected true answer. In some cases, non-power reactor applicants have used assumptions or calculation methods that have produced very conservative, but acceptable results. Subsequently, regulatory requirements changed, or the applicant made changes to the facility or utilization program that resulted in these conservative results being unacceptable. At that point, the applicant had to perform an analysis with assumptions and calculational methods that were more realistic to demonstrate compliance with regulatory requirements, and also had to explain the conservatism in the original analysis.

In this chapter of the SAR, the applicant should discuss the capabilities of the reactor facility to control, collect, handle, process, store for short or long periods, and dispose of liquid, gaseous, and solid radioactive wastes related to reactor operations and utilization in a manner planned to protect the public, the environment, and facility staff. The instrumentation and methods used to monitor radiation exposures to personnel and the release of radioactive materials, including sampling methods, should be discussed by the applicant.

Waste management for the $\mathrm{MSR}^{25}$ has significant differences from conventional water reactors. In an MSR, fission products are released to the liquid salt fuel solution and contained by the Fuel Barrier. Gaseous fission products will be gathered and processed within the Fission Product Barrier. The fission gas may require holdup for decay or further treatment before being released to the environment or disposed as waste. Residue from the cleanup and polishing of the liquid fuel will be laden with fission products and will likely require treatment as radioactive waste.

\subsection{Radiation Protection}

The provisions for radiation protection should be described completely in the sections that follow.

\subsubsection{Radiation Sources}

\section{Areas of Review}

To develop a comprehensive radiation protection program, it is important to understand all sources of radiation exposure at the facility Therefore, the applicant should provide complete

\footnotetext{
${ }^{25}$ There are also salt-cooled reactor designs that propose using fixed-position, coated-particle ceramic fuel. The discussion in this chapter is focused on MSRs operating with liquid fuel.
} 
listings and discussion of all expected radiation and radioactive sources. The reviewer should evaluate information requested of the applicant in the corresponding section of the format and content guide. As indicated there, airborne, liquid, and solid sources, including radioactive wastes, should be discussed.

\section{Acceptance Criteria}

The acceptance criteria for the information concerning sources of radiation include the following:

- $\quad$ All sources of radiation should be discussed by the applicant. This discussion should include the physical and chemical form, type (e.g., neutron, gamma), curie strength or exposure rates, energy level, encapsulation (sealed or unsealed), use, storage conditions and locations, and planned program for disposal of all radioactive material subject to the reactor license.

- $\quad$ The applicant should present the best estimates of the maximum annual dose and the collective doses for major radiological activities during the full range of normal operations for facility staff and members of the public. The doses shall be shown to be within the applicable limits of 10 CFR Part 20.

- $\quad$ Airborne radioactive material sources should be described in sufficient detail to provide the bases for the design and assessment of structures, systems, and components, and of personnel protective measures and dose commitments.

- $\quad$ Conservative best estimates of the predicted concentrations, locations, and quantities of airborne radionuclides during the full range of normal operation in areas occupied by personnel should be discussed.

- $\quad$ Conservative best estimates of the predicted locations and magnitude of external radiation fields during the full range of normal operation in areas occupied by or accessible to personnel should be discussed.

- $\quad$ The applicant should identify models and assumptions that are used for predicting and calculating the dose rates and accumulative doses from traditional gaseous radionuclides such as tritium, ${ }^{41} \mathrm{Ar},{ }^{16} \mathrm{~N}$, and vapors, aerosols, and airborne radioactive particulates in both restricted, controlled (if present), and unrestricted areas. The applicant should identify (1) locations of specific sources (e.g., fuel salt, coolant salt, beam tubes, and gasor air-driven rabbit systems), (2) expected production rates, release rates, and concentration distributions in occupied areas and resultant personnel doses or dose rates, and (3) release points from the control of the reactor facility, dilution air (quantities and sources), quantities and concentrations expected to be released, dispersion and diffusion, concentration at point of interest, applicable average atmospheric conditions, plume spread, expected concentration distributions in unrestricted areas, and applicable radiation dose rates, including gamma-ray shine from elevated plumes and inhaled or ingested dose commitments. The analysis should contain conservative best estimates of 
the predicted annual total doses to at least the following in the unrestricted areas: (1) the maximum exposed individual, (2) the nearest permanent residence, and (3) any location of special interest, such as a classroom or campus dormitory. The discussion and calculations should show that the sums of internal and external doses to the facility staff and the public are within the limits of I0 CFR Part 20 and that ALARA principles are applied.

- $\quad$ Liquid effluent volumes and radionuclide concentrations should be shown to be within the requirements of 10 CFR Part 20. The discussion should include any dilution that occurs before or at the point of release to the unrestricted environment.

- $\quad$ Estimates should be given of solid radioactive waste curie content and volume. The methods used to process solid waste should be briefly discussed.

\section{Review Procedures}

The reviewer should determine that all sources of radiation in the facility are adequately discussed and that the specific topics discussed in the standard format and content guide are complete and sufficiently described. Some of this information may be verified during site visits associated with the licensing process, and some may be assessed by comparison with similar operating facilities that NRC has found acceptable.

If the applicant describes processes involving radioactive material, the reviewer should compare the description of the types of radioactive materials present with the applicable process description, including radionuclide inventories and mass balances and chemical and physical forms, to verify that all radioactive materials associated with the process have been identified.

For a licensed reactor that is in operation, material balance inventory and material transfer data can be reviewed to verify quantities and general locations of special nuclear material (SNM). The reviewer should examine the fuel management program and record keeping of fissile and fissionable material in the MSR cycle and the radiation sources inherent in the fuel cycle.

The reviewer should examine the description and discussion of all sources of radiation to verify that they are described in sufficient detail to provide the bases for the design and assessment of personnel protective measures and dose commitments. The reviewer should evaluate the models used to predict airborne and liquid radionuclide concentrations and the physical and chemical forms of the radionuclide inventories to verify that they are appropriate for the facility and process conditions. If radionuclide data (inhalation or ingestion exposure data or concentration and inventory data) are available for the applicant or for facilities with similar processes and configurations, the reviewer should compare the predicted liquid and airborne radionuclide concentration distributions and possible doses with measured exposure data to validate the conservatism of the best estimates of the radionuclide concentrations. To evaluate consistency, the reviewer should use the applicant's summary of the calculated doses resulting from radionuclides predicted or detected during normal operations in areas that could be occupied by facility staff and the public. 
The reviewer should confirm that all solid sources of radiation at the facility are described and discussed in sufficient detail to permit evaluation of all significant radiological exposures related to normal operation, utilization, maintenance, and radioactive waste management including processing and shipment. The reviewer should determine the origin of the radiation (e.g., the fuel salt in the Active Reactor Core and Vessel), predicted exposure, access control, provisions for source control and storage, and interim or ultimate disposition.

\section{Evaluation Findings}

This section of the SAR should contain sufficient information to support the following type of conclusion, which will be included in the staff's safety evaluation report:

- $\quad$ The description of potential radiation sources and associated doses including the inventories, chemical and physical forms, and locations of radioactive materials, and other facility radiation and operational parameters related to radiation safety presented in the SAR have been reviewed. This review included a comparison of the bases for identifying potential radiation safety hazards with the process and facility descriptions to verify that such hazards were accurately and comprehensively identified. This review and evaluation confirm that the SAR identifies the potential radiation safety hazards associated with [insert name of facility] and this provides an acceptable basis for the development and independent review of the radiation protection program.

\subsubsection{Radiation Protection Program}

\section{Areas of Review}

The reviewer should evaluate the design and effectiveness of the radiation protection program required by 10 CFR 20.1101 to determine that they include the following:

- the radiation protection program that implements the regulations to ensure compliance with the requirements for radiation protection

- $\quad$ organizational structure within which the applicant will administer the radiation protection program and ensure radiation protection, including staffing levels, positions of authority and responsibility, position qualifications, standards, charters, procedures, or other documents that specify the authority, duties, and responsibilities of the personnel in the organization

- interfaces and interrelationships of the radiation protection organization with other facility safety organizations and reactor facility operations

- $\quad$ policy governing the program and the allocation of policy-making responsibilities, including the administrative plans and procedures that implement the facility policy, and how the organization, policy, and program are designed for effective radiation protection 
- $\quad$ plans and procedures for radiation protection, including the document control measures employed

- $\quad$ radiation protection training program, including the scope and content of training provided or required for all personnel, including facility operations and utilization personnel, health physics personnel, non-facility research and service personnel, security, fire, and other emergency personnel, and visitors

- $\quad$ purpose, organization, and functions of any committees with responsibilities relating to radiation protection, including each committee's charter of responsibilities, frequency of meetings, audit and review responsibilities, scope of any audit and reviews, qualifications and requirements for committee members, and relationship to other standing or ad hoc committees for radiation protection at the facility or within the parent organization

- $\quad$ the program for conducting facility radiation protection reviews and audits of all functional elements of the radiation protection program, including the scope of the reviews and audits, the basis for scheduling the review and audits, the qualifications of the auditors, and the process and office responsible for following up on audit findings

- $\quad$ the system for evaluating experience from the radiation protection program, including problems and incidents so that these experiences can be used to improve facility design and the radiation protection program and to develop "lessons learned," identify root causes, and implement effective corrective actions

- $\quad$ the radiation protection program recordkeeping process, including record retention periods, accessibility, review, and archiving, any special review of radiation safety records for accuracy and validity, and the use of records for developing trend analyses, informing management, planning radiation-related actions, and reporting to the regulatory authority and other duly authorized entities

- The radiation protection program should clearly distinguish between trained radiation workers, who may receive specified occupational dose during an accident, and members of the public, whose consequences and likelihoods should be controlled to more stringent levels.

- $\quad$ The application should identify a controlled area, as defined in 10 CFR 20.1003. This controlled area should be identified in the boundary and area maps provided in Chapter 2, Section 2.1.1.2, of the SAR.

\section{Acceptance Criteria}

Acceptance criteria for the radiation protection program include the following:

- $\quad$ The scope and content of the radiation protection program should be clearly based on a commitment of facility management to protect the facility staff, the environment, and the public from unacceptable exposure to radiation. 
- The facility organization chart should show that the management of the radiation protection program is independent of the reactor operations management.

- $\quad$ The program should provide for compliance with all applicable regulations.

- The program should show clearly that all review areas (discussed above) have been addressed and all expected radiation doses have been addressed.

- $\quad$ The program procedures should establish and describe clear lines of responsibility and clear methods for radiation protection under normal and emergency conditions.

- $\quad$ Procedures should be organized and presented for convenient use by operators and technicians at the appropriate locations and should be free of extraneous material. Supplementary or revised procedures should be issued when necessary to reflect radiation protection changes and improvements. Procedures should be periodically reviewed by supervisors and the review committee. New or revised procedures affecting radiation protection should be reviewed and approved by the radiation protection staff, appropriate management, and the review committee.

- $\quad$ All employees and visitors granted unescorted access to the facility should receive training concerning the radiological health and protection program, commensurate with their job duties and functions, or purposes of their visits. Certified individuals, including operators and their supervisors, should be given classroom and on-the-job training in radiation control practices. The radiation protection training program should be part of the ongoing training program established and maintained by the facility to train and requalify individuals as required.

- The review committee or committees responsible for radiation protection should report to a level of management sufficiently high to take any necessary corrective action; should have clearly written charters that describe their purposes, functions, authority, responsibility, and composition, and quorum, meeting frequency, and reporting requirements; should maintain records of recommendations and subsequent actions in sufficient detail to permit reviews of its effectiveness; should have membership that is technically competent in the radiation protection disciplines within the committee's area(s) of responsibility, and should operate in a manner that provides for group discussions among members on all but the more routine matters.

- The committee or committees responsible for auditing the radiation protection program should audit all functional elements of the radiation protection program as often as necessary. The audits should be performed by individuals whose expertise covers the range of technical fields encountered in the audit. Audits should be performed by individuals who are not directly responsible for the activities audited. Audits should be performed in such areas as personnel external and internal dosimetry, portable and fixed instrumentation, respirators (if used by the facility), contamination control radiological monitoring, the ALARA program, nuclear accident dosimetry, radiation source material 
control, radiological health and safety training, posting of radiological areas, and radiation protection program records.

- $\quad$ The facility should have a radiation work permit or similar program to control tasks with significant radiation hazards that are not described in the SAR.

- $\quad$ The radiation protection program records management system should include such records as ALARA program records, individual occupational dose records, monitoring and area control records, monitoring methods records, and training records.

- $\quad$ The radiation protection program should clearly distinguish between trained radiation workers, who may receive specified occupational dose during an accident, and members of the public, whose consequences and likelihoods should be controlled to more stringent levels. The application should identify a controlled area, as defined in 10 CFR 20.1003. This controlled area should be identified in the boundary and area maps provided in Chapter 2, Section 2.1.1.2, of the SAR. The licensee must retain the authority to exclude or remove personnel and property from the area. For the purpose of demonstrating that the operations of the facility meet the criterion of the radiation protection program, individuals who are not workers, may be permitted to perform ongoing activities (e.g., at a facility not related to the licensed activities) in the controlled area, if the licensee:

(1) Demonstrates and documents, in the radiation protection program, that the risk for those individuals at the location of their activities does not exceed the performance requirements; or

(2) Provides training that satisfies 10 CFR 19.12(a)(1)-(5) to these individuals and ensures that they are aware of the risks associated with accidents involving the licensed activities as determined by the radiation protection program, and conspicuously posts and maintains notices stating where the information in 10 CFR 19.11(a) may be examined by these individuals.

\section{Review Procedures}

The reviewer should evaluate the responsibilities and authorities assigned to the radiation protection organization against the acceptance criteria. The reviewer should also confirm that individuals assigned specific radiation protection responsibilities have adequate and clearly defined authority to discharge these responsibilities effectively. The reviewer should evaluate whether the radiation protection organization has sufficient staff to discharge its assigned responsibilities and should examine the interfaces and interrelationships with other facility safety organizations, including the reactor operating organization and the radioactive waste management organization if that responsibility is not part of the radiation protection organization. The reviewer should examine how responsibility is assigned to operations supervisors for the radiation protection of personnel under their control and how mechanisms are established to request and obtain necessary assistance from the radiation protection organization. The reviewer should evaluate whether the administrative plans and procedures provide a framework for the radiation protection organization to discharge its responsibilities 
independently in an effective manner, including interdiction of perceived unsafe practices and communication with upper management to ensure that radiation protection issues are properly resolved. The use of procedures to carry out the radiation protection program should be examined by the reviewer. The reviewer should examine the radiation protection training program and the radiation protection review and audit committee. The reviewer should examine the description of the records management program for the radiation protection program. During the conduct of the review, the reviewer should consider the regulations, guides, standards, and staff reports (NUREGs) in the bibliography at the end of this chapter, as they apply to the nonpower reactor facility. Please note that this list may not be complete and other documents may be available.

\section{Evaluation Findings}

This section of the SAR should contain sufficient information to support the following type of conclusion, which will be included in the staff's safety evaluation report:

- The staff has reviewed the radiation protection program presented in the SAR for the [insert name of facility or operation]. This review included an evaluation of (1) the roles, responsibilities, authorities, organization, and staffing of the radiation protection organization; (2) the roles, responsibilities, authorities, staffing, and operation of committees responsible for the review and audit of the radiation protection program;

(3) the effectiveness and comprehensiveness of the radiation protection training program;

(4) radiation protection plans and information that form the bases of procedures and the management systems employed to establish and maintain them; (5) the effectiveness and comprehensiveness of the program for independent oversight review's and audits of the radiation protection program; (6) the effectiveness and comprehensiveness of the process to evaluate the radiation protection program to improve the program and the process to examine problems and incidents at the facility, and (7) the management of records relating to the radiation protection program. This review confirms that the radiation protection program presented in the SAR both complies with applicable requirements and gives reasonable confidence that management's commitment to radiation protection in all activities will protect the facility staff, the environment, and the public from unacceptable exposure to radiation.

- The staff's evaluation should verify that the license application contains a clear definition of the controlled area, and that the radiation protection program performance requirements clearly distinguish between workers inside the controlled area and members of the public outside the controlled area.

\subsubsection{ALARA Program}

\section{Areas of Review}

To evaluate the provisions at the facility for maintaining worker and public doses and radiological releases ALARA, the reviewer should verify that the applicant's submittal includes, but is not limited to, the following: 
- A description of the ALARA program for the facility.

- A description of the methods to establish and change policy for this program, including the management level and authority by which the policy is established.

- A description of how this program is implemented for all activities at the facility to maintain radiation doses of all personnel and releases of effluents to the unrestricted area ALARA. The description should include criteria for considering economic factors in the ALARA analyses, for establishing ALARA goals, and for revising or terminating a proposed activity.

\section{Acceptance Criteria}

Acceptance criteria for the ALARA program include the following:

- $\quad$ The facility ALARA program should require that radiation doses received by facility staff and the public are maintained as low as is reasonably achievable, economic factors having been taken into account. The facility should have established ALARA goals.

- The highest levels of facility management should be committed to the ALARA program. (For universities, this commitment should come from the upper university administration.) The commitment should be shown by active management involvement in the program and should be clearly stated in writing to all personnel.

- Supervisory personnel should be required to periodically review exposure records for the personnel under their control to determine the trends and factors that contribute to personnel exposures and the methods for reducing exposure.

- $\quad$ Facility management should ensure that sufficient emphasis is placed on and sufficient resources are given to ALARA considerations during design, construction, and operation of facilities, in the planning and implementation of reactor utilization, in maintenance activities, and in the management and disposition of radioactive wastes.

\section{Review Procedures}

The reviewer should determine that the facility ALARA program satisfies the acceptance criteria discussed above. The reviewer should evaluate the provisions of the ALARA policy and program to determine whether applicable requirements, including 10 CFR Part 20, are satisfied.

\section{Evaluation Findings}

This section of the SAR should contain sufficient information to support the following type of conclusion, which will be included in the staff's safety evaluation report:

- $\quad$ The staff has reviewed the ALARA program at the facility. The policies and the bases for procedures give reasonable assurance that doses to occupational workers and the public 
will be maintained below regulatory limits and ALARA. The controls and procedures for limiting access and personnel exposure (including allowable doses, effluent releases, ALARA goals and criteria used for the action levels in radiation alarm systems) meet the applicable radiation protection program requirements and provide reasonable assurance that radiation doses to the environment, the public, and facility personnel will be ALARA. The ALARA program is adequately supported at the highest levels of management for the facility.

\subsubsection{Radiation Monitoring and Surveying}

\section{Areas of Review}

The reviewer should evaluate the procedures and equipment at the facility for routinely monitoring and sampling workplaces and other accessible locations to identify and control potential sources of radiation exposure and release. The specific topics to be reviewed are discussed in this section of the format and content guide.

\section{Acceptance Criteria}

Acceptance criteria for information concerning radiation monitoring include the following:

- $\quad$ The procedures and equipment should be designed to ensure that air, liquids, solids, and reactor radiation beams and effluents are monitored and sampled as necessary.

- $\quad$ The bases of the methods and procedures used for detecting contaminated areas, materials, and components should be clearly stated.

- $\quad$ The bases of the methods and procedures used for monitoring exposures of personnel, including those working in radiation and high radiation areas, should be clearly stated.

- $\quad$ Records should be kept as required by the regulations in 10 CFR Part 20 to document the applicability, quality, and accuracy of monitoring and sampling methods, techniques, procedures, and results.

- A complete range of radiation monitoring and sampling equipment, appropriate to the facility, should be employed throughout the facility, including equipment employed by experimental and operations support personnel. The applicant should discuss the bases of procedures for selection, use, locations, and functions of each monitoring device, including but not limited to the following:

- continuous air monitors (CAMs), including fixed and moving filter CAMs, and gaseous monitors

- $\quad$ portable survey instruments

- $\quad$ remote area monitors (RAMs) 
- $\quad$ effluent monitors

- $\quad$ samplers

- $\quad$ environmental monitors

- contamination-monitoring equipment

- personal dosimeters

- $\quad$ portal monitors

- $\quad$ radwaste storage and release monitors

- $\quad$ criticality monitors

- $\quad$ The calibration of radiation protection instrumentation and procedures should be discussed, including the calibration equipment, procedures and standards governing calibration, control of the calibration process, associated sensitivities to environmental and other conditions, and verification of proper operation. The program should conform to recognized national standards to help ensure that radiation protection instrumentation will measure radiation accurately and will function as needed. The program should ensure that recommended and routine periodic calibrations will be performed on time.

- $\quad$ The applicant should discuss the routine radiation monitoring and sampling provisions at the facility, including the methods used to survey radioactive material releases and the methods used to verify that waste materials will be appropriately monitored and controlled.

- In coordination with the information presented in Chapter 7, "Instrumentation and Control Systems," the applicant should describe the instrumentation and control systems used for radiation monitoring purposes.

- In coordination with the information presented in Chapter 6, "Engineered Safety Features," the applicant should describe the interface between the radiation monitoring system and the engineered safety features.

- $\quad$ Listings of required equipment, limiting conditions for operation, and surveillance requirements as discussed in Chapter 14, "Technical Specifications," should be discussed and justified in this section. 


\section{Review Procedures}

The reviewer should evaluate the design of the instrumentation systems used for both routine and special radiation monitoring and sampling to ensure compliance with the acceptance criteria. The reviewer should confirm that the applicant plans to position air sampling or monitoring equipment in the appropriate locations to measure airborne concentrations of radioactive material to which people are exposed. If the SAR shows that general area air sampling is not adequate to estimate worker intakes, a program of personal breathing-zone air sampling may be required, and the reviewer should evaluate its provisions for and applicability to the subject facility.

The reviewer should confirm that radiation monitoring and alarms, as described in the SAR, provide adequate warning and coverage and are of sufficient sensitivity to ensure that any significant increase in radiation exposure rates or concentration of airborne radioactive material within the restricted area, controlled area (if present), or in the unrestricted area would be detected and would initiate appropriate annunciation or action. The reviewer should coordinate this review with the Chapter 7 review and should evaluate the design of the radiation instrumentation systems used for radiation monitoring and dosimetry to verify compliance with the acceptance criteria. The reviewer should also verify that these radiation monitors and alarm systems will be maintained, operated, calibrated, and subjected to surveillance in compliance with the appropriate standards and are addressed in the technical specifications (TS).

The reviewer should confirm that the facility warning and annunciator systems are designed to alert personnel to a radiological hazard or abnormal condition in sufficient time to enable them to respond in a planned appropriate manner. The reviewer should also confirm that the interface between the radiation monitoring system and the engineered safety features (as discussed in Chapter 6) and the discussion of the radiation monitoring system in the emergency plan are appropriate.

\section{Evaluation Findings}

This section of the SAR should contain sufficient information to support the following type of conclusion, which will be included in the staff's safety evaluation report:

- The staff has reviewed the design of radiation monitoring and sampling provisions at the facility. The fixed and portable equipment used for radiation monitoring and sampling inside the facility is selected, located, calibrated, tested, and maintained in accordance with guidance contained in recognized national standards and the manufacturers' instructions, and with applicable regulations. The methods and bases of procedures used to determine the placement of the equipment, the circumstances under which the equipment is used, and the selection of the equipment function and sensitivity are appropriate to the facility and give reasonable assurance that appropriate types of radiation in significant intensities will be detected, monitored, and sampled consistent with 10 CFR Part 20 requirements and the facility ALARA program. 


\subsubsection{Radiation Exposure Control and Dosimetry}

\section{Areas of Review}

The reviewer should verify that the applicant submitted (1) the design bases for the equipment and procedures utilized for controlling radiation exposures to personnel and releases of radioactive materials from the facility and (2) dosimetry and methods used to assess exposure to radiation and radioactive materials. The topics to be reviewed are discussed in this section of the format and content guide.

\section{Acceptance Criteria}

Acceptance criteria for information concerning radiation exposure control and dosimetry include the following:

- $\quad$ The design of the facility (e.g., containment/confinement) should prevent uncontrolled radiation releases to the environment or to the work areas during normal operations.

- $\quad$ The design of entry control devices (e.g., alarms, signals, or locked entry ways) should alert workers to, or prevent unauthorized entry into, high radiation areas and very high radiation areas, as appropriate.

- $\quad$ The design bases of radiation shielding, ventilation, and remote handling and decontamination equipment should be planned so radiation doses are maintained ALARA and should be within the regulatory limits.

- $\quad$ The personnel protective equipment and materials (e.g., self-contained air packs) employed in the facility, the facility conditions for which this equipment should be employed, and any testing, calibration, and training required for their use, should be discussed and should be within the applicable regulations and standards.

- $\quad$ Acceptable radiation exposure and dose limits should be administratively established for all accessible locations of the facility, including the exposure limits established for facility personnel non-facility research and service personnel, and visitors. Acceptable administrative exposure limits may also be established for other groups (e.g., embryos and fetuses, declared pregnant women, minors, and students) at the facility.

- $\quad$ The applicant should discuss the bases used for developing the ALARA radiation exposure limits and how they are enforced, including the plans and procedures for exposure control and dosimetry during the full range of normal operations and postulated accident conditions, rescue and recovery, and planned special exposures.

- Applicable dosimetry should be used for external radiation monitoring (e.g., whole body, extremities). The frequency of dosimeter readings and action levels should be appropriate, and the dosimetry chosen should be suitable for the radiation sources expected and observed. The applicant should appropriately consider allowances for 
measurement uncertainties in the dosimetry program and the determination of exposure levels, and the standards for the issuance and the accuracy of self-reading personal dosimeters. Applicable and adequate methods should be used for determining internal doses.

- $\quad$ The applicant should maintain records to establish the conditions under which individuals were exposed to radiation, including the historical and current exposures to personnel and any associated trends (both individual and facility). Methods of maintaining records should be established to assist in planning radiation-related activities, implementing the ALARA program, reporting to appropriate regulatory agencies, and meeting the requirements of 10 CFR Part 20.

\section{Review Procedures}

The reviewer should examine the facility exposure control and dosimetry programs for external exposures and internal exposures to facility personnel, the environment (if measured), and the public to confirm that plans and the bases of procedures for the control of external dose to workers and the public consider the following:

- $\quad$ equipment and equipment design

- $\quad$ shielding

- $\quad$ radiation monitors and alarms

- $\quad$ personnel protective equipment

- the dosimetry used for external radiation monitoring, including the frequency of dosimeter readings, action levels, and the suitability of the dosimetry chosen with respect to the radiation sources expected and observed at the facility

The reviewer should also verify that procedures for the control of internal exposure consider the following:

- $\quad$ equipment and equipment design

- $\quad$ engineered controls such as containment/confinement or ventilation systems

- $\quad$ personnel protective equipment

- $\quad$ radiation monitors, alarms, and samplers (if used)

- $\quad$ bioassay methods, frequency, and action levels

- the models and methods used for internal dose evaluation 
The reviewer should examine the engineered controls used to ensure radiation protection safety for each of the sources of radiation and radioactive material described in Section 11.1.1. Some systems (e.g., containment or confinement or ventilation system) may have been reviewed in other chapters of the SAR. Reference may be made here to those evaluations. The reviewer should confirm that radiation protection measures have been implemented for sources of radiation and radioactive material. The reviewer should evaluate the radiation safety controls to determine the following:

- $\quad$ The acceptance criteria are met.

- $\quad$ Radiation protection engineering controls (e.g., the provision of shielding, facility and equipment layout to limit activities in radiation areas, use of confinement or containment systems, design of ventilation systems to control the potential for contamination and control release of radioactive material, and provision of remote handling systems) have been used.

- $\quad$ There is evidence of a commitment to reduce radiation doses to levels that are ALARA. The SAR should adequately justify any use of administrative controls instead of engineered controls.

The reviewer should confirm that the radiation dose limits and bases are identified and the plans and programs to control doses are documented. The reviewer should examine the descriptions of facility exposure conditions and methods used to derive administrative radiation dose limits. The reviewer should verity that dose limits and bases consider all groups (including, e.g., embryos and fetuses, declared pregnant women, minors, and students). The reviewer should examine the bases used for developing these limits and how the limits are enforced.

The reviewer should evaluate how the radiation protection controls provide assurance of the following:

- $\quad$ The acceptance criteria contained in this section of the review plan are met.

- $\quad$ Radiation protection engineered controls (e.g., the provisions of shielding, ventilation systems, and remote handling systems) have been designed to reduce the potential for uncontrolled exposure or release and have been incorporated in the facility.

- $\quad$ There is evidence of a commitment to maintain radiation doses ALARA.

The reviewer should examine how records are kept to establish the conditions under which individuals were exposed to radiation. For facilities with an operating history, the reviewer should also look for trends. Records of historical and current doses to personnel should be consistent with 10 CFR Part 20. 


\section{Evaluation Findings}

This section of the SAR should contain sufficient information to support the following types of conclusions, which will be included in the staff's safety evaluation report:

- $\quad$ The engineered radiation exposure controls employed at the facility have been reviewed. The applicant has given sufficient information about the design of the confinement (containment), radiological shielding, ventilation, remote handling, decontamination equipment, and entry control devices to allow for an assessment of the design of these radiological protection features. The entry control devices employed are adequate to alert workers to, or prevent entry into, radiological areas, including high or very high radiation areas. The confinement (containment) system design provides reasonable assurance that uncontrolled radiological releases to the unrestricted environment, controlled area (if present), or the restricted work area will not occur during any anticipated normal operations.

- The applicant has discussed the procedures for use of personal dosimetry at the facility. Provisions have been made for external and internal radiation monitoring of all individuals required to be monitored. The proposed dosimetry program meets the requirements of the regulations in 10 CFR Part 20.

- The provisions incorporated for personal dosimetry, shielding, ventilation, remote handling, and decontamination equipment provide reasonable assurances that radiation doses are maintained ALARA and within applicable regulations.

\subsubsection{Contamination Control}

\section{Areas of Review}

At a non-power reactor facility, controlling the occurrence and spread of radioactive surface contamination is important for several reasons. Unplanned and unwanted radioactive material could contaminate and interfere with or invalidate the results of experiments or other radiation measurements performed as part of the utilization program. Unsuspected radioactivity in the restricted area could inadvertently be transported or "racked" to the unrestricted area, and thereby constitute an uncontrolled release of radioactive material. Finally, removable or fixed surface contamination in the restricted area of sufficient source strength could measurably impact the radiological health and safety of people working there. The reviewer should evaluate how the applicant's program for contamination control meets all applicable requirements of the regulations and the facility ALARA program. The specific areas of review should include all of the items listed in the format and content guide: For existing programs, information about the effectiveness of the program should also be reviewed.

\section{Acceptance Criteria}

Acceptance criteria for the information on contamination control include the following: 
- $\quad$ The scope of the program should demonstrate that the applicant understands the potential problems caused by radioactive contamination and recognizes that the best way to control it is to establish procedures to prevent it initially.

- $\quad$ The bases of procedures should show that routine monitoring of locations, equipment, and personnel for contamination will be established and maintained.

- $\quad$ The bases of procedures should show that no materials, equipment, or personnel will be permitted to leave an area known to be or suspected of being contaminated without being appropriately monitored.

- $\quad$ The contamination control program should include provisions to avoid, prevent, and remedy the occurrence and the spread of contamination.

- $\quad$ Explicit contamination control training should be established as part of comprehensive radiation protection and radioactive waste management training, as needed.

- $\quad$ The contamination control program should include provisions for recordkeeping in accordance with 10 CFR Part 20 regarding occurrence and spread of contamination, sufficient in content and retention to support cleanup of contamination, maintenance, and planning for eventual decommissioning of the facility.

\section{Review Procedures}

The reviewer should determine whether all acceptance criteria are reasonably addressed and met. The reviewer should evaluate whether the written plans and the bases of procedures for contamination control include; at a minimum, requirements for monitoring of personnel and property for contamination upon exit from established areas in which contamination could be present. The reviewer should evaluate whether appropriate controls are established to prevent the further spread of contamination if detected. The reviewer should evaluate plans for decontamination.

For material and equipment in areas that could be contaminated, the reviewer should verify that plans and the bases of procedures at the facility treat the material and equipment as radioactive or contaminated so that it could be released from areas where contamination could be present only to other areas with monitoring, control, and documentation in accordance with reviewed and approved procedures. The reviewer should examine the plans governing records for the release of potentially contaminated material and equipment to make sure the property and the results of the monitoring operation would be described in sufficient detail to avoid ambiguity.

The reviewer should examine the description of plans for contamination control at the facility to verify that the facility could comply with applicable requirements and regulations for controlling, identifying, monitoring, labeling, packaging, storing, releasing, transporting, and accounting for contaminated material and waste that is contaminated, and for releasing surface-contaminated material to controlled or uncontrolled areas. 


\section{Evaluation Findings}

This section of the SAR should contain sufficient information to support the following types of conclusions, which will be included in the staff's safety evaluation report:

- $\quad$ The plans in the SAR for ensuring control of radioactive contamination for [insert name of facility] have been reviewed. This included review and evaluation of the following:

- $\quad$ the depth and breadth of the plan and bases of procedures for anticipating, identifying, controlling further spread of remedying, and recording information about occurrences of radioactive contaminating materials

- provisions for planning both reactor utilization and operation activities to avoid or prevent uncontrolled occurrence and spread of radioactive contamination

- $\quad$ provisions for routine monitoring and access control to identify radioactive contamination and to assess and limit personnel exposures

- the bases for TS that control activities that have the potential to cause or spread contamination

- The staff examined recordkeeping for contamination and historical information about occurrences of radioactive contamination at the facility, which helps to confirm that the program is effective. The program for contamination control meets all regulatory requirements and ensures the control of radioactive contamination so that there is reasonable assurance that the health and safety of the facility staff, the environment, and the public will be protected.

\subsubsection{Environmental Monitoring}

\section{Areas of Review}

The reviewer should evaluate the environmental monitoring program, if one exists at the facility, to verify that the information submitted includes the following:

- $\quad$ compliance with any commitments made in environmental reports or other documents; standards the applicant used in the environmental monitoring program

- if a program has been established, the effectiveness of the program

- for new facilities not yet in operation, establishment of preoperational baselines used to ascertain natural background so that the radiological impact of facility operation on the environment can be determined 
- the facility policy, the bases for procedures implementing the facility policy, the overall program, and TS or internal requirements of the applicant that promote compliance with environmental quality requirements

- the written plans and the bases of procedures for implementing the environmental monitoring operations, including the document control measures employed to ensure that the plans and procedures, including changes, are reviewed for adequacy and approved by authorized personnel and are distributed to and used at the appropriate locations throughout the facility

- the environmental surveillance program, including information on the identification of possible and probable radioactive contaminants resulting from operation of the facility, selection of sampling materials and locations (include maps), sample collection methods and frequency, sampling and counting equipment, and sample analysis techniques, sensitivities, and detection limits.

\section{Acceptance Criteria}

Acceptance criteria for the environmental monitoring program include the following:

- $\quad$ The documentation should discuss the environmental quality commitments that the program should address and the standards that were used in development of the program.

- $\quad$ The methods used to establish the preoperational baseline conditions for new facilities should be described.

- $\quad$ The methods and techniques to sample and analyze the radiological effect of facility operation should be complete, applicable; and of sufficient validity that the environmental impact can be unambiguously assessed. Results should be compared with pre-construction or pre-operation environmental data.

- $\quad$ The environmental monitoring program should provide confidence that a significant radiological impact on the environment from the facility would be detected and the type and magnitude of the radiological impact would be determined.

\section{Review Procedures}

The reviewer should confirm that the information in the SAR addresses the issues included in the acceptance criteria and contains the information requested in the environmental monitoring section of the format and content guide. The reviewer should examine the plans and methods designed to assess changes in the environment related to utilization and operation of the reactor. The reviewer should also examine plans for verifying and documenting the results. 


\section{Evaluation Findings}

This section of the SAR should contain sufficient information to support the following type of conclusion, which will be included in the staff's safety evaluation report:

- $\quad$ The staff has reviewed the description of the environmental monitoring program presented in the SAR for the [insert name of facility]. This review verified that the environmental monitoring program described is appropriate to the facility and its projected impact. The staff examined the provisions of the program to ensure the safety of the public and protect the environment. This review demonstrates that required and sufficient plans are identified or exist to provide reasonable assurance that an environmental monitoring program can be effectively implemented and sustained during the day-to-day operation of the facility, and that any radiological impact on the environment will be accurately assessed.

\subsection{Radioactive Waste Management}

As noted earlier, the magnitude of the radioactive waste management function and the scope of a waste management program vary widely from one non-power reactor to another. In general, the amount of radioactive waste formed will be related to the power level of the reactor and to the amount and type of utilization. The reviewer, therefore, should be prepared to find and evaluate provisions for managing such wastes that are commensurate with these factors. Furthermore, as noted, radioactive waste management could be assigned as an auxiliary function to an operations or to a radiation protection organization and not have an organizational unit of its own. In any case, the reviewer should explore and evaluate if the applicant has provided for defining, assessing, and managing such wastes to the extent necessary to protect the facility staff, the environment, and the public from unacceptable exposure to radiation.

Insofar as radioactive waste can be treated as one of the many types of radiation sources at a facility, all the foregoing guidance in this document is applicable. However, because there may be some differences in management and ultimate disposition of such sources, the following additional guidance is provided.

\subsubsection{Radioactive Waste Management Program}

\section{Areas of Review}

Whether or not the applicant has established an organizational unit dedicated to management of radioactive wastes, the SAR should discuss the program planned to manage such wastes. The reviewer should expect that the factors addressed by the applicant should include the following:

- $\quad$ philosophy of and approach to management of the wastes

- $\quad$ organization of the management function 
- $\quad$ program staffing and position descriptions, and program personnel responsibilities and qualifications as discussed in the format and content guide

- $\quad$ any review and audit committees related to radioactive waste management

- training for staff

- $\quad$ plans for shipping, disposal, and long-term storage

- $\quad$ program documentation and records, including availability and retention

- audits of the effectiveness of the program

- $\quad$ bases of procedures

- $\quad$ bases of TS

\section{Acceptance Criteria}

The acceptance criteria for the radioactive waste management program include the following:

- $\quad$ The SAR should contain a commitment to comply with applicable regulations and guidelines for managing radioactive wastes.

- $\quad$ The program should be designed to address all technical and administrative functions necessary to limit radiation hazards related to radioactive waste. TS should be proposed and justified if needed to control the program.

- $\quad$ The program should include audit, review, and self-evaluation provisions.

- $\quad$ The program should be sufficiently flexible to accommodate changing radioactive waste loads, changing regulatory requirements, and changing environmental factors, and should remain effective in protecting the health and safety of the facility staff and the public.

\section{Review Procedures}

The reviewer should understand and evaluate how the radioactive waste management program fits into the facility's overall management structure, how such wastes are identified and segregated effectively, how the management and radiation protection organization will ensure that radioactive wastes are continuously controlled from formation to ultimate safe disposal, and what organizational entities are assigned responsibilities in the radioactive waste management program. The reviewer should compare the program under review with programs at other similar facilities that have been approved by NRC. 


\section{Evaluation Findings}

This section of the SAR should contain sufficient information to support the following types of conclusions, which will be included in the staff's safety evaluation report:

- $\quad$ The applicant has described in the SAR the design of the program to manage radioactive wastes in sufficient detail to conclude that

- the applicant has developed the bases for a complete and effective program,

- the program includes review, audit, and assessment provisions, and

- $\quad$ the program complies with all applicable regulations.

- $\quad$ The applicant has described the waste management program in a manner showing that processes effectively remove undesired materials from the liquid fuel without providing a means that fissile material can be removed and collected in the process.

- $\quad$ The description of the waste management program gives reasonable assurance that radioactive wastes will not escape the control of the facility and will not pose a risk of undue radiation exposure to the facility staff the environment, or the public.

\subsubsection{Radioactive Waste Controls}

\section{Areas of Review}

The reviewer should evaluate the radioactive waste control plans at the facility to determine if the plans address all the factors discussed in the format and content guide related to maintaining control of such wastes from initial formation to ultimate disposition. Acceptable control should include methods to decrease and eventually minimize the formation of radioactive wastes. The reviewer should take particular care of the wording used in all documentation to distinguish between processes used by which waste materials are removed from the liquid fuel of the MSR and processes that might be construed as producing special nuclear material.

\section{Acceptance Criteria}

The acceptance criteria for information on radioactive waste controls include the following:

- $\quad$ The applicant should describe how all processes and procedures that could produce radioactive waste material will be evaluated.

- The discussion should show that appropriate monitoring and sampling will be performed, and sufficient analyses will be completed, to assess the extent of the radiation exposure from waste products. 
- The methods to avoid inadvertent exposure of personnel or uncontrolled escape of the radioactive materials should be described.

- Methods to define and maintain continuous control of radioactive materials that require treatment and management as waste should be included.

- $\quad$ Methods should be discussed by which the quantities of radioactive waste can be decreased.

- Wording used in all licensing documents clearly distinguishes the difference between waste removal processes used to clean up the MSR liquid fuel and processes that may be considered production of special nuclear material.

\section{Review Procedures}

The reviewer should compare the plans to identify and maintain control of radioactive wastes with plans at other similar non-power reactor facilities that NRC has found acceptable. The reviewer should also compare the applicant's submittal against the acceptance criteria in this standard review plan.

\section{Evaluation Findings}

This section of the SAR should contain sufficient information to support the following types of conclusions, which will be included in the staff's safety evaluation report:

- $\quad$ The applicant has described in the SAR methods by which the waste products from all procedures and processes will be monitored or otherwise assessed for radioactive material contents.

- When appropriate, controls will be established on the waste streams and products designed to prevent uncontrolled exposures or escape of radioactive waste.

- $\quad$ The descriptions of the plans and procedures provide reasonable assurance that radioactive wastes will be controlled at all times in a manner that protects the environment and the health and safety of the facility staff and the public.

- $\quad$ The applicant has described efforts to evaluate the creation of radioactive wastes at the facility to determine if actions to reduce the amount of waste produced are feasible.

\subsubsection{Release of Radioactive Waste}

\section{Areas of Review}

This topic is briefly treated separately here, even though it may have been addressed within the context of liquid and airborne radioactive effluents. This topic deals with the termination of control of radioactive material by the facility upon release of such effluents to the unrestricted 
environment or, in the case of solid waste, transfer to another party for disposal. Areas of review should include the methods of characterizing the possible effluents and referencing the applicable regulations that establish limits for release. Descriptions of the identities and amounts of radionuclides in the effluents, the release points, and the characteristics of the environment to which they are released should also be reviewed.

\section{Acceptance Criteria}

The acceptance criteria for information on the release of radioactive waste should be based on the following:

- $\quad$ The applicant should describe methods used to identify and characterize liquid and gaseous waste effluents that are released to the unrestricted area that could contain radioactive materials.

- The applicant should identify the radionuclides by quantities, other relevant characteristics, release points, and relevant environmental parameters.

- $\quad$ The applicant should show by appropriate calculations or references that all releases of radioactive effluents would be managed, controlled, and monitored so that limits in applicable regulations would not be exceeded. The applicant should show that procedures are in place for the transfer of solid waste to other parties in accordance with all applicable regulations.

- $\quad$ The applicant should discuss methods to verify that releases have not exceeded applicable regulations or guidelines.

\section{Review Procedures}

The reviewer should compare the discussions in the SAR with the regulations in 10 CFR Part 20, Subpart K, and with any applicable guidelines. Furthermore, comparisons should be made with acceptable provisions at other similar non-power reactors that NRC has found acceptable.

\section{Evaluation Findings}

This section of the SAR should contain sufficient information to support the following types of conclusions, which will be included in the staff's safety evaluation report:

- $\quad$ The applicant has described radioactive waste effluents expected to be released from the restricted to the unrestricted area. The discussion includes the type and quantities of radionuclides, methods and locations of release, methods of assessing the potential doses to people in the unrestricted area, and methods of comparing the consequences of releases with limits in applicable regulations. The applicant has also described the release of solid waste from the facility for disposal. 
- The discussions provide reasonable assurances that releases of liquid and airborne effluents from the facility will not exceed applicable regulations and will not pose unacceptable radiation risks to the environment, or the public.

\subsection{Respiratory Protection Program}

\section{Areas of Review}

The areas of review should include detailed information about the following two areas of the respiratory program:

(1) Establishment, maintenance, and implementation of a respiratory protection program.

(2) Design and implementation of programs to control airborne concentrations of radioactive material by using ventilation systems, containment systems, and respirators.

\section{Acceptance Criteria}

The applicant should do the following:

- Install appropriately sized ventilation and containment systems in areas of the plant identified as having potential airborne concentrations of radionuclides that could exceed the occupational derived air concentration values specified in 10 CFR Part 20, "Standards for Protection against Radiation," Appendix B, "Annual Limits on Intake (ALIs) and Derived Air Concentrations (DACs) of Radionuclides for Occupational Exposure; Effluent Concentrations; Concentrations for Release to Sewerage."

- Describe surveillance requirements, including preventive and corrective maintenance and performance testing, to ensure that the ventilation and containment systems operate when required and are within their design specifications.

- $\quad$ Describe the criteria for the ventilation and containment systems, including minimum flow velocity at openings in these systems, maximum differential pressure across filters, and types of filters to be used.

- $\quad$ Describe the frequency and types of tests to measure the performance of ventilation and containment systems, the acceptance criteria, and the actions to be taken when the acceptance criteria are not satisfied.

- $\quad$ Establish a respiratory protection program that meets the requirements of 10 CFR Part 20, Subpart H, "Respiratory Protection and Controls to Restrict Internal Exposure in Restricted Areas."

- $\quad$ Prepare written procedures for the selection, fitting, issuance, maintenance, testing, training of personnel, monitoring, and recordkeeping for individual respiratory protection equipment and for specifying when such equipment is to be used. 
- $\quad$ Revise the written procedures for the use of individual respiratory protection equipment, as applicable, when making changes to processing, facility, or equipment.

- Maintain records of the respiratory protection program, including training in respirator use and maintenance.

\section{Review Procedures}

The reviewer should determine whether the respiratory protection program provides adequate protection of personnel from airborne concentrations exceeding the limits of Appendix B to 10 CFR Part 20 and the overall adequacy of the program. The methods used for the identification and evaluation of potential hazards and estimated doses should provide realistic and accurate predictions. The applicant should evaluate potential hazards and estimated doses by performing surveys, bioassays, air sampling, or other means as necessary.

As for the respiratory protection to be used, the reviewer should ensure that the equipment has been tested and certified to provide the appropriate degree of personal protection. The applicant must also commit to testing of respirators for operability before usage. The reviewer should also examine the description of respirator usage, training, fit testing, selection, storage, maintenance, repair, and quality assurance through the written procedures.

After evaluating the acceptance criteria, the reviewer will perform a safety evaluation. The reviewer will prepare a safety evaluation report (SER) on the licensing action for the licensing project manager.

\section{Evaluation Findings}

The reviewer will draft an SER addressing the topic reviewed explaining why the NRC staff has reasonable assurance that the respiratory protection program is acceptable and that the health and safety of the workers is adequately protected. The NRC staff may propose license conditions to impose requirements in those areas in which the application is deficient. The NRC staff's SER should include the following kind of statement and conclusion:

- $\quad$ The applicant has committed to an acceptable radiation protection program that includes a program to control airborne concentrations of radioactive material with engineering controls and respiratory protection.

\subsection{References}

American National Standards Institute/American Nuclear Society, ANSI/ANS 15.7, "Research Reactor Site Evaluation,” ANS, LaGrange Park, Illinois, 1977.

American National Standards Institute/American Nuclear Society, ANSI/ANS 15.11, "Radiation Protection at Research Reactor Facilities," ANS, LaGrange Park, Illinois, 1993. 
American National Standards Institute/American Nuclear Society, ANSI/ANS 15.19, "Shipment and Receipt of Special Nuclear Material by Research Reactor Facilities," ANS, LaGrange Park, Illinois, 1991.

Code of Federal Regulations, Title 10, "Energy," and Title 49, "Transportation," US Government Printing Office, Washington, D.C., revised periodically.

US Nuclear Regulatory Commission, NUREG-0851, "Nomograms for Evaluation of Doses from Finite Noble Gas Clouds,” January 1983.

US Nuclear Regulatory Commission, NUREG/CR-2260, “Technical Basis for RG 1.145,” 1981.

US Nuclear Regulatory Commission, Regulatory Guide 1.109, "Calculation of Annual Doses to Man from Routine Releases of Reactor Effluents."

US Nuclear Regulatory Commission, Regulatory Guide 1.145, "Atmospheric Dispersion Models for Potential Accident Consequence Assessments at Nuclear Power Plants."

US Nuclear Regulatory Commission, Regulatory Guide 8.9, "Acceptable Concepts, Models, Equations, and Assumptions for a Bioassay Program."

US Nuclear Regulatory Commission, Regulatory Guide 8.9, proposed Revision 1, "Interpretation of Bioassay Measurements," Task DG-8009.

US Nuclear Regulatory Commission, Regulatory Guide 8.10, "Operating Philosophy for Maintaining Operational Exposures As Low As Is Reasonably Achievable."

US Nuclear Regulatory Commission, Regulatory Guide 8.13, Revision 3, "Instructions Concerning Prenatal Radiation Exposure.” 